Florida International University FIU Digital Commons

$11-9-2009$

\title{
Phonics Instruction using Pseudowords for Success in Phonetic Decoding
}

Jessica M. Cardenas

Florida International University, lurod14@att.net

DOI: $10.25148 /$ etd.FI09120818

Follow this and additional works at: https://digitalcommons.fiu.edu/etd

Part of the Curriculum and Instruction Commons

\section{Recommended Citation}

Cardenas, Jessica M., "Phonics Instruction using Pseudowords for Success in Phonetic Decoding" (2009). FIU Electronic Theses and Dissertations. 139.

https://digitalcommons.fiu.edu/etd/139

This work is brought to you for free and open access by the University Graduate School at FIU Digital Commons. It has been accepted for inclusion in FIU Electronic Theses and Dissertations by an authorized administrator of FIU Digital Commons. For more information, please contact dcc@fiu.edu. 


\title{
FLORIDA INTERNATIONAL UNIVERSITY
}

Miami, Florida

\section{PHONICS INSTRUCTION USING PSEUDOWORDS FOR SUCCESS IN PHONETIC DECODING}

\author{
A dissertation submitted in partial fulfillment of the \\ requirements for the degree of \\ DOCTOR OF EDUCATION \\ in \\ CURRICULUM AND INSTRUCTION
}

by

Jessica Marie Cardenas

2009 
To: Interim Dean Marie McDemmond

College of Education

This dissertation, written by Jessica Marie Cardenas and entitled Phonics Instruction using Pseudowords for Success in Phonetic Decoding, having been approved in respect to style and intellectual content, is referred to you for judgment.

We have read this dissertation and recommend that it be approved.

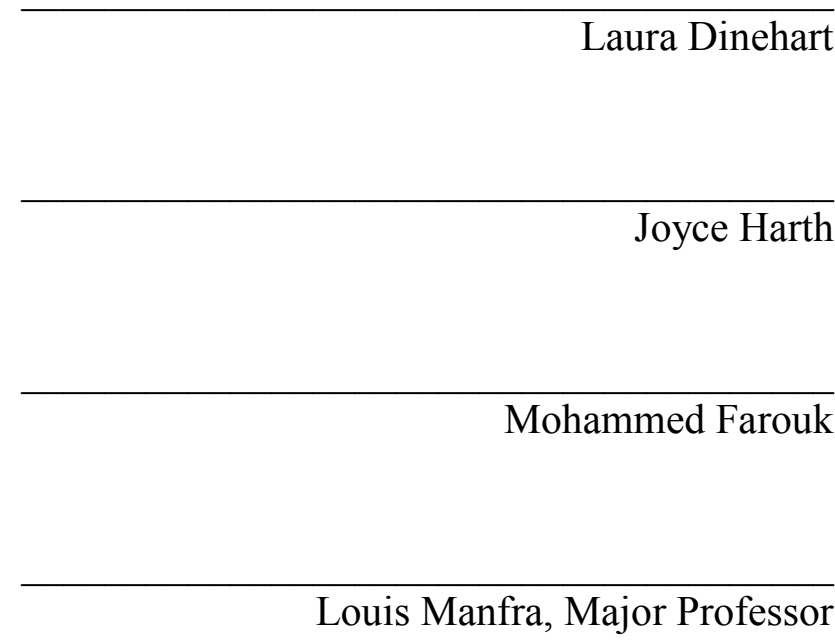

Date of Defense: November 9, 2009

The dissertation of Jessica Marie Cardenas is approved.

\begin{tabular}{r}
\hline $\begin{array}{r}\text { Interim Dean Marie McDemmond } \\
\text { College of Education }\end{array}$ \\
\hline Dean George Walker \\
University Graduate School
\end{tabular}

Florida International University, 2009 
(C) Copyright 2009 by Jessica Marie Cardenas

All rights reserved. 


\title{
ABSTRACT OF THE DISSERTATION \\ PHONICS INSTRUCTION USING PSEUDOWORDS \\ FOR SUCCESS IN PHONETIC DECODING
}

\author{
by \\ Jessica Marie Cardenas \\ Florida International University, 2009 \\ Miami, Florida \\ Professor Louis Manfra, Major Professor
}

This study examined a Pseudoword Phonics Curriculum to determine if this form of instruction would increase students' decoding skills compared to typical real-word phonics instruction. In typical phonics instruction, children learn to decode familiar words which allow them to draw on their prior knowledge of how to pronounce the word and may detract from learning decoding skills. By using pseudowords during phonics instruction, students may learn more decoding skills because they are unfamiliar with the "words" and therefore cannot draw on memory for how to pronounce the word. It was hypothesized that students who learn phonics with pseudowords will learn more decoding skills and perform higher on a real-word assessment compared to students who learn phonics with real words.

Students from two kindergarten classes participated in this study. An authorcreated word decoding assessment was used to determine the students' ability to decode words. The study was broken into three phases, each lasting one month. During Phase 1, both groups received phonics instruction using real words, which allowed for the exploration of baseline student growth trajectories and potential teacher effects. During 
Phase 2, the experimental group received pseudoword phonics instruction while the control group continued real-word phonics instruction. During Phase 3, both groups were taught with real-word phonics instruction. Students were assessed on their decoding skills before and after each phase.

Results from multiple regression and multi-level model analyses revealed a greater increase in decoding skills during the second and third phases of the study for students who received the pseudoword phonics instruction compared to students who received the real-word phonics instruction. This suggests that pseudoword phonics instruction improves decoding skills quicker than real-word phonics instruction. This also suggests that teaching decoding with pseudowords for one month can continue to improve decoding skills when children return to real-word phonics instruction. Teacher feedback suggests that confidence with reading increased for students who learned with pseudowords because they were less intimidated by the approach and viewed pseudoword phonics as a game that involved reading "silly" words. Implications of these results, limitations of this study, and areas for future research are discussed. 


\section{TABLE OF CONTENTS}

CHAPTER

PAGE

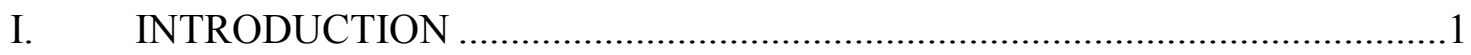

Statement of the Purpose and Problem ..............................................................

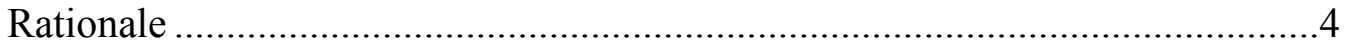

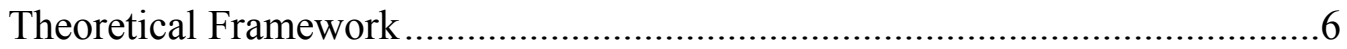

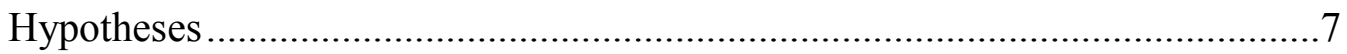

Significance of the Study ……………………………................................

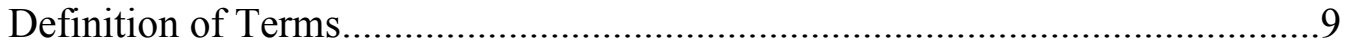

Organization of the Remaining Chapters ...........................................................10

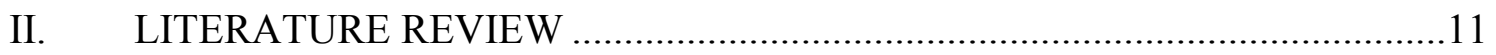

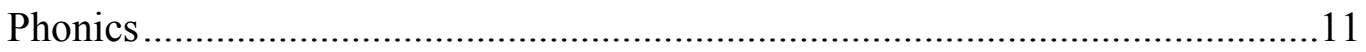

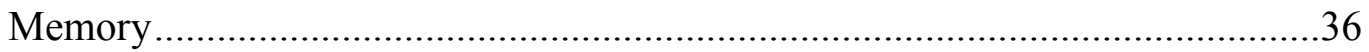

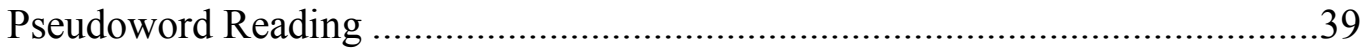

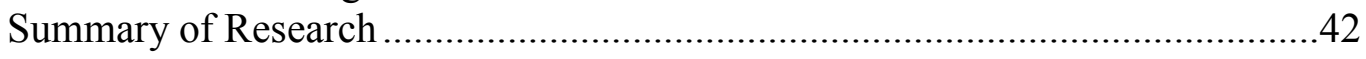

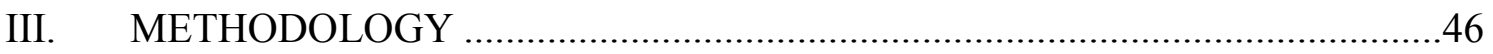

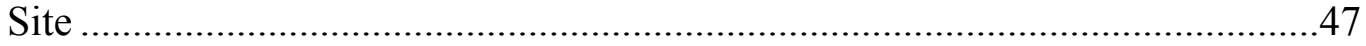

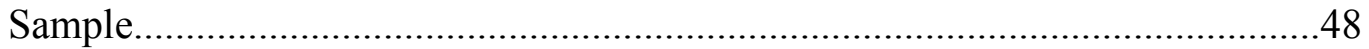

Phonetic Word List Assessment and Pilot Study................................................51

Pseudoword Phonics Curriculum.....................................................................55

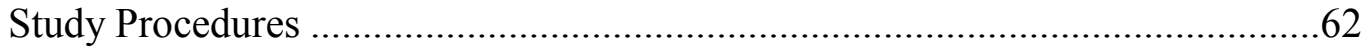

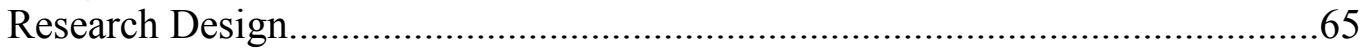

Statistical Analysis Plan................................................................................67

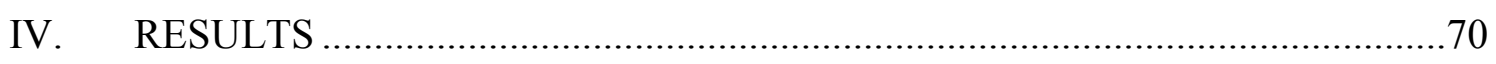

Exploring Demographic and Extraneous Factors ………………………...........70

Exploring Hypotheses ................................................................................... 81

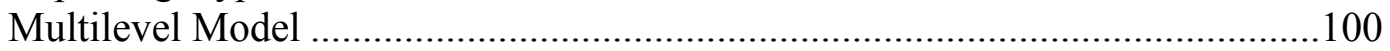

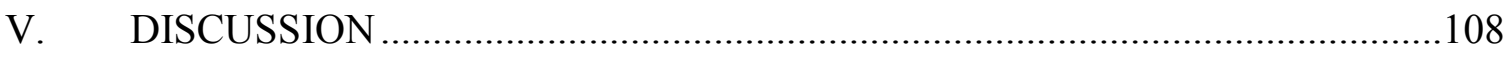

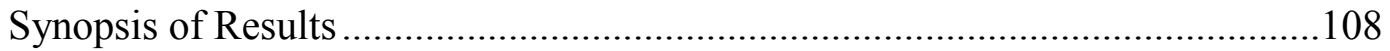

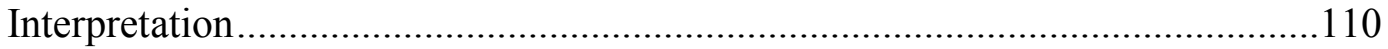

Applications and Implications ....................................................................116

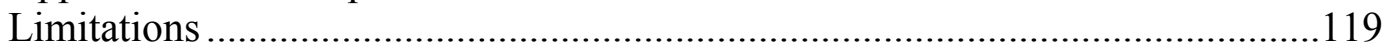

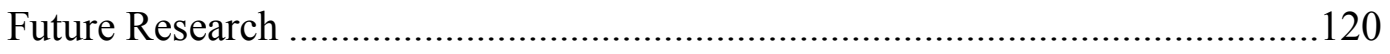

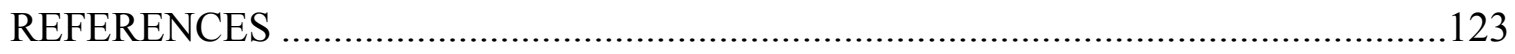

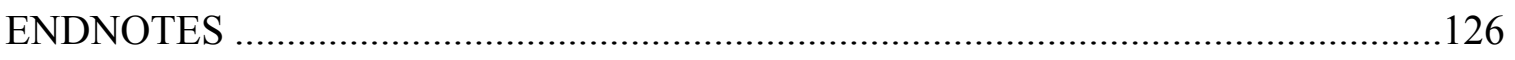

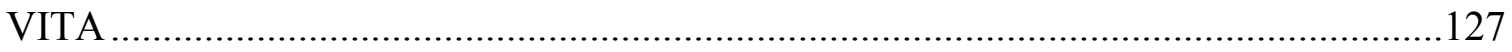




\section{LIST OF TABLES}

TABLE

PAGE

1. Mean $(S D)$ of Demographic Variables for the Overall Sample.

2. Mean $(S D)$ of Demographic Variables for Experimental Group and Control Group .50

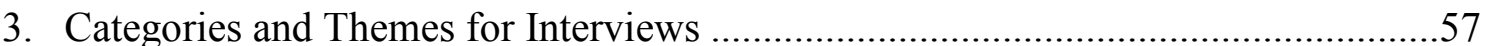

4. Positive and Negative Views of Using Nonsense Words to Teach Phonics.

5. Mean $(S D)$ of Scores on the PWLA for Experimental Group, Control Group, and Overal

6. Mean $(S D)$ Differences in Sex for the Overall Sample across

Time Points and Phases

7. Mean $(S D)$ Differences in Ethnicity for the Overall Sample across

Time Points and Phases

8. Mean $(S D)$ Differences in ESE and ELL for the Overall Sample across

9. Correlation of Age and Absences by Score across Time Points

10. Mean $(S D)$ Scores for the Overall Sample across Time Points and Phases. .83

11. Mean $(S D)$ Scores for Experimental and Control Group across Time Points .95

12. Data for Multi-level Models A and B .104 


\section{LIST OF FIGURES}

FIGURE

PAGE

1. Implementation Schedule for Study on Pseudoword Phonics Curriculum. .64

2. Graph for Linear and Non-Linear Models for Hypothesis 1 .82

3. Graph for Linear and Non-Linear Growth at Each Time Point and Between Each Phase

4. Graph of Linear Growth for Boys and Girls .85

5. Graph for Non-Linear Growth for Boys and Girls .86

6. Graph of Linear Growth for Hispanic and Non-Hispanic Students.....

7. Graph of Non-Linear Growth for Hispanic and Non-Hispanic Students .88

8. Graph of Linear Growth for 5.5 Year Olds and 6 Year Olds

9. Graph of Non-Linear Growth for 5.5 Year Olds and 6 Year Olds .90

10. Graph for Differences in PWLA Scores While Controlling for Demographic Variables

11. Graph for Non-Linear Models for Hypothesis 1 .94

12. Graph of Non-Linear Growth for Experimental and Control Group..... .96

13. Graph of Non-Linear Growth for Experimental and Control Group While Controlling for Demographic Variables

14. Graph of Sustained Growth for Boys and Girls in Experimental Group

15. Graph of Non-Linear Growth from HLM Data for Boys and Girls in Both Groups

16. Individual Growth Graphs for Boys and Girls in Both Groups .106 


\section{CHAPTER I}

\section{INTRODUCTION}

It is widely acknowledged that reading failure begins during the early years of schooling (Ehri, 1998; Juel, 1988, 1996; Pikulski \& Chard, 2005). It is during this period that children develop a strong, basic foundation in the five areas of reading: (a) phonemic awareness, (b) phonics, (c) fluency, (d) vocabulary, and (e) comprehension (National Reading Panel, 2000). Each of the five areas builds upon one another and provides the essentials for successful reading. These five skills can be categorized into two overarching factors that are essential for reading: (a) decoding (phonemic awareness and phonics) and (b) construction of meaning (vocabulary and comprehension). Decoding tends to be considered the basic skill or building block of reading, while construction of meaning tends to be considered the advanced skill. In order for an individual to be successful at reading, it is generally believed that the individual should achieve a level of automaticity in decoding, which focuses his/her attention on the process of constructing meaning from text. As such, teaching decoding skills in the early years is critical to the long-term success of young readers (Adams, 1990; Chall, 1996; Stahl, Duffy-Hester, \& Doughtery Stahl, 1998).

Children, who become fluent in decoding early on, tend to become better readers in the long run. Once they feel confident in decoding, they are likely to develop a sense of enjoyment toward reading because they realize that they can rely on this skill to help identify unknown words that are encountered. It has been found that once young children fail to understand and grasp the concept of decoding, they begin to dislike reading because it becomes a struggle (Juel, 1996). Even students who use a guessing strategy to 
compensate for their lack of decoding skills tend to make little or no progress in reading because at some point or another they realize that the guessing strategy does not always work (Ehri, 1998). Since children who struggle in decoding tend to read less than children who are more fluent in decoding, they tend to lose the opportunity to gain vocabulary, background knowledge, and information about text structure; all of which are important reading skills to acquire. In comparison to children who succeed in decoding and become successful readers, it is more likely for children who struggle in decoding early on to continue to struggle in reading as they get older (Juel, 1996; Stanovich, 1986).

The present study explored whether or not a phonics curriculum using pseudowords would increase students' success in phonetic decoding. Two major hypotheses guided the study: (a) children who receive phonetic decoding instruction, regardless of the method of instruction, will show improvement in word decoding and will likely improve increasingly more as the study progresses; and (b) children who receive phonics instruction through a Pseudoword Phonics Curriculum (PPC) will show more improvement in decoding skills compared to children who receive regular realword phonics instruction.

The present study contributes to the literature by exploring a potentially more effective method of teaching phonics. It is possible that this type of instruction may result in improved decoding skills of young students learning to decode through phonics instruction because of the lack of exposure to any of the pseudowords used to teach decoding. Students should learn and use true decoding skills because they will not have seen, said, or memorized any of the pseudowords used in the PPC. Therefore, students 
should be able to focus on developing decoding skills without relying on memory or context clues, such as using beginning and ending letters to guess words.

The remainder of this chapter provides a clearly articulated statement of the purpose and the assumptions underlying the study, followed by a rationale for the importance of this study. Then, the hypotheses and significance of the study are presented. Finally, the definitions of terms are introduced and a description of the organization of the remaining chapters is delineated.

\section{Statement of the Purpose and Problem}

Current reading research suggests that children who begin school struggling in reading are more likely to remain poor readers throughout schooling and life (Adams, 1990; Juel, 1988; Stanovich, 1986; Torgesen \& Burgess, 1998). Therefore, it is important for teachers in the field of early childhood education to provide effective early reading instruction in order to help decrease the number of students who continue to experience failure, loss of self-confidence, and a constant struggle in reading throughout their lifetime. One of the problems is that early readers tend to recall words from memory while they are reading, rather than developing and using basic decoding skills. When children rely only on whole-word memory when reading, they do not develop the skills they need to decode unknown words because they do not practice decoding them. If children have already memorized the words that are being used to teach decoding, then they may not learn the decoding skills being taught because they can simply recall how to say the word from memory. Doing so may cause deficits in the fundamentals of reading and may lead to failure in reading as children progress throughout their years in school and encounter more and more difficult and unfamiliar words (Byrne, Fielding-Barnsley, 
\& Ashley, 2000). What continues to remain unclear are the most effective instructional strategies that teachers can implement to increase the likelihood that their students will learn to decode instead of recall words from memory or use guessing strategies to read words during phonics instruction.

Decoding is defined here as the ability to analyze graphic symbols of a familiar language to ascertain the intended meaning (Harris \& Hodges, 1995). In order to read, children must learn the conventional code in which English is written to understand the written message. One method of learning to decode words, which was explored in the present study, is phonics. Phonics is an approach for teaching reading, especially in beginning instruction, that stresses sound-symbol relationships. Phonics involves the association of speech sounds with letters and the blending of sounds into syllables and words (Harris \& Hodges, 1995). The underlying assumption of the present study was that the use of pseudowords to teach phonetic decoding would reduce students' chances of recalling memorized words, and in turn increase their ability to use the decoding skills learned to decode unfamiliar written words. Therefore, this study investigated whether or not using a PPC in a kindergarten classroom setting will increase students' ability to decode words on an author-created assessment.

\section{Rationale}

The rationale for this study was based on a global desire to learn more about children's early reading development, with a primary focus on decoding. As an early childhood educator, I have developed an interest in identifying the best approach to help children acquire the decoding skills that are necessary for learning to read. 
Through my experience teaching first grade, I have noticed that young children often memorize the words they frequently encounter in books and phonics lessons. As a result, their ability to read relies mostly on recalling memorized words, thereby developing and practicing decoding skills less and less. I have noticed that some of my students guess the pronunciation of unfamiliar words based on the first letter of the words. For example, if the unfamiliar word is stand, the student might say stairs because the first two letters $(s t)$ trigger their recall of stairs not stand. Unlike the word stand, the word stair has been stored in the child's lexicon. As such, the child is relying on recalling memorized words rather than decoding the unfamiliar word. At some point, the goal of reading is to be able to read words by sight, leading to more fluent reading. However, referring to the example above, if a student encounters an unfamiliar word, the ability to decode becomes a necessary skill.

Results from reading assessments, such as STAR Reading and the Dynamic Indicators of Basic Early Literacy Skills (DIBELS) have also provided rationale for this study. According to the STAR Reading computer software program, most of my first grade students read on or above grade level at the beginning of the school year. However, when I assess their nonsense word fluency (which includes a measure of lettersound correspondence and the ability to blend letters into nonsense words in which letters represent their most common sounds) using the DIBELS, some of my highest readers (second grade reading level and above) score below average. I began to notice that the students' inability to sound out letters and blend them together to read a word became an issue as they began to come across more and more unfamiliar words. 
I was concerned that the problem would continue to intensify. At that time, I thought that teaching students phonics through the use of nonsense words, such as those seen in the DIBELS assessment, might be a solution to the problem. I examined the effects of such a method by implementing this approach during small group instruction with my lowest level readers. After a few weeks, I saw some improvement in my students' decoding skills. They were able to apply the decoding skills learned with nonsense words to reading real words in text and in isolation. It occurred to me that decoding instruction using pseudowords before exposing children to real words might allow students to master decoding skills and result in more successful reading.

\section{Theoretical Framework}

The Information Processing Theory (IPT) supports the idea that memory is broken into sub-processes of encoding (organizing information), storage (keeping information), and retrieval (recalling information). First, information enters an individual's sensory memory. Then, the information moves into short-term memory (also referred to as working memory) where it is processed. Finally, some of the information is permanently stored in long-term memory where it can be retrieved at a later time. The IPT assumes that people are limited in their capacity to store and process information and should, therefore, develop strategies to avoid dependence on long-term memory. This theory can be applied to children's reading development. If children have a limited capacity to store and process information, such as visual representations of words, then they will likely develop strategies that will help them read words that have not been stored in their long-term memory. One approach to teaching children how to read is decoding. If children learn to sound out the individual letters within words and 
blend the sounds together to read the words, then they will not need to worry about memorizing every word they encounter. However, since it is natural for children to begin storing words in their long-term memory after several exposures, this may interfere with typical phonics instruction because children might recall words from memory instead of practicing decoding skills. An alternate to using real words in phonics instruction is to use pseudowords. A pseudoword is a pronounceable combination of alphabetic characters that do not make a known word (Harris \& Hodges, 1995). Using pseudowords to teach phonics may allow children to focus on learning and practicing decoding skills without the interference of retrieving words from long-term memory.

\section{Hypotheses}

This study was guided by two detailed hypotheses. Based on research that addresses the importance of phonics instruction in teaching children decoding skills (Adams, 1990; Chall, 1996; Stahl et al., 1998), the first hypothesis states that children who receive phonetic decoding instruction, regardless of the method of instruction (i.e., all children in the study), will show growth in word decoding, and will likely increase more in their decoding as the study progresses. This hypothesis was explored to determine the rate by which phonics instruction, in general, improves children's decoding skills. The second hypothesis states that children who receive phonics instruction through the PPC will show more improvement in decoding skills than children who receive regular phonics instruction. Since pseudowords have not been previously seen, said, or memorized by students, they may be more suitable for phonics instruction because students should be able to focus on developing decoding skills without relying on memory or context clues. 


\section{Significance of the Study}

This study is significant because it explored a method of teaching phonics that may increase the rate by which students learn to decode words. It is possible that a PPC will increase students' success in phonetic decoding. While there are several studies that have used pseudowords to assess children's phonetic decoding skills (Byrne \& FieldingBarnsley, 1993; Pullen, Lane, Lloyd, Nowak, \& Ryals, 2005), no studies exist (to the author's knowledge) that have examined the impact of using pseudowords to teach phonetic decoding skills.

According to several theories (further discussed in Chapter 2), knowledge of letters and sounds, as well as the ability to decode words, is an essential component of children's early literacy development (Adams, 1990; Ehri, 1978, 1998). However, many children do not acquire the necessary decoding skills through regular real-word phonics instruction. It is possible, that factors such as recalling memorized words and using guessing strategies are preventing children from developing and practicing decoding skills. These factors may also prevent teachers from identifying students who are struggling with decoding. For example, when a student reads words during phonics instruction, the teacher may not realize that the student is using other strategies, other than decoding, to read the words. Not only will pseudoword phonics potentially help teachers identify struggling decoders early on, but it may also help students focus exclusively on developing their decoding skills without the interference of other reading strategies that struggling readers tend to use. 


\section{Definition of Terms}

The key terms used throughout the proposed study are briefly defined here. A more thorough definition is found within each chapter, where appropriate.

Decode. To analyze spoken or graphic symbols of familiar language to ascertain their intended meaning. The term is used primarily to refer to word identification rather than to identification of higher units of meaning (Harris \& Hodges, 1995).

Phonetic word. A misnomer for a phonically regular word whose pronunciation may be accurately predicted from its spelling (Harris \& Hodges, 1995).

Phonic analysis. In teaching practice, the identification of words by their sounds. It involves the association of speech sounds with letters and the blending of these sounds into syllables and words (Harris \& Hodges, 1995).

Phonics. A way of teaching reading and spelling that stresses symbol-sound relationships, used especially in beginning instruction (Harris \& Hodges, 1995).

Pseudowords (also known as nonsense words). A pronounceable combination of graphic characters, usually trigrams, that do not make a real word (according to dictionaries) but do have all the characteristics of a known real word. They are sometimes used in reading to test phonics knowledge and in spelling to test for desired syllabic patterns while avoiding known words (Harris \& Hodges, 1995). For purposes of this study, pseudowords are referred to as words that the children have never heard and consider to be nonsense words.

Rime. The first vowel in a word and all the sounds that follow (Harris \& Hodges, 1995). 
Sight word. A word that is immediately recognized as a whole and does not require word analysis for identification (Harris \& Hodges, 1995).

Unfamiliar words. Printed words that are not recognized by sight. Organization of the Remaining Chapters

Chapter 2 presents a review of the literature, which includes research-based information related to phonics, memory, and pseudoword reading. It covers topics such as the "Great Debate" between phonics and whole language approaches, the need for teaching phonics to beginning readers, teaching methods that have been used in the past and are currently being implemented in classrooms today, the role that memory plays in learning to read, and the use of pseudowords in reading. Chapter 3 describes the methodology that is used to conduct the study. It includes descriptions for the site and sample, procedures of the study, word decoding assessment, pseudoword phonics instruction, research design, and statistical analysis plan. Chapter 4 reports the results of the study. Finally, chapter 5 provides a synopsis of the results, an interpretation of the findings, applications and implications of the study, limitations of the study, and areas for future research. 


\section{CHAPTER II}

\section{LITERATURE REVIEW}

This review includes literature on research-based information on phonics, memory, and pseudoword reading. It goes into depth on the well-known Great Debate between the use of phonics versus the whole-language approach for teaching reading in elementary school. In addition, this chapter includes a discussion on the need and importance of teaching phonics in early literacy settings. The various phonics teaching methods, including systematic, analogy-based, embedded, and synthetic phonics approaches are also discussed. This is followed by theories and research on children's reading processes in the brain; specifically, the significant role that memory plays in beginners' reading development. Finally, this review of the literature includes information on how and why pseudoword reading has been used in the past and the findings from those projects.

\section{Phonics}

One of the five areas in the development of early literacy is phonics. Phonics is a method of teaching that emphasizes sound-symbol relationships in language and is usually used in the early stages of reading instruction (Rasinski \& Padak, 2001). It can also be defined as the conscious, concentrated study of the relationship between sounds and symbols (letters), with a primary purpose of learning to read and write (Savage, 2004). It is important for children to acquire knowledge of the alphabetic principle before phonics is taught because they build on one another (Adams, 1990). The alphabetic principle suggests that letters work together, and systematically, to represent sounds of spoken language (Savage, 2004). Children should understand that all 26 
symbols that make up the English alphabet are worth learning and discriminating because they each stand for sounds that occur in spoken words (Adams, 1990). Research has shown that early success in reading is associated with having an understanding of the alphabetic principle (Stahl, Duffy-Hester, \& Doughtery, 1998).

Once the alphabetic principle is grasped, phonics instruction will be more useful. Subsequently, the process of teaching phonetic decoding, which is the ability to associate letters with their corresponding sounds to create words, can begin. Although phonics is essential in learning to read, it is not an end in itself, but a means to help children learn to read words with automaticity (Stahl et al., 1998). After gaining a strong foundation in phonetic decoding, children can apply their decoding skills to other reading aspects, such as automatic word recognition and comprehension (Stahl et al., 1998). If children do not acquire phonetic decoding skills first, then it may hinder their success in other areas of reading because children may encounter difficulties when they come across unfamiliar words.

The Great Debate: Phonics vs. Whole Language

For many years, a topic of much debate has been whether or not phonics instruction should be present in primary classrooms and, if so, to what extent and with what approach. As early as the sixteenth century, there has been a great emphasis on letter names and sounds in teaching reading and writing (Savage, 2004). In the early 1800s, German schools began to implement the "whole-word" method. This method focused on children learning to recognize and pronounce a whole word before studying the elements that made up the word. In the mid-nineteenth century, Americans considered this method and incorporated it into their reading books, in conjunction with 
the letter sound phonics method. In the late 1800 s, the whole-word method diminished and there was renewed interest and emphasis on phonics again. Then, in the $1920 \mathrm{~s}$, the whole-word approach reappeared with the arrival of the Dick and Jane series, which was a series of basal readers that relied heavily on whole-word reading. This approach, also known as the look-say approach, dominated into the 1960s, when the pendulum swung back toward an increased interest in phonics after Rudolph Flesch's Why Johnny Can't Read and Jeanne Chall's Learning to Read: The Great Debate were published and released (Savage, 2004). Flesch challenged the emphasis on teaching reading through a sight method by advocating that phonics is the best, and only, method that should be used in beginning reading instruction (Chall, 1996). In the 1970s, the "whole language" movement evolved after psycholinguists emphasized a holistic approach to reading and writing that relied heavily on the use of children's literature instead of books that were controlled with structured language. At this point, phonics was not completely ignored, but it was integrated into literature-based curriculums. In the 1990s, the phonics debate arose again due to disappointing results on reading achievement tests. Because of the low reading scores, several states passed laws that mandated a stronger emphasis on phonics instruction. Today, phonics is still a very hot topic and has become the centerpiece in early reading instruction (Savage, 2004).

The reason for such debate is that children enter kindergarten and first grade at different levels of reading readiness and therefore have different instructional needs. For instance, children who enter first grade with many hours of literacy preparation from home or preschool are closer to having skills such as independent reading and writing than those who enter school with few or no hours of literacy preparation. Therefore, 
implementing a basic phonics curriculum will provide additional practice and review for higher achieving students, but not teach new concepts as it will for lower achieving students (Adams, 1990).

\section{The Need for Phonics}

Based on theories of psycholinguistics, cognitive development, child development, and learning disabilities, several researchers have demonstrated the significance of phonology (phonemic awareness, phonics, decoding, word analysis, etc.) in the beginning stages of reading. If phonology is not acquired early on, there is a possibility that word recognition, reading comprehension, and fluency will suffer (Chall, 1996). One must be aware of the ultimate goal in reading (comprehension) and successively identify its prerequisites. Adams (1990), states that:

To have extracted the full meaning of written text, readers must first have understood its individual sentences. To have understood its individual sentences, readers must first have correctly analyzed the clauses and phrases for those sentences. Whereas proper analysis of those phrases and clauses depends on having correctly recognized their component words, recognition of each word depends on having processed its spelling patterns or phonological translations. Finally, recognizing the spelling or phonological translation of a word depends on having processed the ordered array of individual letters that comprise it. (p. 237)

From this perspective, learning the alphabetic script and phonological translations is essential in early reading because it will enable the written word to flow quickly and effortlessly from print to meaning. It will also allow readers to actively give thoughtful attention to the task of comprehension. With this in mind, the goal of phonics instruction is to guide and accelerate the learning process of decoding in order to allow children to focus more attention on comprehension (Adams, 1990). 
Linnea Ehri $(1978,1991,1998)$ has conducted a vast amount of research on literacy acquisition. Her research reflects her interest in how children learn to read and spell and what causes difficulties in becoming good readers and spellers. Ehri's theory is that children eventually learn how to read by memorizing words and storing them in their mental lexicons for later retrieval. However, children need grapho-phonetic skills in order to use a mnemonic system to retrieve the words. Knowing words by sight will allow children to focus their attention on comprehending the text being read. She explains her theory more thoroughly through stages of reading development.

According to Ehri (1998), the first stage of reading development is the prealphabetic stage. During this stage, children do not have any concept of letter-sound relationships. Instead, children use visual clues to read. For example, they may recognize the word monkey because the letter $y$ looks like a monkey's tail. The next stage of reading development is the partial-alphabetic stage. During this stage, children learn that letters have corresponding sounds that are used to read words. Because they have acquired some letter-sound knowledge and are beginning to read simple words, children begin memorizing the words after several exposures. At this point, children focus their attention on the initial and final consonants in words, which leads to the confusion of similar words, such as got, great, and goat. The third stage of reading development is the fully-alphabetic stage. During this stage, children become proficient in decoding words based on letter-sound relationships. They are able to read words by blending sounds together. Because children are able to decode words with speed and accuracy during this stage, more and more words are being stored in memory. At this point, children can focus more attention on fluency and reading comprehension. 
However, when an unknown word is encountered, they can decode the word using the decoding strategies learned in the partial and fully-alphabetic stages. The final stage of reading development is the consolidated alphabetic stage. During this stage, children begin to memorize patterns in words and use these patterns to read unknown words with similar patterns. For example, once children learn the pattern -est, then words such as best, rest, pest, and test are more easily read. However, proficiency in the previous stages is a prerequisite for being able to use this strategy.

Ehri also believes that using context to read a word cannot be an approach in itself. Instead, a contextual approach is only used to confirm whether the word read is correctly pronounced. First, one must have knowledge in letter-sound relationships to confirm the pronunciation of words. Then, the reader can use the context to determine if the word read fits in the sentence correctly. She has found that only relying on context to read or "guess" a word does not work the majority of the time. Therefore, she emphasizes the need to teach children to read starting with a phonics approach. The idea is that good readers have a strong foundation in decoding skills and are able to fall back on this knowledge as one of several strategies to read unknown words. On the other hand, poor readers, who also tend to be poor decoders, generally rely heavily on a guessing strategy to read the word.

Ehri (1998) cites theory and evidence on how important the alphabetic processes are in learning to read words and how grapheme-phoneme knowledge is essential in literacy acquisition. According to Ehri (1998), learning to make sense of print (i.e., to read) is not a natural process like learning to speak because the brain is specialized in 
processing spoken language, not written language. Therefore, special experiences are required to engage the brain in decoding print.

Ehri (1998) identifies five different ways that readers might read words:

1. decoding unknown words by blending letter-sounds

2. using a more advanced form of decoding, such as blending familiar spelling patterns

3. retrieving sight words from memory

4. making analogies between unknown words and known words

5. using context cues to predict words

Although reaching a point where most words are stored in memory and recognized by sight (like most adults) is the most efficient way to read words in text, the other four means of reading are also important in being able to identify unknown words. For example, knowledge and the use of letter-sound correspondences will allow the reader to confirm that there is a match between the word's pronunciation and the spelling on the page. Being able to fall back on this form of self-correction allows for more accurate reading and less room for errors that too often disrupt comprehension. Ehri (1998) places great emphasis on knowledge of letter-sound relationships. She states that this knowledge provides a powerful mnemonic system that links the written form of a word to its pronunciation in memory. Once the mnemonic system is well-known, readers will be able to learn to read words and, subsequently, build a lexicon of sight words with ease.

Ehri (1998) describes how alphabetic processes are central in learning to read and provides suggestions for early literacy instruction. She suggests that beginning readers must learn all their letters and learn how to use letter knowledge to group them into 
graphemes that represent sounds. Then, children must become aware that words are made up of phonemes. Most importantly, children need to learn grapheme-phoneme correspondences, for both consonants and vowels. They should be able to segment sounds of words into phonemes, segment letters of words into graphemes, and match the sounds to the letters. Finally, children need to acquire strategies, such as decoding and analogizing, in order to read unfamiliar words. Overall, she emphasized that children who have a good understanding of the alphabetic system should consequently have an easier time retaining words in memory for reading. If the proper alphabetic foundation for learning to read is established, then later goals, such as speed, accuracy, and automaticity, are more likely to be achieved. Ehri (1998) stresses that "there is no way that beginners can attain mature levels of reading and writing without acquiring knowledge of the alphabetic system" (pp. 32-33).

Similarly, the amalgamation theory, also proposed by Ehri (1978), suggests that early literacy primarily deals with adding orthographic information for words to the phonological, semantic, and grammatical information that is already known by the individual. This theory emphasizes that words are acquired by using letters as symbols for sounds, and predicts that phonological recoding plays a significant role in the acquisition of a reading vocabulary from the start. Ehri suggests that a child's knowledge of letters and sounds provides a basis for being able to form connections between letters seen in words and the sounds that are detected in pronunciations. Children who are aware of the relationship between letters and the corresponding sounds are able to store the associations in their memory and recall them when necessary. 
A study that adds support for the importance of phonics instruction is one by Dahl, Scharer, Lawson, and Grogan (1999), which focuses on the great debate between phonics and whole language. Whole language advocates claim to incorporate phonics into their instruction, but do not believe in teaching phonics in isolation. However, the authors declare a lack of evidence on the extent to which whole language teachers really embed phonics within their curriculum and student outcomes, in terms of phonics knowledge. Therefore, the purpose of their mixed methods study was to provide documentation that would inform teachers, parents, and members of the research community about the amount of phonics instruction and its relationship to students' achievement in whole language classrooms.

Whole language community members were asked to nominate prospective sites and teachers for their study. Thirty-eight nominated classroom teachers were visited and interviewed to determine whether they met the criteria to participate (i.e., first grade classroom, no teacher training in Reading Recovery, no commercially prepared phonics program being implemented, no student teachers, fewer than five students receiving Reading Recovery services, willingness to invite researchers into the classroom, childcentered curriculum, meaning-centered processes with embedded skill instruction, wide selection of children's literature including trade books, time set aside for self-selected reading and writing of the children's choice, and cooperative interactions among students). Eight classrooms were selected for the study, with a total of 178 participants.

To answer their first research question on what phonics teaching looked like in whole language first grade classrooms, the researchers collected data through half-day observations, field notes, tape recorded lessons, copies of student work, and interviews. 
They focused on teacher and student interactions with letter-sound relationships, types of letter-sound activities, and teachers' philosophies of the whole language method and their approach to teaching phonics within the curriculum. To answer their second research question (patterns of phonics learning that were evident in comparison to student achievement through pre- and post-tests), they used four quantitative measures of phonics learning: (a) encoding in context, (b) decoding in context, (c) encoding in isolation, and (d) decoding in isolation.

The instructional findings were divided among three categories: (a) what was taught, (b) where phonics instruction occurred, and (c) how teachers conducted instruction. Through extensive qualitative data collection and analysis, the results showed that phonological awareness, phonemic awareness, and phonemic segmentation constituted more than a third of instruction. They also found that phonics instruction addressed consonant and vowel patterns within the context of reading and writing, and phonics skills and strategies were taught in combination, while making reference to procedural explanations. The most common phonics strategies that were seen throughout phonics teaching and learning included: (a) using letter-sound correspondences to work from familiar to unfamiliar words, (b) elongating words to produce the sounds in order, (c) using voice-to-print matching to check the words being read with the words in print, (d) using graphophonemic information for miscues in reading, and (e) rechecking writing by rereading, while paying close attention to letter-sound relationships in the words written.

Phonics instruction appeared to occur evenly throughout whole language activities, therefore being taught while children were engaged in both reading and 
writing. In teaching phonics instruction, teachers seemed to keep track of individual students' progress and tailored appropriate instruction for each individual within reading and writing conferences in which phonics instruction was usually conducted. Besides the individual sessions, teachers also provided differentiated instruction during whole-group reading and writing activities. Achievement findings showed that all students made significant gains in encoding and decoding, both in and out of context, demonstrating achievement in phonics knowledge by the end of first grade.

Overall, these results demonstrate that phonics was being taught in whole language classrooms and that patterns of phonics achievement were present throughout decoding and encoding measures. The authors also added that the phonics instruction that was embedded within the whole language classrooms was systematic, (i.e., it was deliberated, planned, and intensive, in the sense that it occurred frequently, the teacher paid a lot of attention to it, and it was included throughout a variety of instructional activities). Although this study did not contain whole language characteristics because it followed a synthetic-like approach, Dahl and colleagues still provided support for the importance of phonics instruction.

\section{Teaching Methods}

Within the debate of whether to teach reading primarily through phonics or through whole language, there is also a debate of which phonics methods will result in better decoding skills. It is well known that children's ability to decode words is important in their development of becoming independent readers (Stahl et al., 1998). However, the best phonics approach to use in teaching early reading is still unknown. 
Systematic phonics. Research has shown that an early systematic focus on teaching decoding leads to increased reading achievement when compared to a more disorganized and nonsystematic approach. It has also suggested that the most important thing to keep in mind is that all phonics instruction should be systematic because it leads to better decoding (Stahl et al., 1998). In 2000, the National Reading Panel (NRP) sought to answer many of the questions relating to phonics instruction through an extensive meta-analysis. The purpose of their report was to examine research concerning systematic phonics instruction, which entails planned phonics instruction including a carefully selected set of letter-sound relationships that are organized into a logical sequence and taught explicitly. The NRP identified 38 studies that compared the reading performance of three types of "problem readers" who had received systematic phonics instruction to those who were given nonsystematic phonics instruction, such as wholelanguage programs, basal programs, and sight word programs, as well as no phonics instruction at all. The systematic phonics instruction approaches used in the experimental groups included: (a) synthetic phonics (teaches students to convert letters into sounds, then blend the sounds to create recognizable words), (b) analytic phonics (teaches students to analyze letter-sound relationships once a word has already been identified), (c) phonics-through-spelling (teaches children to transform sounds into letters in order to write words), (d) phonics in context (teaches children to use sound-letter correspondences in combination with context cues to identify unfamiliar words they encounter in text), and (e) analogy phonics (teaches children to use parts of written words they are already familiar with to identify new words). Regardless of the approach used, the idea was that systematic phonics instruction helps children acquire knowledge of letter-sound 
relationships such that they can use that knowledge to decode unfamiliar words and recognize familiar words with accuracy and automaticity. After the meta-analyses were conducted, the NRP was able to answer many questions about the impact of systematic phonics instruction on growth in reading in comparison to non-phonics instruction. The findings suggested that:

1. Systematic phonics instruction contributes to children's growth in reading, more so than unsystematic or no phonics programs.

2. The various types of phonics approaches did not differ statistically from each other, suggesting that all specific systematic phonics programs are equal at teaching children decoding skills.

3. Phonics instruction produces larger growth in reading when it starts in kindergarten or first grade (before independent reading).

4. Systematic phonics instruction is better than non-phonics instruction in preventing reading difficulties among at-risk students, as well as helping to remediate difficulties in disabled readers.

5. Systematic phonics enhances growth in word-reading skills (for kindergarteners, first graders, and older struggling readers) and comprehension (for younger students and reading disabled students).

6. Systematic phonics instruction contributes to kindergartners and first graders ability to apply letter-sound knowledge to spell words.

The NRP report is relevant to this study because it consisted of the analysis of phonics instruction with similar characteristics to the one used in this study. The phonics intervention using pseudowords was systematic because it taught beginning readers the 
correspondences between graphemes (letters) and phonemes (sounds), and how to use this knowledge to read and decode words. One limitation of the NRP is that the role of the teachers in both the treatment and control groups used for this meta-analysis were not clearly understood. More information is needed on whether the instruction was scripted, whether teachers were previously trained, and the similarities between teachers' effectiveness and creativity throughout phonics instruction.

Analogy-based approach. Analogy-based phonics approaches begin by teaching children to break down words into component parts by using known words. Children learn how to decode unknown words by using words and word patterns with which they are already familiar. First, children are introduced to common phonogram patterns and word parts. Then, teachers explicitly teach students how to use the key words taught to decode other unfamiliar words. Some studies suggest that children need to have lettersound knowledge before they can benefit from analogy reading, whereas, others have found no difference between varied approaches (Stahl et al., 1998).

In 1992, Bruck and Treiman conducted a study that focused on determining whether teaching young children to pronounce new words based on analogies is best taught when based on analogies to rimes, initial consonant vowel units, or vowels only. The participants in their study consisted of 39 English-speaking first grade students from the Montreal area. All classes followed a whole-language philosophy, with no systematic teaching of phonics. There were 13 participants in each training condition.

The children were taught 10 consonant-vowel-consonant (CVC) clue words and separated into three different analogy-training groups. Depending on the training received, the children were required to learn target words that shared the rime, consonant- 
vowel $(\mathrm{CV})$, or same vowel as the clue words learned. After the training trials, children were given a retention test, which required the children to read each of the target words without being shown the clue words. On the following day, the children were given a generalization test, which consisted of reading 20 nonwords that were derived from the clue words.

The results of their study showed that rime-based analogies had the best shortterm results, but not the best long-term results because it appeared as though memories of the taught words faded more rapidly in children taught by rime-based methods. The findings also suggested that children in the rime and CV group did not apply the strategies they were taught to pronounce the nonwords. Instead, the children used single grapheme-phoneme information to do so. Although all children showed improvement in the generalization tests because they were all able to learn some information about the links between graphemes and phonemes through training, those in the vowel group showed greater improvements because they were shown the connections more explicitly. These results suggest that vowel analogy training may be more beneficial because vowels are harder to pronounce than consonants. It was also found that beginning readers might profit more from a small-unit segmentation strategy than a large-unit segmentation strategy. Instruction of larger units only is not sufficient enough because children tend to pronounce unfamiliar words on a phoneme-by-phoneme basis. In fact, they need instruction on the relationship between single graphemes and phonemes with a special emphasis on vowels. The authors suggest that once children grasp the concept of single graphemes and phonemes, then it is possible that they may benefit from instruction on 
using analogical strategies to process larger orthographic units. Bruck and Treiman (1992) conclude that:

In order to take full advantage of their inclination to segment spoken and printed words into onsets and rimes and to use this information productively for pronouncing unfamiliar words, children must learn something about the relations between individual graphemes and individual phonemes. (p. 386)

Another analogy-based study (Ehri \& Robbins, 1992) investigated the reading skills of beginning readers who were able to read words by analogy. They wanted to know whether children in an analogy condition would read more transfer words than those in a control condition. They were also exploring whether the differences between both groups would be apparent for decoders and nondecoders.

The participants in their study consisted of 102 kindergarten and first grade students (52 nondecoders and 50 decoders) from five elementary schools in northern California. Participants went through three sessions, each consisting from 15 to 20 minutes. Session 1 was a series of pretests (word-reading test, nonsense word reading, letter naming) and three trials of the word-training task, which made sure students could read words until they reached criterion. Session 2 continued the word-training tasks until students reached criterion, then had the participants read transfer words with no corrective feedback followed by corrective feedback. Finally, Session 3 included a spelling dictation test, which tapped participants' memory for the words that were previously practiced.

Their findings suggested that reading unfamiliar words by using analogies to known words is an easier reading strategy than reading unfamiliar words phonetically. However, in order for beginning readers to read words by analogy they must have some 
skill in phonological recoding. The authors added that children tend to use reading by analogies as a temporary strategy, which was later replaced by phonological recoding once the analogy strategy is perfected. They concluded that decoders used both analogy and phonological decoding strategies to read unknown nonwords. Prior phonological recoding skills should assist beginning readers in reading unknown words by analogy to known words. However, more research is needed to determine how this occurs.

Based on the findings from this study, it can be argued that providing students with synthetic phonics instruction using pseudowords early on (in kindergarten) may improve students decoding skills even if one believes in using an analogy-based approach. The early, synthetic phonics instruction that was used in the current study may provide a foundation for the analogy-based strategies that may be subsequently implemented.

Embedded phonics approach. An embedded phonics approach is one that occurs in the context of authentic reading and writing experiences (Stahl et al., 1998). It is also known as a whole-to-part approach, which consists of phonics instruction that is integrated into reading activities in which children's literature is the primary tool for helping children learn to read (Savage, 2004). This approach is similar to reading instruction based on a whole-language perspective. An example of a phonics program that uses an embedded phonics approach is Reading Recovery. During this phonics program, children spend most of the reading instruction time reading and writing connected text and very little time on phonics. Lessons begin with rereading books of the students' choice. The students then reread the book used the previous day, while the teacher makes running records. During that time, the teacher addresses some reading 
weaknesses immediately by having students make and break words using magnetic letters. Then, the students write sentences, cut them up, and reassemble the words to create the sentences again. Finally, the teacher introduces a new book, which children attempt to read independently. Similarly, in whole-language classrooms, phonics instruction is embedded in the context of reading and is sensitive to the individual needs of the students. The methods, strategies, and instruction within whole-language classrooms vary from classroom to classroom and teacher to teacher. Particular wholelanguage programs may or may not challenge students to read difficult texts and may or may not provide students with the necessary phonics instruction needed. However, by using an embedded phonics approach (labeled whole-language or not), it is generally believed that children will increase in word recognition abilities and phonological awareness through the context of reading and writing (Stahl et al., 1998).

Synthetic phonics. Because there are several types of approaches to teaching phonics as previously noted by the NRP (2000), synthetic phonics warranted further investigation for the purpose of this study. As opposed to analogy-based phonics and embedded phonics, synthetic phonics programs simply teach children to transfer letters into sounds and blend the sounds to decode words. This approach is designed to help children master phonics with a part-to-whole technique in which students learn lettersound correspondences and use that knowledge to blend the sounds to pronounce/read words.

Lyndsay Macnair wrote an excerpt explaining her experience using synthetic phonics (Macnair, Evans, Perkins, \& Goodwin, 2006). She described how synthetic phonics lessons usually last approximately 30 to 40 minutes and are split into six parts: 
(a) warm-up (oral activities), (b) revision (review previous lessons), (c) new sound (introduce a new letter and corresponding sound), (d) word making (blend, segment, create words), (e) letter formation (write the new letter), and (f) consolidation (reinforce lesson with reading and writing activities). This approach concentrates on teaching and practicing letters and sounds and blending them to make words. Little phonics time is spent on reading sentences or books. Synthetic phonics instruction is also very structured with routines.

Macnair states that she was most surprised with the speed and eagerness that her students later approached reading. They began to display competent word attack skills and were reading new words without hesitation. They viewed reading new words as a challenge instead of a fear. The synthetic phonics program also resulted in her students sounding out and writing phonetically-spelled words. She felt that teaching with this approach had a great impact on her students' capabilities and confidence in reading and writing. She concluded by stating, "In my opinion the measure of its success is the joyful expressions of a class of children reading a new book for the first time or a piece of writing to a friend" (Macnair et al., 2006, p. 49).

Although this excerpt does not provide empirical evidence that a synthetic approach to phonics is the best approach, it does suggest some ideas to take into consideration for the development of the synthetic-like phonics intervention that was used for the current study. The pseudoword phonics curriculum used in the present study consisted of manipulating, blending, segmenting, and reading pseudowords, not real words. Similarly though, it put great emphasis on letter-sound correspondences. 
Johnston and Watson (2004) conducted two empirical studies in which they concluded that synthetic phonics led to better decoding than either an analytic phonics approach or an analytic phonics approach that incorporates phonological awareness training. Three groups of 5-year-olds participated in the first experiment, which started two weeks after they entered school. The first group received instruction using an analytic phonics approach where the children learned letters and sounds within the context of words they had already been taught. They were only taught the relationship between letters and sounds in the initial position of words (beginning sounds). The second group also received phonics instruction using an analytic approach, however, this group was taught how to segment and blend phonemes in spoken words (phonological awareness). The third group received instruction using a synthetic phonics approach in which the children were taught letters and sounds at a more rapid pace than the second group. After the first few letters were taught, the children were shown how to blend and synthesize the sounds together to create and read unfamiliar words. The teachers were given a script to follow on a daily basis, which consisted of the same list of words for all three groups. The participants were given a pre-test before the interventions were implemented, then they received instruction 20 minutes a day for 16 weeks, and then were given a post-test. Fifteen months after the 16 -week phonics programs, all the participants were given a second post-test. Within this time, the two analytic groups undertook the synthetic phonics intervention. Because the children were not taught individually, the authors suggested that there might have been teacher effects. Therefore, their analyses were carried out with classes, rather than participants as the random variable. 
In their first experiment, it was noted that the synthetic phonics group covered more letters and sounds and received more exposure to letters in different positions in words compared to the two other groups. This gave them reason to provide the analytic groups with synthetic phonics. The purpose of their second experiment was to control for the differences in speed of letter and letter sound learning, as well as letters being taught in all positions. This experiment started 6 weeks after the beginning of the new school year. The new participants were divided into three groups: (a) no-letter training group (given pronunciations, but attention was not drawn to letter sounds within words), (b) accelerated letter learning group (learned two letter sounds a week, but only in the initial position of words), and (c) synthetic phonics group (learned two letter sounds a week, but in all positions of words). In addition to their normal classroom analytic phonics programs, two 15-minute training lessons for 10 weeks were implemented. The children were given a post-test after the 10 weeks, then 3 months after the training, and then again 9 months after the training (start of the second year of schooling). By the time the posttests were administered at 3 months and 9 months after the training, all the children had already received instruction concerning letters and sounds in all positions in words.

The results of the first experiment showed that the synthetic phonics approach helped students acquire better decoding skills than the analytic phonics program and the analytic plus phonological awareness program in developing reading, spelling, and phonemic awareness ability. Findings also suggested that the synthetic approach taught children how to read irregular words better than the other two groups. In the second experiment, when speed of letter learning was controlled, the synthetic phonics group still outperformed the analytic phonics group. The authors concluded that synthetic phonics 
helped students develop more decoding skills than analytic phonics and phonological awareness training in teaching reading, spelling, and phonemic awareness. Although both approaches (synthetic and analytic) teach children that letter sounds are a guide to the pronunciation of unknown words, the difference in how the letter sounds are taught seems to be important for developing decoding skills. In a synthetic phonics approach, children learn about the function of letters and sounds in all positions in words, as well as sounding out and blending them together. In an analytic phonics approach, the teacher initially teaches letters and sounds that appear at the beginning of words and teaches children to read by sight word recognition until attention to letters in all positions in words is taught at a later time.

Although several other studies have shown that phonological awareness is a prerequisite for phonics instruction (letter-sound correspondences), the findings from Johnston and Watson's (2004) study suggest that synthetic phonics will help children develop the phonological awareness skills because this approach consists of sounding out and blending letters. Synthetic phonics also teaches spelling by having children analyze spoken words phonemically and then select the appropriate corresponding letters. Findings also suggest that even children who enter school with no prior phonological skills show a significant gain in phonemic awareness after receiving systematic phonics instruction. Finally, even when speed for letter sound learning was controlled, a synthetic phonics approach produced better results in children's decoding than an analytic approach because it allowed children to become aware of the phonemic structure of spoken words by teaching them (a) that there is a correspondence between letters and phonemes, (b) that letter sounds can be blended together to pronounce unknown words, 
and (c) that spelling words consists of building up letters that correspond to the phonemes in spoken words. A synthetic phonics approach also led to better reading of pseudowords and irregular words, increased the ability to read words by analogy, and resulted in a low incidence of reading failure.

Since a synthetic phonics approach has a positive effect on children's early reading development and helps children acquire more decoding skills than an analytic phonics approach, it will be used in the present study. Not only did Johnston and Watson's (2004) study add support for the choice of phonics method used in the present study, it also suggested some designs and teaching methods that were taken into consideration. Similar to the data collection procedures used in their study, the current study also included analyses with classes instead of individual participants to reduce the possibility of teacher effects. The synthetic phonics lesson used in their study was considered when developing the pseudoword curriculum that was implemented in the current study. Although their study did not include it in their description, synthetic approaches typically use pseudowords for decoding practice because they provide children the opportunity to apply their knowledge of sound-symbol relationships in reading words (Savage, 2004).

Another study that provides support for the use of a synthetic phonics approach to teach beginning readers is Foorman, Francis, Novy, and Liberman (1991). The purpose of the study was to explore the relations between phonemic segmentation, word reading, and spelling. They examined how more letter-sound (more-LS) instruction or less lettersound (less-LS) instruction would affect average first graders' progress in reading and spelling. The participants were 80 first graders from three different schools in Houston, 
Texas. Half of the subjects were enrolled in three public school classrooms that taught reading with an emphasis on basal series and words in meaningful contexts, whereas the other half of the subjects were enrolled in three classrooms in two parochial schools that also used basal series, but with an emphasis on letter-sound correspondences. The participants were given the Gates-MacGinitie Reading Test, Basic R, Form 1 (letter sounds, vocabulary, letter recognition, and comprehension) and the PPVT-R (untimed word reading test of 60 words) in October. Spelling tests, reading tests, phonemic segmentation tests, and Rosner's Test of Auditory Analysis Skills (deletion of initial, medial, and final sounds) were administered in October, February, and May.

The researchers found that the students in the more-LS classes had developed knowledge of orthographic strategies, whereas the students in less-LS classes were still developing alphabetic strategies. In addition, those who received more-LS instruction showed a higher growth rate for reading regular and exception words compared to those who received less-LS instruction.

Although these results seem accurate, the researchers suggest that the conclusions be looked at with caution because of the limitations within the analyses. These limitations included: (a) 25 participants were excluded from the analyses because of high initial phonemic segmentation scores, (b) power was reduced because of the omission of subjects, and (c) variability in percentage gain was reduced because of the restricted range in the phonemic segmentation test. However, based on the results available, they concluded that the students in the more-LS instruction classes, who showed more improvement in reading regular and exception words aloud, may increase the probability of enhancing their lexical access and comprehension in the future. In addition, since 
children in the more-LS classrooms accumulated knowledge about spelling regular words, they also had greater recognition of the correct pronunciation of words. It appears that first graders' ability to segment and blend sounds helped them relate their knowledge of regular word spellings to correct word readings. This demonstrates the possibility of the more-LS classrooms generating more accelerated growth in reading than the less-LS classrooms.

While many still argue what good phonics instruction looks like and which phonics approach is most beneficial, few people in the field of education argue against the idea that "the ultimate purpose of phonics is learning to read and write more effectively and efficiently, and that phonics instruction that produces the ability and the inclination to read and write must indeed be judged as good" (Savage, 2004, p. 134). Stahl et al. (1998) suggest that, regardless of the approach, good phonics instruction should (a) develop the alphabetic principal, (b) develop phonological awareness, (c) provide a thorough grounding in letters, (d) not teach rules, use worksheets, or dominate instruction, (e) provide sufficient practice in reading words, (f) lead to automatic word recognition, and $(\mathrm{g})$ only be one part of reading instruction. The approach that one takes should depend on the needs of each individual child (Stahl et al., 1998). If, for example, a child has a low literacy background then he or she may benefit from more direct instruction in order to learn the concepts that others may have learned through home experiences. On the other hand, children with reading backgrounds may benefit from a reading program that involves more complex materials and self-selected texts (Stahl et al., 1998). 


\section{Memory}

Psychological theories of reading development suggest that learning to read involves the process of developing word recognition procedures that will enable children to access the meanings and pronunciations of printed words (Stuart, Masterson, \& Dixon, 2000). These procedures must be able to aid in the child's ability to read both familiar and unfamiliar words. Children must develop a sight vocabulary of familiar words that can be instantly recognized as well as a system for translating print to sound for the pronunciation of unfamiliar words in order to access their meaning.

In Groff (2001), which examined the literature on approaches used to teach beginning readers to read, it was found that memory played a significant role in spelling as well as reading. The findings suggest that poor readers are also poor spellers, but good readers are not always good spellers because correct spelling demands more than just correct reading. Good readers who spell poorly most likely lack in phonological awareness and decoding skills, and therefore rely on visual memory while reading in order to compensate for their weaknesses. Good readers who are also good spellers use visual memory to read and spell but have their phonological awareness and decoding skills to fall back on when they encounter unfamiliar words. Automatic phonological translations provide good readers with a backup system for visually recognizing less familiar words (Adams, 1990). According to Byrne, Fielding-Barnsley, and Ashley (2000), children who continue to memorize words while reading and are poor decoders are more likely to develop reading difficulties.

With similar findings to that of Byrne et al. (2000), Stuart et al. (2000) conducted two training studies that were designed to investigate the relationship between 
phonological awareness, sound-to-letter mapping knowledge, and printed word learning. They also investigated the relationship between visual memory and teaching methods used with 5-year-olds at the early reading stages of development. The participants were pre-tested on initial sound segmentation and sound-to-letter matching to form two groups of 10 children each: good graphophonic skills group (GP+) and poor graphophonic skills group (GP-). The first training experiment consisted of nine sessions. Within each session, two books, which contained lively illustrations for each target word, were read to the children immediately followed by a flashcard testing of each target word. A total of 36 exposures per word were made after the entire training period. After all nine sessions, the children were given a post-test on recall and recognition (i.e., previously used flashcards). The results of this training experiment suggested that visually-based logographic reading may exist, but this is only true as a default strategy for the less graphophonic skilled children who have no other option available to them. Visual memory was significantly correlated with GP- children's word learning, but was never correlated with that of GP+ children even though both groups did not differ in visual memory scores at pre-test.

The second training experiment consisted of three training conditions: learning words in isolation through flashcards, learning words in illustrated contexts through books, and a combination of the two (learning words in the illustrated context with previous exposure to the isolated words with flashcards). Each group consisted of ten 5year-old non-readers. Equal numbers of GP- and GP+ were placed in each group. Eight training sessions were implemented to later determine children's recall, which were tested under three conditions as well: isolated word, word-picture matching, and word in 
sentence structure. The results of this training experiment showed that teaching children new vocabulary through the use of flashcards led to more successful acquisition of vocabulary and took less time than teaching them through repeated reading of books. In addition, children's graphophonic skills did influence their speed of sight vocabulary acquisition regardless of the method that was used to expose children to the new vocabulary.

Overall, their findings from training experiments one and two suggest that children who were more phonologically aware and who were also aware that speech sounds are represented by letters performed higher than children in other training groups. In regards to memory, their study showed that children who are engaged in repeated reading of texts will quickly memorize the text and learn to recite it accurately. However, children with GP + can not only memorize text through rote memory, but can also match the sounds in their heads with the words on the page. In other words, these children can use their letter-sound knowledge to check whether the words read aloud correspond to the words on the page. This, in turn, allows children to store frequently read words in memory, as sight vocabulary, while also having the advantage of using their graphophonic skills as a checking device. On the other hand, the GP- children did not have the ability to make those systematic links between orthography and phonology, and relied solely on memory of pre-existing semantic representations. Unfortunately, these children will, often times, fail to understand that corresponding letters to sounds is a requirement in learning to read, and consequently, will interpret learning to read as the ability to memorize text. 
Overall, the results of these two training studies suggest that phonological awareness, knowledge of the alphabet, sight vocabulary development, and the establishment of phonological recoding procedures all play a significant role in successful initiation into printed word recognition. However, because of the small sample size used in their study (training experiment one: $N=20$, training experiment two: $N=30$ ), further research needs to be conducted on this topic.

The results of Stuart et al.'s (2000) training experiments added support for the present research study because systematic phonics instruction was used in order for students to develop a strong foundation in letter-sound knowledge, blending, manipulating, and decoding. Through the use of pseudowords within phonics instruction, the possibility of memorizing words was eliminated in the present study. Based on their findings, it seemed possible that a phonics curriculum that focuses on pseudoword reading may result in children becoming skilled in graphophonics. Subsequently, this may suggest that children will not need to exclusively rely on memory, but instead have the ability to fall back on their decoding skills when reading.

\section{Pseudoword Reading}

The ability to decode unknown words when reading text is a predictor of skilled readers. With this idea in mind, Pullen, Lane, Lloyd, Nowak, and Ryals (2005) investigated whether explicitly teaching the essential components of beginning reading instruction to nine struggling first grade students would promote their skills in decoding pseudowords. They implemented an intervention that consisted of manipulative letters used to blend, sound out, and spell words. Children's decoding skills were monitored by repeatedly measuring pseudoword reading. The intervention employed several elements 
of effective reading instruction. The intervention was explicit and systematic, emphasized developing phonological awareness and decoding skills, used repeated reading to build fluency, incorporated appropriate texts, and was based on small-group instruction. To make certain that the interventions were implemented with consistency throughout each group (three groups of three), teachers were observed during instruction twice throughout the course of the intervention using a checklist. In order to examine the latency effects of the training, students' performance was monitored daily with a pseudoword reading measure.

Pullen et al. (2005) mention that they selected this measure because, according to Curtis (1980), the ability to read pseudowords has been found to be a reliable predictor of reading achievement. Assessing students with pseudoword measures increases the likelihood that they have not had previous encounters with the words, thereby causing students to convert the print to speech and rely on their phonetic decoding ability to identify the pseudowords accurately. Therefore, using a pseudoword reading task allowed the researchers to examine participants' automaticity in decoding while confirming that the tasks were not affected by simple memory for the words. The results of their study showed that students demonstrated an increase in decoding skills, as evidenced by the pseudoword reading tasks, due to the intervention that included the use of manipulative letters. In the discussion section of their article, the authors suggest that children who can read pseudowords with accuracy and fluency tend to have little difficulty decoding running text composed of familiar and regularly pronounced words. Consequently, pseudoword decoding was also highly correlated with reading comprehension. 
A limitation of their study, which the authors openly admit, is that the study was conducted toward the end of the school year resulting in a limited amount of time to collect data. Because of this limitation, the authors also inform their readers that, although the data revealed changes in pseudoword reading skill, the findings should be viewed with caution. Additionally, the small number of participants $(N=9)$ in their study may leave some doubt as to whether or not the findings would be true in most cases.

Even with the limitations in mind, Pullen et al.'s (2005) study still provided support for the current research study. If pseudoword reading tasks are used to monitor students' phonetic decoding skills, then this supports the notion that pseudoword instruction may be a new approach to phonics instruction because they do not allow the opportunity to rely on memory of words. Another aspect of their study that helped in the implementation of the current study is that the researchers periodically observed the teachers using a checklist during implementation of the intervention to increase consistency throughout the course of the study and across all teachers.

After collecting and analyzing data from their longitudinal study, which included teaching phonemic awareness to young children, Byrne and Fielding-Barnsley (1993) found that pseudowords were only deciphered (in a post-test) by those children who had a clear understanding of the alphabetic principle. These results led them to suggest that if pseudoword reading is treated as an alternative for reading real words that have yet to be encountered previously, then children who become competent in this sort of reading will become more independent and successful readers. The problem that seems to occur is that children begin to memorize the words they read and often forget the basics of 
decoding. This may cause reading failure when children encounter more difficult and unfamiliar phonetically spelled words.

Since this theory on phonetic decoding instruction using pseudowords has no empirical support, the current study provided empirical data for the relation between phonetic decoding instruction using pseudowords and success in phonetic decoding and reading.

\section{Summary of Research}

The importance of phonics instruction is widely acknowledged (Dahl, et al., 1999; Ehri, 1978, 1998; Johnston \& Watson, 2004; National Reading Panel, 2000), but what continues to remain unclear are the best practices and most effective instructional strategies that teachers should implement to ensure their students' mastery of phonetic decoding skills. Ehri's (1998) theory on early reading stresses the importance of lettersound knowledge based on the notion that children progress though a series of sequential phases of reading and that reading is not a natural process like learning to speak. She emphasizes that the brain must undergo special experiences, which are necessary in order to decode print. Furthermore, early readers cannot excel in reading and writing without knowledge of the alphabetic system and its corresponding sounds. This theory supports the amalgamation theory Ehri (1978) proposed 20 years earlier, which argues that phonological recoding plays a significant role in early reading because words are acquired by using letters as symbols for sounds.

Dahl et al. (1999) provides additional support for the importance of phonics. In the midst of the great debate between phonics and whole language, Dahl et al. (1999) wanted to investigate whether phonics was being embedded within whole language 
classrooms and students were benefiting from the instruction. After extensive data collection and analysis, Dahl et al. (1999) found that phonics instruction was being implemented within the eight classrooms observed and children were demonstrating phonics knowledge. Their findings support the central role that phonics plays in children's early reading development, whether implemented in isolation or within other contexts.

In order for students to benefit from phonics instruction, one must keep in mind that it must be explicit and systematic (National Reading Panel, 2000). After conducting a meta-analysis of several research studies that compared systematic phonics instruction classrooms to non-systematic or no phonics instruction classrooms, the NRP reported the significance of using a systematic approach when teaching phonics. They found that systematic phonics approaches contributed to children's growth in reading, helped prevent reading difficulties among at-risk students, enhanced word-reading skills and comprehension, and contributed to children's ability to apply letter-sound knowledge to spelling. According to this meta-analysis, good phonics instruction should be systematic.

There are a number of ways in which systematic phonics instruction can be implemented, including analytic, analogy-based, phonics through spelling, embedded, onset-rime, and synthetic. Macnair et al. (2006) and Johnston and Watson (2004) provide support for the effectiveness of synthetic phonics. Synthetic phonics instruction focuses on teaching children letters and sounds, while manipulating and blending them to create and read words. Lyndsay Macnair, a teacher who volunteered to implement the synthetic phonics approach in her first grade classroom, reports that it had a great impact on her children's capabilities and confidence in reading and writing. Johnston and Watson 
(2004) found that using a synthetic approach, as opposed to an analytic approach, resulted in the development of sight word recognition, phonological awareness, and growth in early reading development overall.

Because learning to read involves the process of developing word recognition procedures that will enable children to access the meanings and pronunciations of text, Stuart et al. (2000) conducted a study to investigate the relationship between phonological awareness, sound-to-letter mapping knowledge, printed word learning, visual memory, and teaching methods. Their study suggested that children who show significant gains in reading are more phonologically aware and understood that sounds are represented by letters. Regarding memory, students with less graphophonemic skills were able to make visual representations. However, students with more graphophonemic skills were able to fall back on their letter-sound knowledge when they encountered an unknown word. In contrast, students with less graphophonemic skills did not have the knowledge to do so, therefore relying solely on memory. This provides support for the importance of letter-sound knowledge in the development of early reading.

To avoid the possibility of relying on memory and failure to develop a strong foundation of letter-sound knowledge, pseudowords may be used as a new phonics approach that will help students develop better decoding skills. Byrne and FieldingBarnsley's (1993) suggestion of using pseudoword reading as an alternative for reading real unfamiliar words adds support for this notion. Their suggestion stemmed from a pseudoword reading post-test that was administered to measure decoding skills. They found that pseudowords were only deciphered by children who had a clear understanding of the alphabetic principle. Pullen et al. (2005) used a pseudoword reading assessment to 
measure students' decoding skills on a daily basis. They mentioned that the reason for using this assessment was because Curtis (1980) had previously found pseudoword reading to be a reliable predictor of reading achievement. Similar to that of Byrne and Fielding-Barnsley (1993), they agreed that the pseudoword assessment would ensure that students did not have the pseudowords stored in memory because they did not have previous encounters with the words. This type of assessment would, therefore, provide accurate results of decoding abilities.

The literature reviewed in this chapter covered research related to the constructs explored in this study: systematic, synthetic-like phonics instruction using pseudowords and students' success in phonetic decoding. The present research study contributes to the literature by providing more information about the great debate between phonics and whole language, the need for phonics, approaches for teaching phonics, the relationship between memory and early reading, the use of pseudowords as an assessment tool, and a new approach for phonics instruction. 


\section{CHAPTER III}

\section{METHODOLOGY}

The purpose of this study was to investigate the effects of a phonics curriculum using pseudowords on students' success in phonetic decoding using a two group (experimental, control) non-randomized longitudinal design with repeated measures. This study examined a systematic, synthetic-like phonics curriculum (taught students to convert letters into sounds, then blend the sounds to create words) consisting of the manipulation of consonants and vowels to create and decode pseudowords within a kindergarten classroom. The goal was to determine if a Pseudoword Phonics Curriculum (PPC) would increase students' ability to read unfamiliar, phonetic words, as assessed by the Phonetic Word List Assessment (PWLA).

This study consisted of three phases of phonics instruction and four assessment time points using the author-created PWLA (described below). During the first phase of the study, baseline data were collected to determine students' normal growth after receiving regular real-word phonics instruction and to ensure equality between both groups. During the second phase, data were collected to determine the relationship between the PPC and students' progress in phonetic decoding. The experimental group received pseudoword phonics instruction, while the control group continued to receive regular real-word phonics instruction. During the third phase of the study, data were collected to determine sustained growth after students in the experimental group returned to a regular real-word phonics setting. The three phases occurred in order and with no breaks in between. Before and after each phase, which lasted 28 school days, students received the PWLA. Students were assessed at Time 1 (before Phase 1), then received 
regular phonics instruction for 28 school days, and then were assessed again at Time 2 (after Phase 1 and before Phase 2). Immediately following, students received either regular phonics instruction (control group) or pseudoword phonics instruction (experimental group), and then were assessed again at Time 3 (after Phase 2 and before Phase 3). Finally, both groups received regular phonics instruction and were reassessed for the last time at Time 4 (after Phase 3).

This chapter describes the methodology used for this study. The first and second sections provide an overview of the site where the study was conducted and the convenient sample of students who participated in the study. The third section describes the process by which the PWLA was created, the items in the assessment, and how the assessment was administered. The fourth section does the same for the Psuedoword Phonics Curriculum (PPC) that was implemented in the experimental classroom. In the fifth section, the procedure of the study is described in detail. This chapter concludes with two sections (six and seven) on the research design of the study and a description of the statistical analyses that were conducted.

\section{Site}

In the summer of 2008 , the researcher identified a private school that would be willing to participate in this study. The director of the school and the researcher took graduate level courses together at Florida International University (FIU). When the director heard about the study, she volunteered to have the study conducted at her school, The Biltmore School.

The Biltmore School is a Reggio Emilia inspired private school in Miami, Florida. The Biltmore School is accredited by the Association of Independent Schools of Florida 
(AISF) and the Southern Association of Colleges and Schools (SACS), and is currently an International Baccalaureate (IB) candidate school. The Biltmore School is comprised of students who represent a total of 19 different cultural backgrounds. The school borders two different neighborhoods, Coral Gables and West Miami. The population of Coral Gables is composed of $47 \%$ White Non-Hispanic, $46 \%$ Hispanic, $3 \%$ Black, and $4 \%$ other races and ethnicities. The estimated median household income in Coral Gables is approximately $\$ 81,000$. The population of West Miami is composed of $15 \%$ White Non-Hispanic, $84 \%$ Hispanic, $1 \%$ Black, and $7 \%$ other races. The estimated median household income in West Miami is approximately $\$ 42,000$. Students who attend The Biltmore School for kindergarten are required to pay a tuition ranging from $\$ 550$ (previously attended) to $\$ 860$ (new to the school) a month. However, some kindergarten students pay a reduced tuition because they receive special funding from a statesponsored program, known as Voluntary Pre-K (VPK). This program offers funding for all 4 year olds who attend private school, primarily those in preschool. However, if a student enters kindergarten at the age of 4 years old, then s/he is also eligible to receive funding from VPK. Therefore, students who entered kindergarten at The Biltmore School at age 4 paid reduced tuition rates because they received funding from the VPK program. This program has altered the socioeconomic composition of the school in comparison to previous years. During the course of the study, there were eight VPK students enrolled in the participating kindergarten classes who paid reduced tuitions.

\section{Sample}

Thirty kindergarten students (15 girls, 15 boys) with a mean age of 67.7 months old participated in the present study. The majority of students (67\%) were of Hispanic 
descent. Twenty-three percent of the sample included Exceptional Student Education (ESE) students who had a learning disability, suffered from an attention deficit disorder, or had a speech delay. In addition, $13 \%$ of the students were students whose first language was not English; therefore labeled as English Language Learners (ELL). During the first month of the study (Phase 1), there was an average of 1.27 student absences. One student, who was withdrawn from the school after Time 1, was omitted from the study. Complete demographic information, including means and standard deviations for the sample, is presented in Table 1.

Table 1.

Mean (SD) of Demographic Variables for the Overall Sample $(N=30)$

\begin{tabular}{lc}
\hline Variable & Overall Averages \\
& $M(S D)$ \\
\hline Age & 67.7 months $(5.0)$ \\
Girls & $.50(.51)$ \\
Hispanic & $.67(.48)$ \\
ESE & $.23(.43)$ \\
ELL & $.13(.35)$ \\
Absences (Phase 1) & 1.27 days $(1.70)$ \\
\hline
\end{tabular}

According to the data input specialist of the school, the participants were randomly assigned to two kindergarten classrooms during the beginning-of-the-year registration period. Table 2 depicts complete demographic information, including means 
and standard deviations, for each kindergarten class (one of which was the experimental group, the other was the control group).

Table 2.

Mean (SD) of Demographic Variables for Experimental Group and Control Group

\begin{tabular}{lcc}
\hline Variable & $\begin{array}{c}\text { Experimental Group } \\
(n=16)\end{array}$ & Control Group \\
& $M(S D)$ & $M(S D)$ \\
& $67.81(5.95)$ & $67.57(3.90)$ \\
Age & $.69(.48)$ & $.29(.47)$ \\
Hirls * & $.69(.48)$ & $.64(.50)$ \\
ESE & $.19(.40)$ & $.29(.47)$ \\
ELL & $.06(.25)$ & $.21(.43)$ \\
Absences (Phase 1$)$ & $1.06(1.53)$ & $1.50(1.91)$ \\
\hline
\end{tabular}

Note. * Significant independent $t$-test between the experimental and control group, $p<.05$.

Chosen by the director of the school, one classroom was the experimental group, consisting of 16 students, while the other classroom was the control group, consisting of 14 students. The average age of the students within each group was approximately 68 months old. Girls made up $69 \%$ of the experimental group ( 11 girls) and $29 \%$ of the control group (4 girls); therefore the classrooms were disproportionate in sex distribution. After conducting independent $t$-test analyses between the experimental and control group, a significant difference in sex, $t(28)=2.32, p<.05$, was uncovered. Because there is a 
significant difference in sex, it will be considered and analyzed throughout the results section. Both groups were similar in ethnicity, with the experimental group having $69 \%$ Hispanic students (11 Hispanic students) and the control group having 64\% Hispanic students (9 Hispanic students). The experimental group consisted of 19\% ESE students (3 ESE students), while the control group consisted of 29\% ESE students (4 ESE students). In addition, the experimental group had 6\% ELL students (1 ELL student) and the control group had 21\% ELL students (3 ELL students). Although independent $t$-tests did not show a significant difference between the two groups on ESE and ELL, the researcher was aware of the differences throughout the course of this study.

The groups were also similar in number of student absences: the experimental group averaged 1.06 absences and the control group averaged 1.5 absences during Phase 1 (the baseline growth phase). Two students (one from experimental and one from control) were absent on the last assessment time point, therefore, their progress was not included in the analyses that explored the data between Time 3 and Time 4.

\section{Phonetic Word List Assessment and Pilot Study}

The data were collected using an author-created Phonetic Word List Assessment (PWLA). The purpose of this assessment was to determine each student's progress in decoding skills. Content validity of the PWLA was examined using the pilot test described below in conjunction with expert judgment of the teacher and researcher. The assessment consisted of 60 phonetic words ( 15 three-letter words, 15 four-letter words, 10 five-letter words, 10 six-letter words, 8 seven-letter words, 1 eight-letter word, and 1 ten-letter word). In order for students to begin the assessment with confidence and comfort, the words presented in the assessment ranged from least difficult (3-letter 
words) to most difficult (10-letter word). To avoid ceiling effects, the PWLA purposely included difficult items along with easier items. If students were able to master the assessment with $100 \%$ accuracy, then their growth and improvement in decoding would have been impossible to determine.

Each student was assessed individually either by the researcher or a trained graduate student from FIU. The assessment included six index cards containing 10 words each. In order for the assessment to seem like a fun activity for the students, rather than a test-like format (print and white space), the index cards included a colorful illustration of a boy and a girl, each with a speech bubble containing five words. The students were encouraged to try their best to read all the words on each card. They were not corrected if words were read incorrectly. However, to avoid frustration, students were allowed to ask the administrator for help if they did not know how to read a word. Any word read by the administrator was counted as incorrect.

Each word read correctly was worth one point; therefore the maximum points one could achieve on this test was 60 points. The more words a student read correctly, the more points s/he received, and the more phonetically inclined s/he was assumed to be. Although the students were not timed throughout the assessment, the assessments did not take longer than 30 minutes per student to administer.

A pilot study was conducted to aid in the development of the PWLA. None of the students included in the pilot studies were included in the data collection for the current study. The following steps were taken in creating the PWLA:

1. Compiling words: The PWLA was created using words found on a Montessori website. The original word list consisted of 50 phonetic words 
(20 three-letter words, 20 four-letter words, 5 five-letter words, and 5 sixletter words).

2. Trial administration with gifted fourth graders: After the list was compiled and the PWLA index cards were created, 10 gifted fourth grade students were assessed to increase the likelihood that all words could be read by young fluent readers. Based on the results, four words were omitted from the list because some of the students were unable to read them.

3. Revision of Phonetic Word List: A word list was found in Bear's (2008) book and was used to alter and change some of the words on the PWLA. According to Bear, the lists in his book were based, to some extent, on Ed Henderson's list, also known as the McGuffey list. The revised PWLA contained the same number of words as the original Phonetic Word List.

4. Trial administration with gifted second graders: Ten second grade gifted students were then assessed using the revised PWLA. Second grade students were chosen, as opposed to fourth grade students, because second grade students were more likely to use some of their previously learned phonics skills to read the words, instead of relying on word recognition. Also, if second grade students were unable to read any of the words on the list, then the words would need to be omitted because a kindergarten student should not be expected to read a word that a second grader would have difficulty with. None of the words were omitted because all second grade students read the Phonetic Word List with 100\% accuracy. 
5. Trial administration with kindergarteners: For a true pilot of the outcome measure, 5 kindergarten students (intended sample) were assessed using the PWLA. These students represented typical higher achieving students within a regular Miami Dade County Public School (MDCPS) kindergarten classroom. Student 1 decoded $20 \%$ of the words correctly, Student 2 decoded $40 \%$ of the words correctly, Student 3 decoded $70 \%$ of the words correctly, Student 4 decoded $86 \%$ of the words correctly, and Student 5 decoded all of the words with $100 \%$ accuracy. In order to alter the assessment to avoid ceiling effects throughout the study, the teacher was asked to provide some information about the student who read the words with $100 \%$ accuracy and some suggestions for making the word list more difficult for students at his level. She mentioned that he came into kindergarten already knowing how to read and the only time he reads phonetic words incorrectly or makes mistakes is when he is rushing through his work. She suggested that adding words with more letters might be the key to a more difficult assessment.

6. Revision of Phonetic Word List to include more difficult words: A list of 45 five through ten-letter words was created based on the list in Bear's (2008) book. This list was then given to the same second grade gifted students as indicated above. The results were then analyzed. Any words that were misread by the students were omitted from the list. Five 5-letter words, five 6-letter words, eight 7-letter words, one 8-letter word, and one 10-letter word (all read by second grade gifted students with 100\% 
accuracy) were added to the PWLA. In addition, 5 three-letter words and 5 four-letter words were omitted from the original PWLA in order to keep the list to a maximum of 60 words.

7. Trial administration with kindergarten Student 5: The kindergarten student who was able to read the PWLA with $100 \%$ accuracy was reassessed with the revised Phonetic Word List. He was able to read 83\% of the words correctly. Since this student represented a high-achieving kindergarten student, it was assumed that no kindergarten student would be able to read all the words on the PWLA correctly, which would allow the researcher to monitor participants' growth and improvement in decoding skills across the study.

\section{Pseudoword Phonics Curriculum}

The Pseudoword Phonics Curriculum (PPC) followed a format similar to the school's phonics curriculum that was implemented throughout the first half of the school year. The PPC consisted of changing all real words used in the phonics lessons to pseudowords or words that the children would consider nonsense words.

Two intervention pilot studies were conducted in order to develop the PPC. The first pilot study dealt with teachers' perceptions of using pseudowords to teach phonics. The second pilot study developed and implemented a PPC in a kindergarten classroom setting. Teachers and students who participated in the pilot studies were not included in the present study. 


\section{Pilot Study on Teachers' Perceptions}

In the first pilot study, three kindergarten teachers were interviewed, each with a different number of years of kindergarten teaching experience. Each teacher taught kindergarten at a different school, but within the same school system (MDCPS). Within this school system, teachers are required to follow the same reading curriculum. However, approaches, strategies, forms of implementation, and teaching styles may vary from teacher to teacher. Information was gathered on their perceptions of teaching kindergarteners phonics through the use of pseudowords. Through extensive individual audio interviews, they were asked questions regarding their views on children's early reading development and what they believed a primary reading curriculum should entail. They were also asked to provide information about the reading curriculums they were currently implementing and the importance of phonics in early reading instruction. Then, they were asked to express their views on the importance and relevancy of information provided by the Nonsense Word Fluency portion of the Dynamic Indicators of Basic Early Literacy Skills (DIBELS) assessment. The interview questions ultimately lead to, and helped me gather supporting information for the following question: What are three kindergarten teachers' perceptions about teaching beginning readers phonics through the use of pseudowords?

The three kindergarten teachers, each with different levels of teaching experience, all agreed on the essential role that phonics plays in a child's early reading development. Throughout the course of this pilot study, several categories and themes emerged from the interviews. Within each category, themes with which the teachers' quotes associated 
were identified. Table 3 displays the categories and themes that stemmed from this pilot study.

Table 3.

Categories and Themes from Interviews

\begin{tabular}{ll}
\hline \multicolumn{1}{c}{ Category } & \multicolumn{1}{c}{ Theme } \\
\hline 1. How children learn to read & - being read to \\
& - letter-sound knowledge \\
2. How phonics is taught & - letter of the week \\
& - phonics centers / hands-on \\
3. Overall views on phonics & - can't read without it \\
4. Assessing using nonsense words & - ability to blend \\
& - knowledge of letter-sounds \\
\hline
\end{tabular}

All the teachers agreed that the key to children's process in learning to read is that they should be continuously read to at home and must develop a strong foundation in their ability to recognize letters and their corresponding sounds. It was evident that the teachers not only had similar beliefs about how children learn to read and the importance of phonics, but they also had very similar teaching styles as well. They all used a letterof-the-week approach when teaching their students letters and letter-sounds, and emphasized on the use of phonics centers and hands-on activities that incorporated letter blocks, interactive word walls, magnetic letters, felt letters, and picture matching. 
Two of the three teachers had currently implemented a minimal use of pseudowords in her reading instruction because it was part of the basal series. Both teachers stated that they use it for additional sounding out and blending practice. All three teachers mentioned the use of pseudowords to assess their students using an early literacy skills test. A common theme that emerged from this category was that they all felt it was a good form of assessment. They also stated that it provided them with insight on their students' knowledge of letter-sounds and their ability to blend the sounds together to read words. One of the teachers mentioned that "if DIBELS assesses this form of decoding, it must signify that there has been research on its success" (Ms. F). To the present author's knowledge, after extensive hours of research, the research in this area is very limited. There has been research on its success as an evaluative tool (Byrne \& Fielding-Barnsley, 1989, 1993; Curtis, 1980; Gough, 1983; Pullen et al., 2005; Shankweiler et al., 1999), but not as an alternative method to traditional phonics instruction using real words.

During the interviews, when the topic of using pseudowords to teach phonics came up, controversy arose. Because it was a new concept to all three teachers, it became apparent that they were not sure how they felt about it, thereby going back and forth on whether or not pseudoword phonics instruction would improve children's decoding skills. After the interviews were analyzed, it was found that each teacher provided some negative and positive aspects to this type of instruction. Table 4 clearly shows the wavering views teachers had regarding the use of pseudowords to teach phonics. 
Table 4.

Positive and Negative Views of Using Nonsense Words to Teach Phonics

\begin{tabular}{|c|c|c|}
\hline Teacher & Positive Views & Negative Views \\
\hline Ms. B & $\begin{array}{l}\text { - will not be scared to sound out } \\
\text { words they do not know } \\
\text { - may have no effect or may have } \\
\text { an effect, but will not hurt }\end{array}$ & $\begin{array}{l}\text { - has not seen the effects that } \\
\text { nonsense words have } \\
\text { - unsure about focusing only on } \\
\text { nonsense words }\end{array}$ \\
\hline Ms. S & $\begin{array}{l}\text { - will gain the decoding skills } \\
\text { necessary to read successfully } \\
\text { - would give a good indication of } \\
\text { how students' decoding skills are } \\
\text { developing } \\
\text { - will be targeting more sounds that } \\
\text { cannot be targeted phonetically } \\
\text { through the use of real words }\end{array}$ & $\begin{array}{l}\text { - assessments (DIBELS) will not be } \\
\text { accurate } \\
\text { - unsure about the value in teaching } \\
\text { phonetically spelled nonsense } \\
\text { words as opposed to meaningful } \\
\text { phonetically spelled words } \\
\text { - should be able to read nonsense } \\
\text { words based on the background } \\
\text { knowledge that we have taught } \\
\text { them (with real words) }\end{array}$ \\
\hline Ms. F & $\begin{array}{l}\text { - interesting way to teach students } \\
\text { how to read and decode words } \\
\text { - gives them the opportunity to } \\
\text { manipulate sounds and read words } \\
\text { that they might not usually hear } \\
\text { - allows them to understand the } \\
\text { process they will need in the } \\
\text { future with new text and more } \\
\text { difficult text } \\
\text { - assessments should be geared to } \\
\text { instruction } \\
\text { - will allow students to think a } \\
\text { different way when encountering } \\
\text { a new, difficult or unfamiliar } \\
\text { word }\end{array}$ & $\begin{array}{l}\text { - } \text { students who have not yet } \\
\text { mastered all the letters and sounds } \\
\text { get easily confused } \\
\text { - unable to use prior knowledge to } \\
\text { confirm the word they read }\end{array}$ \\
\hline
\end{tabular}

According to Ms. S, one downfall of this type of instruction may be that children will miss out on meaningful phonetically-spelled words that could be tied into stories being read in class. Therefore, a better approach might be to not only focus on pseudowords, but a combination of both pseudowords and real words (Ms. B). Ms. F 
stated that pseudoword phonics instruction may not work because she has noticed the difficulties and confusion that some of her students have encountered when presented with pseudowords.

In contrast, many more positive things were said about teaching phonics through the use of pseudowords. According to the teachers, it is possible that students will not be scared to sound out words that they have never seen before (Ms. B), they will gain decoding skills necessary to read successfully (Ms. S), and it will allow students to think a different way when encountering a new, difficult, or unfamiliar word (Ms. F). Throughout our interview, Ms. S continued to make an interesting point about phonics instruction using pseudowords. She thought that pseudoword phonics instruction might present better results in children's decoding skills than real-word phonics instruction because:

...throughout the use of pseudowords, the pseudoword learners will be targeting more sounds that cannot be targeted phonetically through the use of real words. If you're manipulating letters and it doesn't matter in which order you put them cause they're pseudowords then you have so many more combinations... They may be more successful if they have more sounds to manipulate.

Since more combinations of words can be made, this type of instruction might increase the amount of practice the children will have in decoding. After further discussion, all three teachers stated that they would be willing to implement this type of instruction in their classrooms.

My initial perception of using pseudowords to teach phonics was that students would show more improvement in decoding than when using real words. Upon completion of this pilot study, I found that I had stronger feelings about the positive 
impact that teaching phonics using pseudowords would have on children's decoding skills and their overall reading success. With the help of all three teachers, I became more open-minded to the topic and, not only considered the positive comments that were made, but also took into account the negative aspects that this type of instruction may entail.

\section{Pilot Study on the Pseudoword Phonics Curriculum}

The second pilot study was conducted to investigate the use of pseudowords in place of real words in a kindergarten phonics reading program. A kindergarten teacher at a MDCPS (who did not participate in the present study) agreed to participate in this week-long pilot study. Previous to the implementation of the PPC, the researcher reviewed the phonics program that the teacher was implementing at the time. The teacher was implementing the Houghton Mifflin reading series, which was required by MDCPS. The researcher changed all words used in the phonics lessons to pseudowords, while maintaining the original lesson format. For example, the real word pot was changed to create the pseudoword flot when the short sound of the letter "o" was introduced in the lesson. After the words were taught in isolation, the students read books from a phonics library. At this point, in order to evaluate how the students transitioned from pseudoword phonics instruction to reading real words in text using the skills learned, the words were not changed.

After a week of teaching her students using the PPC, the teacher was asked to reflect upon her experiences and her students' experiences throughout the lessons. She admitted that she originally thought it would be harder to teach phonics using pseudowords. However, after following the PPC, she reported that "it was a great 
experience." She also reported feeling confident that her students were using their knowledge of phonics to sound out the pseudowords, knew their sounds, and were not just recognizing familiar words. She mentioned that on the first day, her students kept reminding her that those were not real words, but "after the initial shock, they did great." She felt that, because of the pseudoword reading exercises, her students realized that they had the tools needed to help them read. Finally, she added that she may have seen better results if she would have continued the lessons for a longer period of time, but that the researcher was probably right about her hypothesis.

\section{Study Procedures}

The current study was conducted during the second semester of the school year, after the school's winter vacation. It lasted 18 weeks.

Prior to the study, I met with both of the participating teachers to review the phonics curriculum that was being implemented at the time in order to develop the PPC with a similar format. For example, if students were learning the short $o$ sound and reading words such as mop, jog, and Tom, then students receiving the PPC would also be learning the short $o$ sound, but instead they would be reading words such as gop, mog, and vom. The school's phonics curriculum was implemented on a daily basis within a 45-minute block. The first 15 minutes was whole-group instruction focusing on a specific letter of the week or day. Together, the class and the teacher created a web with words that began with the letter of the week (or day) while using objects around the classroom for ideas. For the remaining 30 minutes, the class was split up into two groups. One group worked on phonemic awareness and sound to symbol relationship activities out of their individual copy of the Modern Curriculum Press Phonics Workbook 
with the teacher's assistance for 15 minutes, while the other group worked on a planned small-group phonics activity with the paraprofessional for 15 minutes. Then, after 15 minutes, the groups switched.

Because it was important for the teachers to be consistent throughout the study, each teacher was given a schedule to follow. The researcher made it very clear to the teachers that both classrooms must stay consistent with the phonics instruction for purposes of validity. During the study, the researcher observed phonics instruction, lesson plans, and student work (bi-weekly) to increase the likelihood of the curriculum being accurately implemented. In order to reduce bias and increase consistency, after receiving a thorough training, one graduate student from FIU assisted the researcher in administering the PWLA to all the participants. Figure 1 shows the complete and detailed multiple time-points design that was used for this study.

Time 1 was used to determine the baseline of each student's ability to decode phonetic words by administering the PWLA on day one. Then, after 28 school days of regular phonics instruction (Phase 1) for both groups, all the participants were reassessed using the same assessment (Time 2). The assessment was administered to monitor students' progress after receiving regular phonics instruction and making sure that performance differences did not exist between the experimental and control group.

Table 5 depicts the mean and standard deviation of scores on the PWLA for each group and overall at Time 1 and Time 2. Change scores over the first 28 school days were also analyzed. Since significant differences did not exist between student assessment scores on Time 1 and Time 2, teacher effects and typical age-related growth differences between the experimental and control group were not expected to be an issue. 


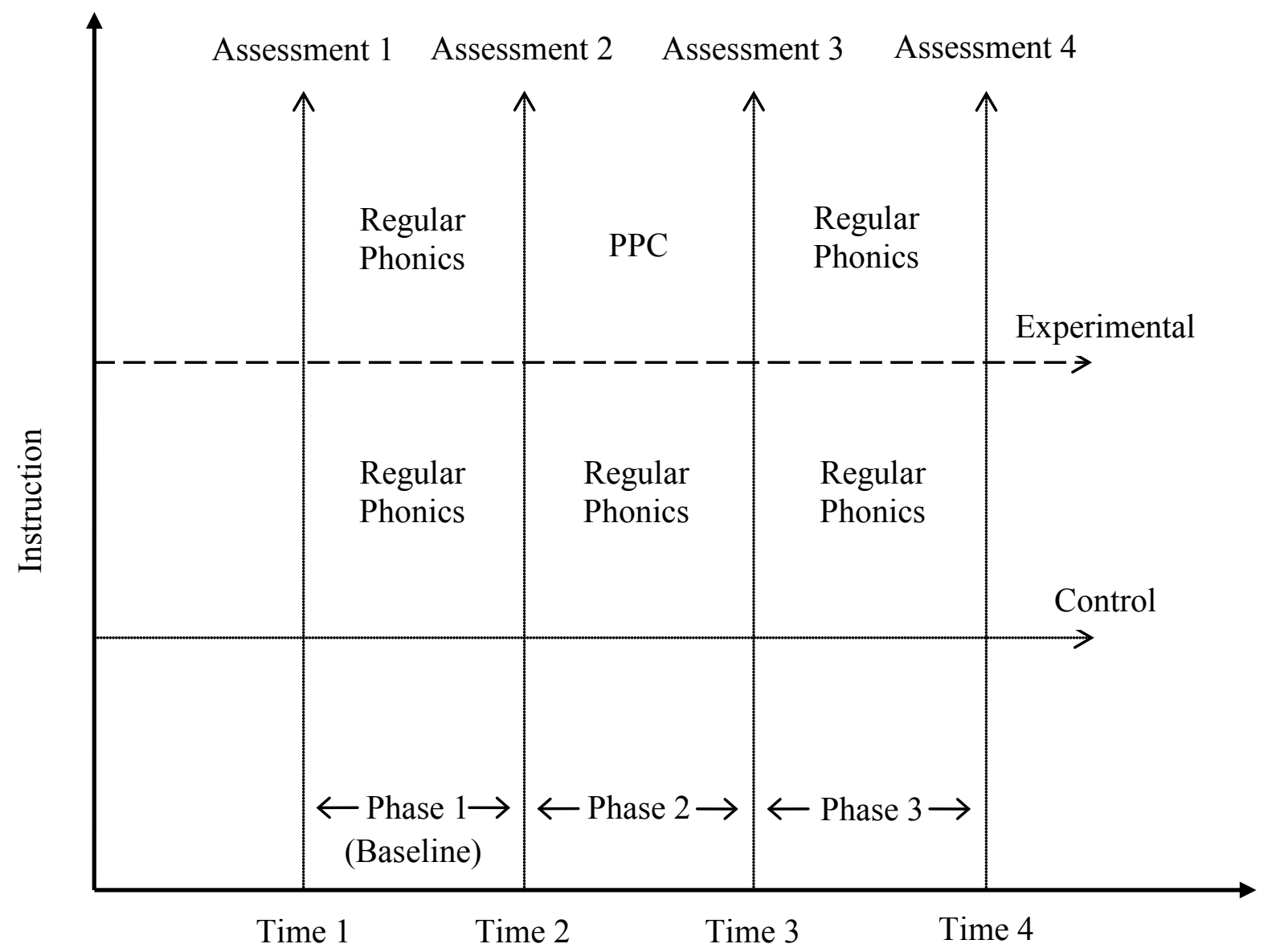

Timepoints

Figure 1. Implementation schedule for study on Pseudoword Phonics Curriculum.

Phase 2 was implemented throughout the next 28 school days. During this phase, the experimental group received instruction using the PPC, whereas the control group continued to receive instruction using the regular phonics curriculum. The students were then reassessed at Time 3 to determine the effects of the PPC or progress in decoding. Finally, during Phase 3 (28 school days), both groups received regular phonics instruction as they did in Phase 1 and were reassessed at Time 4. 
Table 5.

Mean (SD) of Scores on the PWLA for Experimental Group, Control Group, and Overall

\begin{tabular}{lccc}
\hline Scores & Experimental Group & Control Group & Overall \\
& $(n=16)$ & $(n=14)$ & $(\mathrm{N}=30)$ \\
& $M(S D)$ & $M(S D)$ & $M(S D)$ \\
\hline Score (T1) & $4.44(10.97)$ & $5.79(14.85)$ & $5.07(12.71)$ \\
Score (T2) & $9.0(15.73)$ & $9.43(16.83)$ & $9.20(15.97)$ \\
Score (Change) & $4.56(4.76)$ & $3.64(1.98)$ & $4.13(3.26)$ \\
\hline
\end{tabular}

\section{Research Design}

A two group (experimental, control) non-randomized longitudinal time design (Newman \& Newman, 2006) with repeated measures was used to allow the researcher to create a baseline growth (between Time 1 and 2) and control for any dependent data, external factors, or typical age-related growth. For example, assessing students at Time 1 and then again at Time 2 after receiving regular instruction, allowed the researcher to determine each student's normal growth, regardless of the classroom. The growth could be the result of several factors, such as teacher effects on students' learning or maturity of the students in each classroom.

This research design also controlled for extraneous factors that may have, inadvertently, caused improvements or growth in the outcome measure. In the context of this study, one example of within-subject control was to explore the individual growth of students. This method allowed the researcher to control for typical age-related change and development. By creating a baseline for each student, the researcher was able to 
analyze each student's normal growth and considered this growth when interpreting the results. For example, if between Time 1 and Time 2, a student's decoding skills increased by $5 \%$ and increased another $5 \%$ between Time 2 and Time 3 , then one could assume that his/her demonstrated growth was due to maturity and not necessarily what $\mathrm{s} /$ he learned from the PPC. However, if the student's decoding skills increased by $20 \%$ between Time 2 and Time 3, then the demonstrated growth can be attributed to the PPC because his/her normal growth between Time 1 and Time 2 was only 5\%.

Between-subject control was maintained by comparing the results of the experimental group who received the PPC to the control group who did not receive the PPC during Phase 1. This method helped control for dependent data such as teacher effects. Since both the control group and the experimental group received regular realword phonics instruction during Phase 1 (T1 to $\mathrm{T} 2$ ), the difference in growth between the two groups can be attributed to classroom or teacher effects. For example, if the students in the control group show higher growth in phonetic decoding than the students in the experimental group during Phase, then it is possible that the teacher of the students in the control group had a greater impact on her students' ability to decode. By using the multiphase design, teacher and classroom effects can be measured and statistically controlled. Similarly, other external factors, such as one class having a paraprofessional, parent volunteers, or small-group instruction are also not an issue.

Often, interventions are designed to benefit individuals for a sustained timeperiod beyond the intervention itself. It can be argued, though, that participants' growth trajectory is temporary and has only been altered as a result of participation and receipt of extra attention during the intervention. An additional time point (Time 4) was added to 
the present study to determine if the PPC caused a more permanent change in growth trajectories as oppose to a temporary change only seen during the experimental phase. The fourth time-point was used to determine the sustainability of students' decoding skills after returning to a classroom with regular phonics instruction. During the final phase (Phase 3), the experimental group and the control group received regular phonics instruction. The outcome measures at Time 4 allows for the exploration of whether students continued to show improved growth in decoding (more permanent change) or returned to their baseline growth rate (temporary change).

\section{Statistical Analysis Plan}

Preliminary analysis was conducted to determine the variables (ethnicity, ELL, ESE, sex, etc.) that should be included or excluded from further analyses. Next, the hypotheses were explored by conducting multiple regression analyses. Additionally, since the structure of the data included within-subject nesting, multi-level models were used to further analyze the data.

When analyzing the outcome of students' phonetic decoding skills after receiving real-word or pseudoword phonics instruction, the issue of a nested design became a concern because there were multiple assessments within each child (i.e. a repeated measures design). This data structure is common in educational research (Raudenbush \& Bryk, 2002) and requires special analytic techniques. If traditional data analysis techniques are applied to nested data, then the assumption of independence will be violated because each of the four scores on the PWLA provided by a given child are dependent on that child ${ }^{1}$. When the assumption of independence is violated, the chances of finding a significant result when no true difference exists increases. A single-level 
statistical test that yields a significance of $p<.05$ may actually be as high as $p=.50$ (Hox, 1995, 1998). In other words, the violation of the assumption of independence increases a researcher's chance of making a type I error (i.e., finding an effect when an effect does not exist).

Taking the research design into consideration, the statistical techniques that the researcher used for the current study are multilevel analyses in a regression framework using Hierarchial Linear Models (HLM). In contrast to the single-level method, HLM estimates a growth curve for each individual to establish a group growth curve using maximum likelihood estimations. The single-level method would be less accurate because it provides only examinations of group growth curves that are based on group means rather than individual growth.

The results of the regression analyses were used as a starting point for articulating a multilevel model for change. This was done to avoid the use of irrelevant control factors in the model. Therefore, the models that were tested with HLM are described in the Results chapter after the regression analyses are presented.

The basic model consisted of two levels: (a) within-child level; and (b) child level. The within-child level treated students' ability to decode phonetically spelled words (i.e., number of words correct on the PWLA) as a function of the three phases within the study. The specific within-child model (Level 1) for PWLA score $Y_{\mathrm{ij}}$ of the $i$ th student in the $j$ th classroom was:

$Y_{\mathrm{ij}}=\beta_{0 \mathrm{j}}+\beta_{1 \mathrm{j}} \mathrm{DTIME}_{\mathrm{ij}}+\beta_{2 \mathrm{j}} \mathrm{DTIME}_{\mathrm{ij}}+\beta_{3 \mathrm{j}} \mathrm{DTIME}_{\mathrm{ij}}+\epsilon_{\mathrm{ij}}$, 
where DTIME $1_{\mathrm{ij}}$, DTIME $2_{\mathrm{ij}}$, and DTIME $3_{\mathrm{ij}}$ were dummy coded variables to represent each time point of the study (Time 1 was the reference point with 0s for DTIME1, DTIME2, and DTIME3); and $\in_{\mathrm{ij}}$ was a Level 1 residual.

The child-level model (Level 2), which included the main effect for group (experimental group, control group) and interactions between group and time (from Level 1), were as follows:

$\beta_{\mathrm{mj}}=\gamma_{0 \mathrm{~m}}+\gamma_{1 \mathrm{~m}} \mathrm{GROUP}_{\mathrm{j}}+\eta_{\mathrm{mj}}$

where GROUP was a dummy variable for the group $(1=$ experimental; $2=$ control $)$; and $\eta_{\mathrm{mj}}$ was a Level 2 residual (random effect).

If both the control and experimental group improve in decoding, as assessed by the PWLA, then my first hypothesis will be supported. Additionally, if the results yield significant differences between the control and experimental groups at Time 3 and experimental students demonstrate sustainability of growth during Phase 3, then my second hypothesis will also be supported. This will indicate that students who receive phonics instruction by manipulating letters to create and read pseudowords will show a significant positive increase in their ability to decode phonetic words. Students in the experimental group will not only do better on the PWLA immediately after receiving instruction using the PPC, but will also demonstrate that improvements hold even after returning to the regular phonics curriculum. 


\section{CHAPTER IV}

\section{RESULTS}

The results section is divided into three parts. The first part consists of exploratory data analyses, which contains an examination of whether or not the demographic and extraneous factors played a role in decoding. The next part addresses the two hypotheses: (1) children who receive phonics instruction, regardless of the method of instruction, will show growth in word decoding, and will likely increase more in their decoding as the study progresses; and (2) children who receive phonics instruction through the PPC will show more improvement in decoding skills than children who receive real-word phonics instruction. The last part of this section presents a multilevel individual growth model for the relation between pseudoword phonics instruction and children's decoding skills across 3 months.

\section{Exploring Demographic and Extraneous Factors}

Initial exploratory data analyses were run on the demographic and extraneous factors to determine their relationship to children's decoding skills. All variables explored were either dichotomous or continuous factors. This section is organized by variable type. First, independent $t$-tests were used to examine mean differences in decoding skills based on the Phonetic Word List Assessment (PWLA) for the dichotomous variables, including sex, ethnicity, Exceptional Student Education (ESE), and English Language Learners (ELL). Next, bivariate correlations were conducted to determine if there were significant associations between the continuous factors and decoding skills. The continuous variables explored include age and number of absences. 
If significant mean differences and/or correlations were revealed, those factors were explored in subsequent analyses.

\section{Exploring Differences in Dichotomous Variables}

First, mean differences in PWLA scores for boys and girls were explored. Table 6 presents means and standard deviations of PWLA scores for boys and girls at each time point and during each phase (as change scores). Mean scores and standard deviations for boys and girls can be found in the top portion of Table 6 , and change scores can be found in the lower portion of Table 6 . As presented in the table, both girls and boys increased in PWLA scores from time point to time point. Girls and boys started off with approximately the same level of decoding skills. By Time 2, boys had a larger increase in scores than girls, with a difference of about two points. Then, at Time 3, girls and boys continued to show improvement in decoding, but boys continued to show larger gains; however, the rate of increase from Phase 1 (T1 to T2) to Phase 2 (T2 to T3) was about the same for both sexes. Greater differences were seen during the final phase of the study (T3 to T4), where boys showed an average increase of approximately 10 points, while girls increased by only 4 points. Therefore, boys consistently increased in PWLA scores at each time point and continued to show more and more growth from time point to time point. On the other hand, while girls were increasing in PWLA scores throughout the course of the study, their growth between the time points (change scores) was not as large in Phase 3 as it was in Phase 2.

Although descriptive statistics demonstrated that mean differences in PWLA scores between boys and girls were evident, independent $t$-tests were conducted to determine whether or not boys and girls scored significantly different on the PWLA at 
each time point and during each phase (change score). Results of the independent $t$-tests are also presented in Table 6 (right-hand side). The $t$-tests did not reveal any significant differences for any time point or for any change score.

Table 6.

Mean (SD) Differences in Sex for the Overall Sample across Time Points and Phases

\begin{tabular}{|c|c|c|c|c|}
\hline \multirow[t]{2}{*}{ Scores } & Girls & Boys & & \multirow[b]{2}{*}{$p$ value } \\
\hline & $M(S D)$ & $M(S D)$ & $t$ value & \\
\hline \multicolumn{5}{|l|}{ Score } \\
\hline $\mathrm{T} 1(N=30)$ & $4.47(11.06)$ & $5.67(14.54)$ & -.25 & .80 \\
\hline $\mathrm{T} 2(N=30)$ & $7.53(14.20)$ & $10.87(17.91)$ & -.57 & .58 \\
\hline $\mathrm{T} 3(N=30)$ & $14.80(17.83)$ & 20.47 (19.19) & -.84 & .41 \\
\hline $\mathrm{T} 4(N=28)$ & $18.43(21.25)$ & $31.71(22.27)$ & -1.62 & .12 \\
\hline \multicolumn{5}{|l|}{ Change Scores } \\
\hline $\mathrm{T} 1-\mathrm{T} 2(\mathrm{P} 1)$ & $3.07(3.58)$ & $5.20(6.19)$ & -1.16 & .26 \\
\hline $\mathrm{T} 2-\mathrm{T} 3(\mathrm{P} 2)$ & $7.27(8.15)$ & $9.60(9.51)$ & -.72 & .48 \\
\hline T3 - T4 (P3) & $4.38(8.27)$ & $9.79(9.05)$ & -1.66 & .11 \\
\hline
\end{tabular}

Since the control group had more boys ( 10 boys, 4 girls) than the experimental group ( 5 boys, 11 girls) and the exploratory analysis suggested that boys performed better than girls on the PWLA after receiving phonics instruction, sex differences in PWLA scores between the experimental and control group were further explored in the following sections. It is possible that girls showed larger increases in decoding after receiving 
pseudoword instruction, but did not continue to increase as rapidly when they returned to a regular phonics curriculum setting. However, the large increase in boys' mean scores may suggest that boys show increases in decoding during and after receiving phonics instruction, regardless of the type of instruction (pseudoword or regular). There is a possibility that boys benefit more from phonics instruction than girls, overall. Further analyses also investigated the possibility of an interaction occurring between girls' and boys' scores on the PWLA since girls increased in change scores from Time 1 to Time 3 and decreased during the last phase, while boys demonstrated growth in change scores throughout the study.

The second dichotomous variable explored was ethnicity. Mean differences in PWLA scores for Hispanics and non-Hispanics were analyzed first. Table 7 presents means and standard deviations of PWLA scores for Hispanics and non-Hispanics at each time point and during each phase (change score). Based on the mean scores presented in the table, it is clear that non-Hispanic students performed better than Hispanic students on the PWLA at all time points and in change scores.

Mean scores at Time 1 suggest that non-Hispanic students began the study with greater phonetic decoding skills than Hispanic students (six point difference). Taking this advantage into consideration, change scores were also examined. It was found that non-Hispanic students scored higher at Time 2, but more noteworthy, showed a greater increase in PWLA scores between Time 1 and Time 2 (Phase 1) than Hispanic students. At Time 3, both groups continued to show gains in their ability to decode phonetically spelled words, as assessed by the PWLA. However, the change scores of non-Hispanic students from Time 2 to Time 3 (Phase 2) were greater than the change scores of the 
Table 7.

Mean (SD) Differences in Ethnicity for the Overall Sample across Time Points and Phases

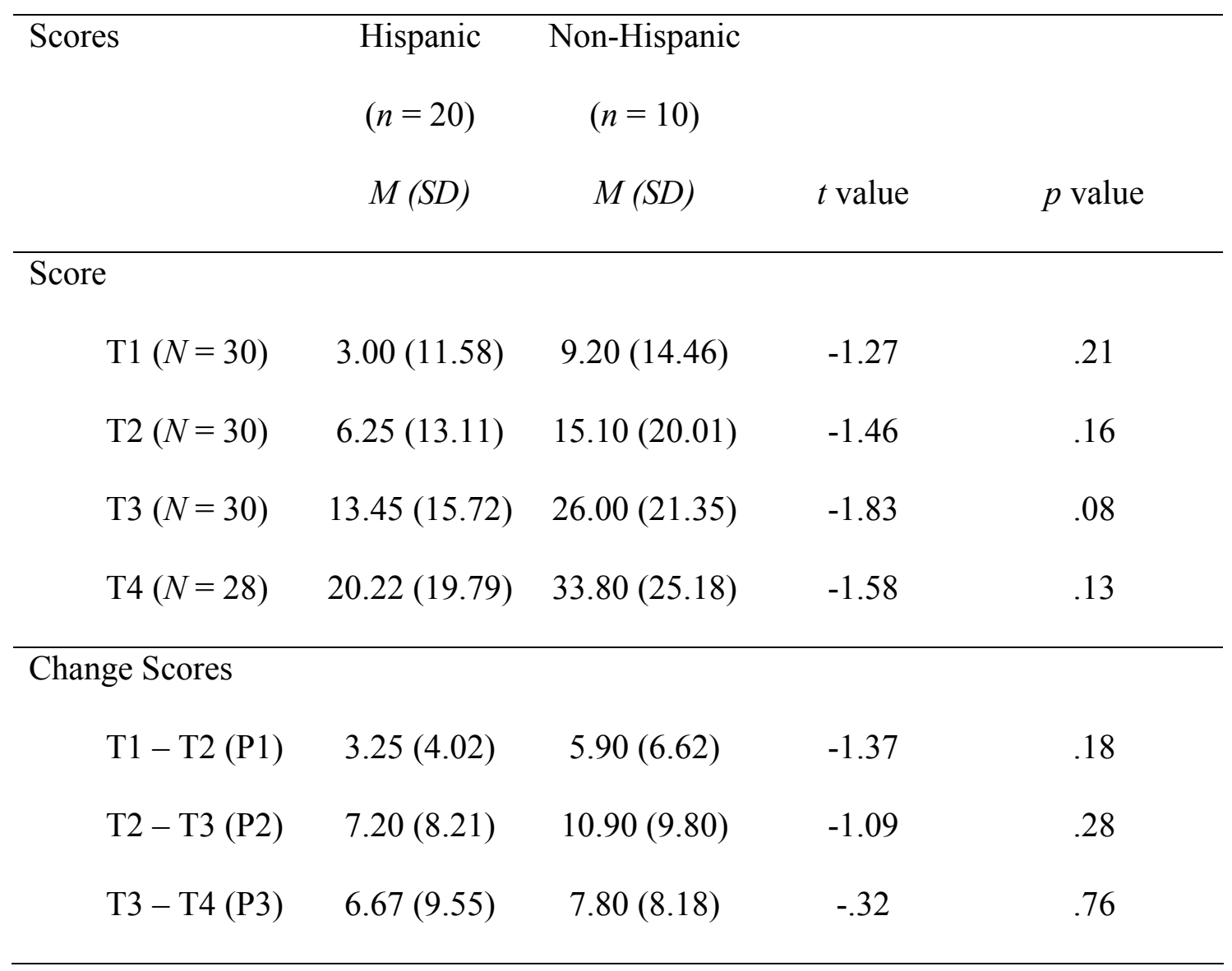

Hispanic students. The interesting thing to note from these mean scores and change scores is the decrease in change scores that occurred between Phase 2 and Phase 3. Although both groups continued to increase in PWLA scores between Time 3 and Time 4, their change scores decreased. While non-Hispanics were showing greater increases in scores and change scores throughout the previous time points and phases, their change scores decreased three points from Phase 2 to Phase 3. Interestingly, Hispanic students only decreased .5 points from Phase 2 to Phase 3 . It is possible that the non-Hispanic 
students scored very high on the PWLA at Time 1 and Time 2 (closer to the possible 60 points), therefore leaving less opportunity to show as much growth as the lower scoring Hispanic students from Time 3 to Time 4.

Although descriptive statistics demonstrated that there were mean differences in PWLA scores between Hispanic students and non-Hispanic students, independent $t$-tests were also conducted to determine whether or not Hispanic students and non-Hispanic students scored significantly different on the PWLA at each time point and during each phase (change score). Results of the independent $t$-tests are also presented in Table 7. The tests were not significant at any time point or during any phase. A marginal significance was found at Time $3, t(28)=-1.83, p<.10$. Although the mean scores were not significantly different from each other based on ethnicity, the large differences in mean scores and change scores found between the two groups (Hispanic and nonHispanic) and the decrease in change scores for both groups at P3, call for further exploration. Based on mean scores, change scores, and findings from the independent $t$ tests, it was possible that there is a relationship between students' ethnicity, their familiarity with the English language, and the amount of information they gather from phonics instruction based on their performance on the PWLA. Although the experimental group and control group have a proportionate number of Hispanic students and non-Hispanic students (both have more Hispanic than non-Hispanic), this variable was still considered in subsequent analyses to determine whether or not there was a relationship between ethnicity and PWLA scores.

In addition to the sex and ethnicity variables, the ESE and ELL variables were also explored. Means and standard deviations of PWLA scores for these dichotomous 
variables, at each time point and during each phase, are presented in Table 8. Based on the mean scores presented in the table, it is clear that both ESE and non-ESE students showed gains at every time point. Similar to the Hispanic variable (see Table 7), nonESE students began the study with higher decoding skills than ESE students at Time 1 (6point difference). Although both groups showed growth in decoding at Time 2, non-ESE students showed more growth in change score than ESE students, who only grew in PWLA scores by .86 points. However, ESE students showed great gains between Phase 1 and Phase 2 and maintained the increase in change score from Phase 2 to Phase 3. The non-ESE students continued to increase from Time 2 to Time 3 and Time 3 to Time 4 , but decreased in change score (by 2 points) from Phase 2 to Phase 3. This decrease in change score may have occurred because non-ESE students scored high on the PWLA at Time 1, which provided less opportunity to show as much growth as ESE students who may have scored close to zero (out of a possible 60 points) on the PWLA at Time 1. Independent $t$-tests were also conducted to determine whether a significant difference existed between ESE students' PWLA scores and non-ESE student PWLA scores at each time point and for each change score. The results from the $t$-tests are also presented in Table 8. According to the analyses, ESE and non-ESE students performed significantly different from one another at Time $3, t(28)=-2.32, p<.05$, and Time $4, t$ (26) $=-2.10, p<.05$. Significant differences were also found when analyzing the change scores between Time 1 and Time 2 (Phase 1), $t(28)=-2.05, p=.05$, and a marginal significance was found between Time 2 and Time 3 (Phase 2), $t(28)=-1.84, p<.10$. Therefore, non-ESE students seemed to respond better to phonics instruction (regardless of the type of instruction) more so than ESE students. However, the change scores for 
Table 8.

Mean (SD) Differences in ESE and ELL for the Overall Sample across Time Points and Phases

\begin{tabular}{|c|c|c|c|c|c|c|c|c|}
\hline \multirow[t]{3}{*}{ Variable } & & \multicolumn{4}{|c|}{ Score } & \multicolumn{3}{|c|}{ Change Scores } \\
\hline & & $\mathrm{T} 1$ & $\mathrm{~T} 2$ & T3 & $\mathrm{T} 4$ & T1-T2 & T2-T3 & T3-T4 \\
\hline & & $N=30$ & $N=30$ & $N=30$ & $N=28$ & & & \\
\hline \multicolumn{9}{|l|}{ ESE } \\
\hline Yes & $M$ & 0.29 & 1.14 & 4.43 & 9.00 & 0.86 & 3.29 & 3.83 \\
\hline$N=7$ & $S D$ & 0.49 & 1.95 & 7.72 & 18.00 & 1.46 & 6.16 & 9.97 \\
\hline No & $M$ & 6.52 & 11.65 & 21.65 & 29.45 & 5.13 & 10.0 & 7.95 \\
\hline \multirow[t]{2}{*}{$N=23$} & $S D$ & 14.26 & 17.55 & 18.94 & 21.78 & 5.39 & 8.96 & 8.68 \\
\hline & $t$ & -1.14 & -1.56 & $-2.32 *$ & $-2.10^{*}$ & $-2.05^{*}$ & $-1.84^{+}$ & -1.00 \\
\hline \multicolumn{9}{|l|}{ ELL } \\
\hline Yes & $M$ & 0.00 & 2.00 & 7.75 & 3.00 & 2.00 & 5.75 & 1.00 \\
\hline$N=4$ & $S D$ & 0.00 & 1.83 & 11.59 & 2.00 & 1.83 & 10.21 & 1.00 \\
\hline No & $M$ & 5.85 & 10.31 & 19.15 & 27.72 & 4.46 & 8.85 & 7.80 \\
\hline \multirow[t]{2}{*}{$N=26$} & $S D$ & 13.51 & 16.91 & 18.97 & 22.27 & 5.36 & 8.69 & 9.21 \\
\hline & $t$ & -.85 & -.97 & -1.16 & $-1.89^{+}$ & -.90 & -.65 & -1.26 \\
\hline
\end{tabular}

ESE students at Phase 2 (experimental phase) and Phase 3 (sustainability) implied that ESE students may have benefited from pseudoword instruction and were able to maintain what they learned through the end of the study. Since the number of ESE students was proportionate between the two classes, it may be possible that ESE students demonstrate 
smaller growth in phonetic decoding at first, then show greater increases later on in the school year (regardless of type of instruction).

Means and standard deviations of PWLA scores for ELL and non-ELL students are also presented in Table 8. Based on the mean scores presented, both ELL and nonELL students demonstrated increases in decoding skills at Time 1, Time 2, and Time 3. However, ELL students decreased in scores at Time 4. Since there were only four ELL students in the sample, many factors may have affected one of the four students' scores (e.g., distraction or lack of interest during assessment, absences during the study) and, in turn, may have affected the results. Independent $t$-tests were also conducted to determine if ELL and non-ELL students had significantly different PWLA scores at each time point and for each phase (change score). Although there were large differences in mean scores and change scores between the two groups, $t$-tests did not reveal significant differences at any time point or during any of the three phases.

While it seemed that the ESE and ELL variables warranted future investigation, the small number of ESE (7 out of 30) and ELL (4 out of 30) students within the sample, did not allow for separate exploration. However, this seems to be an area of importance for future research.

\section{Exploring Continuous Variables}

This section contains bivariate correlations which examine whether or not there were associations between the continuous variables (age and number of absences) and the dependent measure (PWLA scores). Table 9 presents the correlation of age, number of absences, and student scores on the PWLA for the overall sample, across all time points. Significant correlations did not exist at any time point between number of absences and 
scores on the PWLA. There was a marginally significant correlation $(p<.10)$ between students' number of absences and their scores on the PWLA at Time 3. Since the correlations between score and absences were near zero at the other time points, the researcher took a closer look at the descriptive statistics for absences at Time 3 (which consists of the days after the assessment at Time 2 through the assessment at Time 3), in comparison to all other time points. There seem to have been more students absent at Time 3 ( 11 out of 30 students had more than 2 absences) than at Time 2 (6 out of 30 had more than 2 absences) and Time 4 ( 7 out of 30 had more than 2 absences). Therefore, the larger number of absences at Time 3 may have caused the correlation to be marginally significant.

Bivariate correlations also yielded no significant differences at any time point between age and score on the PWLA. However, at Time 3, there was a marginally significant correlation between students' age and their score on the PWLA. Because the correlations at all other time points were similar, and appeared to be non-zero, it was possible that students' age may have been related to their scores during the treatment phase (T2 through T3). Therefore, the researcher continued to explore age in further analyses.

\section{Summary of Exploratory Analyses}

Initial exploratory data analyses were conducted on both dichotomous and continuous variables. The data included the following 2-level dichotomous variables: sex (girl, boy), ESE (yes, no), ELL (yes, no), and Hispanic (yes, no). Descriptive statistics (mean scores and standard deviations) and independent $t$-tests were used to analyze 
Table 9.

Correlation of Age and Absences by Score across Time Points

\begin{tabular}{lcccc}
\hline Variable & \multicolumn{5}{c}{ Score } \\
\cline { 2 - 5 } & T1 & T2 & T3 & T4 \\
\hline Age & .19 & .28 & $.33^{+}$ & .24 \\
Absences & --- & -.04 & $-.32^{+}$ & -.00 \\
\hline${ }^{+} p<.10$ & & & &
\end{tabular}

differences in PLWA scores for each of the variables listed. Although there were no statistical significances in mean scores for the sex and Hispanic variables, there seemed to have been trends that warranted further exploration in the subsequent sections. Table 6 shows that boys had greater mean scores than girls. Similar mean differences existed when comparing Hispanic students to non-Hispanic students, with non-Hispanic students performing higher than Hispanic students. Therefore, these variables were considered in subsequent analyses. Because of the small number of ESE and ELL students within the sample, these variables were not explored in subsequent analyses.

The continuous variables included in the exploratory analyses were age, number of absences, and PWLA score. Bivariate correlations were conducted to determine whether associations existed between the variables. Since correlations revealed a marginally significant association between absences and PWLA scores at Time 3, absences were further explored when conducting subsequent analyses. Students' age was also marginally associated with the scores students received on the PWLA. Therefore, this variable was also considered in subsequent analyses. Overall, there seemed to have 
been trends related to sex, ethnicity, age, and absences, all of which warranted further exploration in the subsequent sections.

\section{Exploring Hypotheses}

This study was guided by two detailed hypotheses. Based on research that addresses the importance of phonics instruction in teaching children decoding skills (Adams, 1990; Chall, 1996; Stahl et al., 1998), the first hypothesis stated that children who receive phonetic decoding instruction, regardless of the method of instruction (i.e., all children in the study), will show growth in word decoding, and will likely increase more in their decoding as the study progresses. The second hypothesis stated that children who receive phonics instruction through the PPC will show more improvement in decoding skills than children who receive regular phonics instruction. Since pseudowords were not previously seen, said, or memorized by students, the PPC should allow students to focus on developing decoding skills without relying on memory or reading context clues.

\section{Addressing Hypothesis 1}

The first hypothesis was divided into two sub-hypotheses. Hypothesis 1a stated that children who receive phonetic decoding instruction, regardless of the method of instruction (i.e., pseudowords vs. real words), will show growth in the PWLA from Time 1 to Time 4 as shown in Figure 2. Hypothesis 1b, also depicted in Figure 2, stated that these children will likely produce higher change scores as the study progressed. In order to address these two sub-hypotheses, regression analyses were conducted. Table 10 presents the means and standard deviations of scores for each time point, as well as change scores for each phase. 


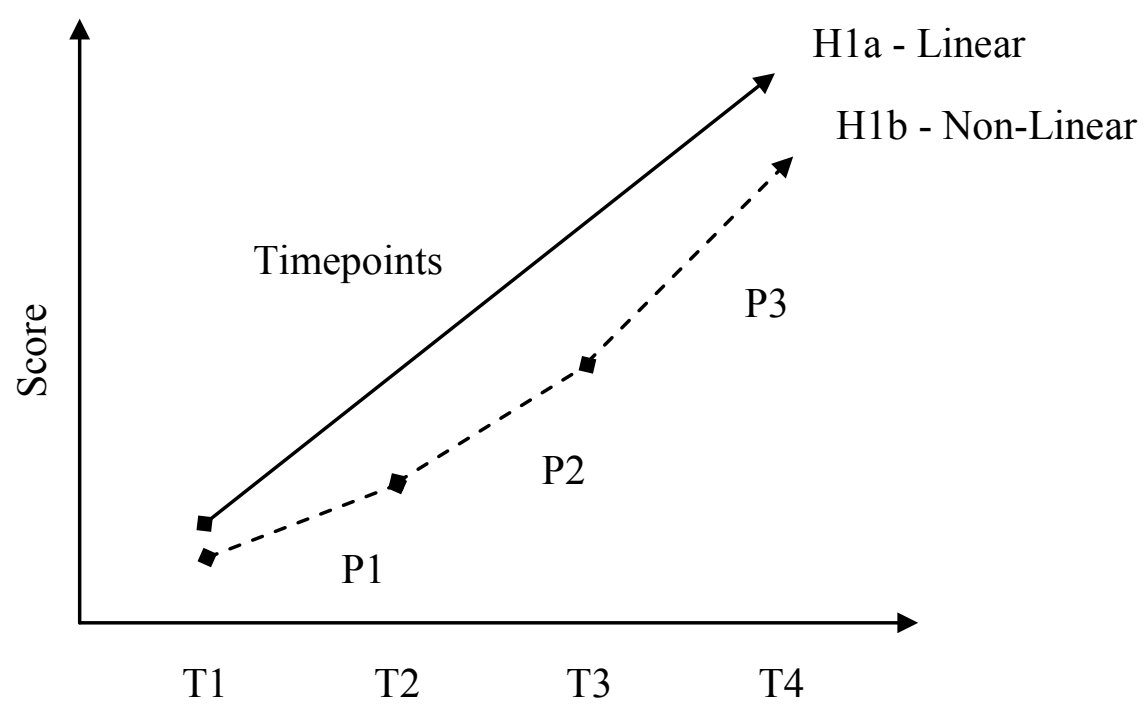

Figure 2. Graph for linear and non-linear models for Hypothesis 1.

Table 10 shows that students' scores increased from Time $1(M=4.44)$ to Time 4 $(M=28.53)$. Change scores for each phase indicate that there was a larger rate of increase during Phase 2 (pseudoword instruction was taking place for the experimental groups), than during Phase 1 (baseline growth) and Phase 3 (sustainability). The change score for Phase $3(M=9.13)$ was larger than the change score for Phase $1(M=4.56)$. This suggested that children showed increases in decoding from Time 1 through Time 4 after receiving phonics instruction (regardless of method) and showed higher change scores during Phase 2 and Phase 3 compared to Phase 1.

Regression models were conducted to explore the linear and non-linear growth patterns suggested by Hypothesis 1a and Hypothesis 1b, which are illustrated in Figure 2. The first regression model examined Hypothesis 1a, which explored linear change across the four time points. The second regression model examined Hypothesis $1 \mathrm{~b}$, which explored a non-linear change across the four time points, allowing for different slopes (i.e., higher rates of change) during each of the three phases. 
Table 10.

Mean (SD) Scores for the Overall Sample across Time Points and Phases

\begin{tabular}{|c|c|c|c|c|c|c|c|}
\hline \multirow[t]{3}{*}{$M(S D)$} & \multicolumn{4}{|c|}{ Score } & \multicolumn{3}{|c|}{ Growth/Change } \\
\hline & $\mathrm{T} 1$ & $\mathrm{~T} 2$ & $\mathrm{~T} 3$ & $\mathrm{~T} 4$ & T1-T2 & T2-T3 & T3-T4 \\
\hline & $N=30$ & $N=30$ & $N=30$ & $N=28$ & $(\mathrm{P} 1)$ & $(\mathrm{P} 2)$ & (P3) \\
\hline$M$ & 4.44 & 9.00 & 19.75 & 28.53 & 4.56 & 10.75 & 9.13 \\
\hline$S D$ & 10.97 & 15.73 & 18.21 & 23.12 & 5.74 & 9.81 & 10.93 \\
\hline
\end{tabular}

The results from the first regression analysis (Hypothesis 1a) accounted for a significant portion of the variance, $R^{2}=.16, F(1,116)=22.13, p<.001$. This indicated that there was significant linear growth by children in their ability to decode phonetically spelled words (as assessed by the PWLA) across the four time points. This finding is illustrated in Figure 3.

The second regression analysis (which explored Hypothesis 1b) was also significant, $R^{2}=.16, F(3,114)=7.41, p<.001$. The growth during Phase $1(\beta=.10, p=$ $.37)$ was smaller than the growth during Phase $2\left(\beta=.29, p<.01 ; \beta_{\mathrm{P} 2}-2\left(\beta_{\mathrm{P} 1}\right)=.09\right)$ and Phase $3\left(\beta=.45, p<.001 ; \beta_{\mathrm{P} 3}-3\left(\beta_{\mathrm{P} 1}\right)=.15\right)$. As shown in Figure 3 , the change between Time 1 and Time 2 (i.e., Phase 1) was less steep than the change between Time 2 and Time 3 (i.e., Phase 2) and Time 3 and Time 4 (i.e., Phase 3). Therefore, although students showed growth in decoding skills during Phase 1, they demonstrated a higher increase in decoding during Phase 2 and Phase 3, as predicted by Hypothesis $1 \mathrm{~b}$.

Similarities were found when comparing the lines for both sub-hypotheses (Figure 2) to the lines that demonstrated actual linear and non-linear growth on the PWLA at 


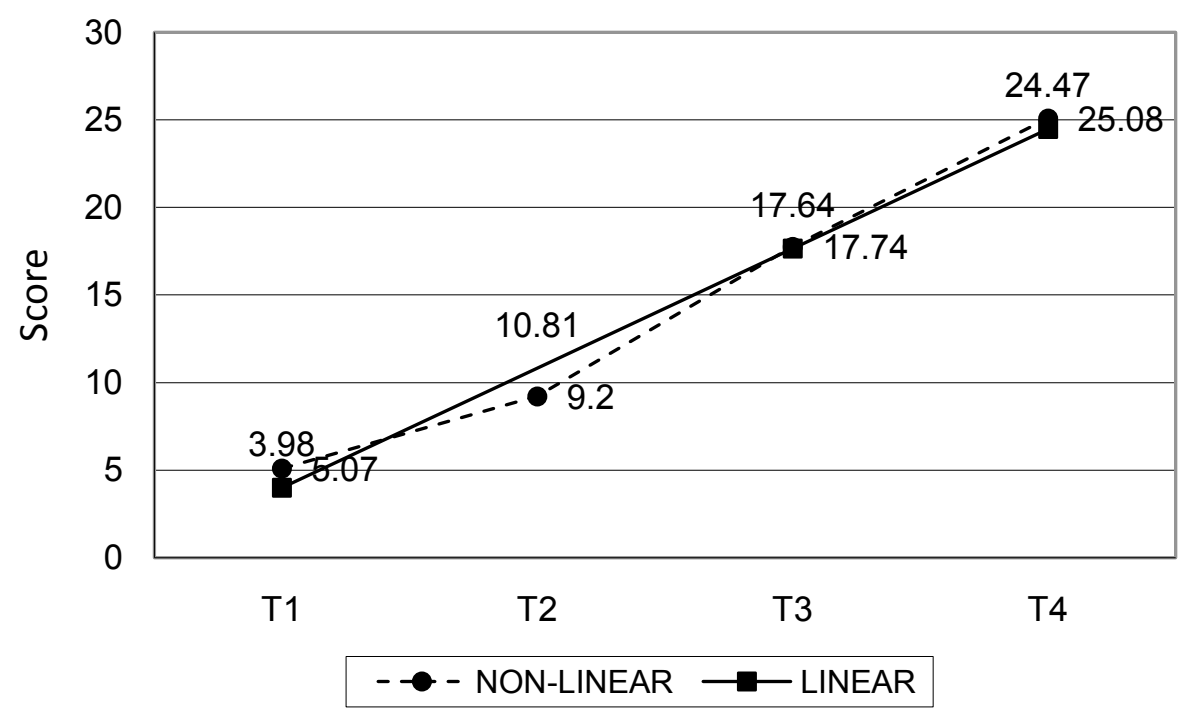

Figure 3. Graph for linear and non-linear growth at each time point and between each phase.

each time point and between each phase (Figure 3). Both figures (Figure 2 and 3) represent graphs with linear lines that show an overall increase in students' PWLA scores from Time 1 to Time 4. The graphs also depict non-linear lines that increase from one phase to the next. This means that students' ability to decode phonetically spelled words increased from Time 1 to Time 2 (i.e., Phase 1), from Time 2 to Time 3 (i.e., Phase 2), and then from Time 3 to Time 4 (i.e., Phase 3). The similarities found between both graphs provide visual support (in addition to the statistics from the regression analyses) for the researcher's first hypothesis; that children will show growth in the PWLA from Time 1 to Time 4 and will produce higher change scores during each phase of phonetic decoding instruction (regardless of the method of instruction).

Exploratory analyses warranted further exploration for sex, ethnicity, age, and absences. Therefore, the following section includes an exploration of how the 
demographic variables related to the models (linear and non-linear) that were used to test the first hypothesis.

Sex. The first regression analysis explored linear growth in boys' and girls' PWLA scores between Time 1 and Time 4, and the interaction between sex and time. The regression model was significant, $R^{2}=.20, F(1,114)=9.25, p<.01$. The results from the analysis indicated that the difference in scores between boys and girls was marginally significant, $\beta=-.15, p<.10$, with girls scoring lower than boys at all time points. The interaction between sex and time was not significant, $\beta=-.22, p=.19$. This suggested that boys were able to decode more phonetically spelled words than girls at each time point, but the amount of increase (i.e., the slope) across the study was similar (as shown in Figure 4).

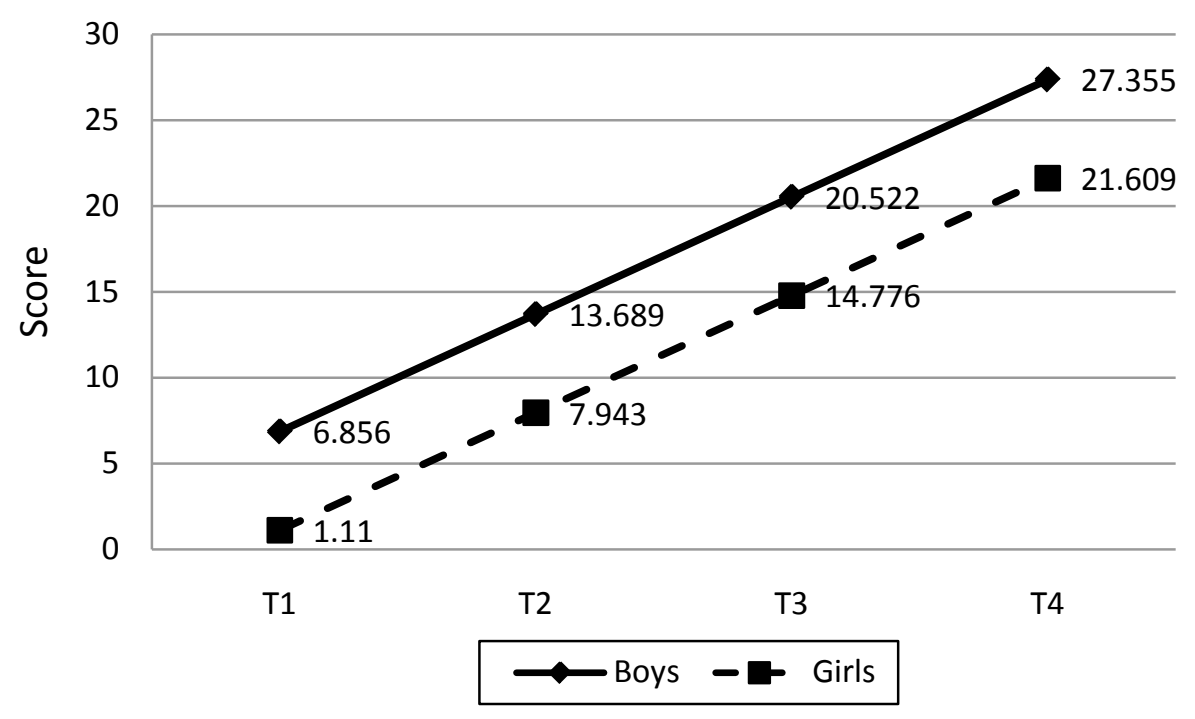

Figure 4. Graph of linear growth for boys and girls.

The second regression analysis explored non-linear growth in boys' and girls' PWLA scores during each phase of the study, as well as the interaction between sex and 
the time points. The regression model was significant, $R^{2}=.20, F(3,110)=3.93, p<$ .01 . These results from the analysis indicated that the difference in scores between girls and boys was marginally significant, $\beta=-.15, p<.10$. The interactions between sex and Phase $1(\beta=-.04, p=.81)$, Phase $2(\beta=-.08, p=.62)$, and Phase $3(\beta=-.21, p=.19)$ were not significant. This analysis indicated that girls followed the same slopes as boys (parallel slopes) during each phase, but were lower scoring overall. Figure 5 displays the difference in slopes for boys and girls during each phase.

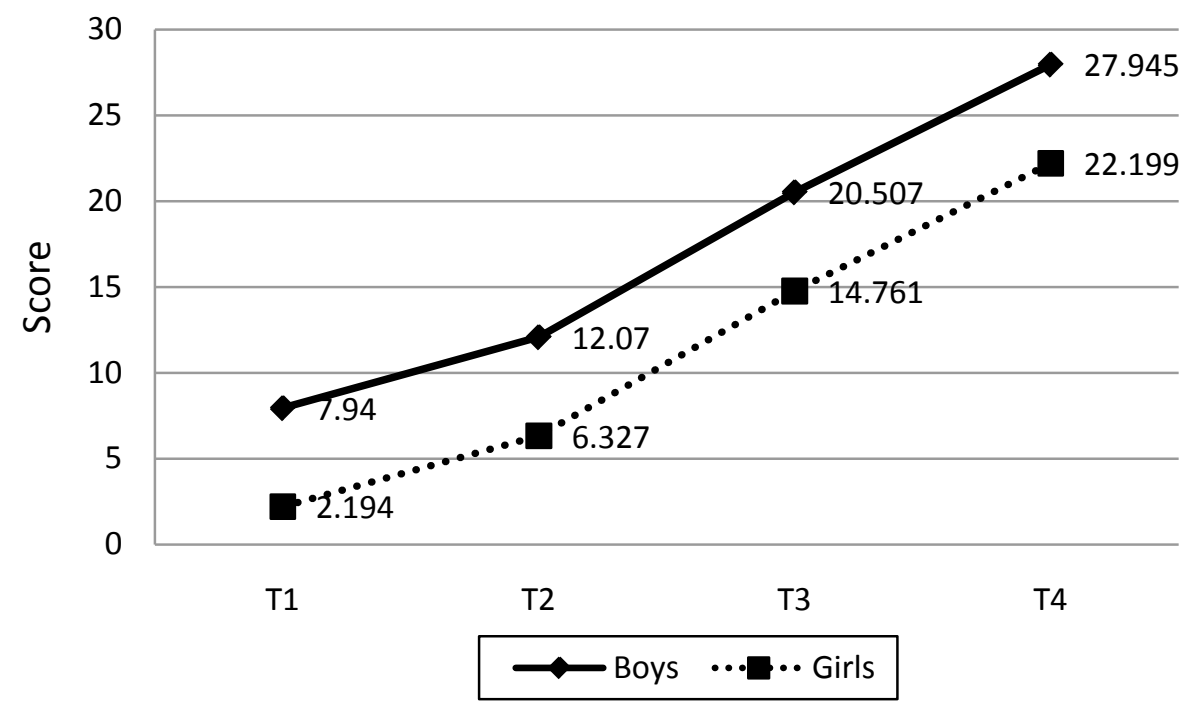

Figure 5. Graph for non-linear growth for boys and girls.

Ethnicity. Another regression analysis was conducted to explore linear growth for Hispanic and non-Hispanic students' PWLA scores between Time 1 and Time 4, and the interaction effect for ethnicity by time. The regression model was significant, $R^{2}=.23, F$ $(1,114)=11.43, p<.01$. The results from the analysis indicated that the difference in scores between Hispanic students and non-Hispanic students reached significance, $\beta=-$ $.26, p<.01$, with Hispanic students scoring lower than non-Hispanic students at all time 
points. The interaction effect was not significant, $\beta=-.16, p=.38$. These results indicated that non-Hispanic students were able to decode more words on the PWLA than Hispanic students at each time point (as shown in Figure 6).

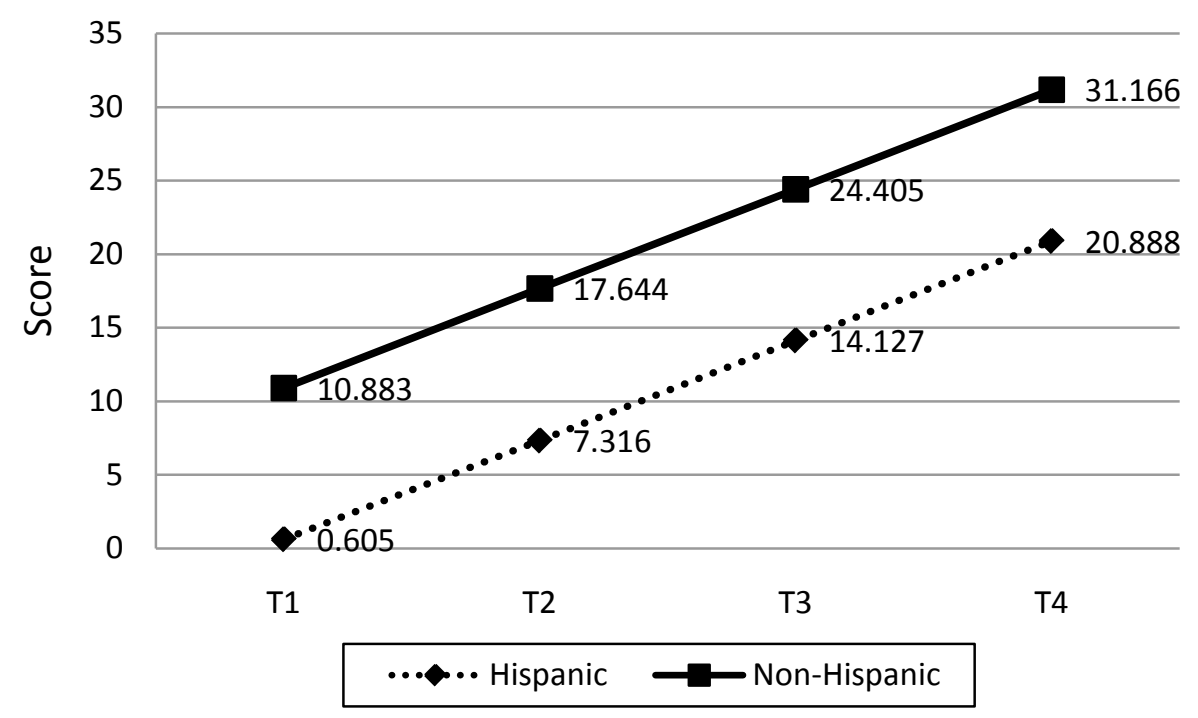

Figure 6. Graph of linear growth for Hispanic and non-Hispanic students.

The next regression analysis was conducted to explore non-linear growth for Hispanic and non-Hispanic students' PWLA scores during the three phases of the study and to determine if an interaction between ethnicity and phase existed. The results of this analysis were significant, $R^{2}=.23, F(3,110)=4.81, p<.01$. The difference between Hispanic and non-Hispanic students' scores during each phase was significant, $\beta=-.26, p$ $<.01$. The interactions at Phase $1(\beta=-.05, p=.78)$, Phase $2(\beta=-.13, p=.50)$, and Phase $3(\beta=-.14, p=.44)$ were not significant. This indicated that Hispanic students scored significantly lower than non-Hispanic students on the PWLA during each phase. Non-linear trends continued to demonstrate that the change during Phase 2 and Phase 3 
was higher than the change during Phase 1 for both Hispanic and non-Hispanic students as shown in Figure 7.

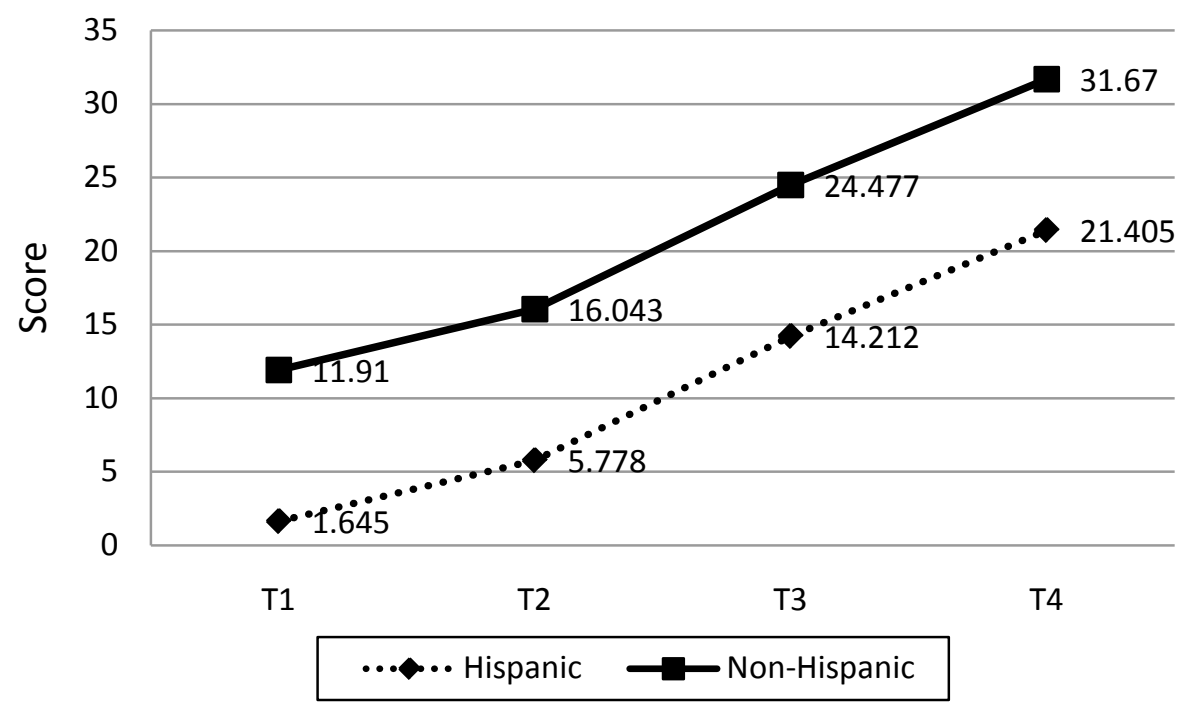

Figure 7. Graph of non-linear growth for Hispanic and non-Hispanic students.

Age. A regression analysis was also conducted to determine whether there was a relationship between students' age and time. The regression analysis was also conducted to determine if age interacted with time. The results of this model were significant, $R^{2}=$ $.22, F(1,114)=10.67, p<.01$. The results from the analysis indicated that there was a significant difference in PWLA scores from Time 1 through Time 4 for age, $\beta=.24, p<$ .01 . The interaction was not significant, $\beta=.81, p=.48$. Older kindergarteners were able to decode more phonetically spelled words (as assessed by the PWLA) than younger kindergarteners at each time point as shown in Figure 8.

A non-linear analysis was also conducted to explore the relationship between students' age and the non-linear model of students' PWLA scores during each phase of the study. The regression was also conducted to determine if an interaction between age 
and time existed. The results of this analysis were significant, $R^{2}=.22, F(3,110)=4.54$, $p<.01$. The results indicate that there was a significant difference, $\beta=.24, p<.01$, in PWLA scores between younger and older students, where older students outperformed younger students on the PWLA during each phase. Interactions between age and time at Phase $1(\beta=.62, p=.66)$, Phase $2(\beta=1.15, p=.42)$, and Phase $3(\beta=.85, p=.55)$ were not significant. Non-linear trends continued to demonstrate that students showed more growth in phonetic decoding skills during Phase 2 and Phase 3, than during Phase 1, regardless of age differences as shown in Figure 9.

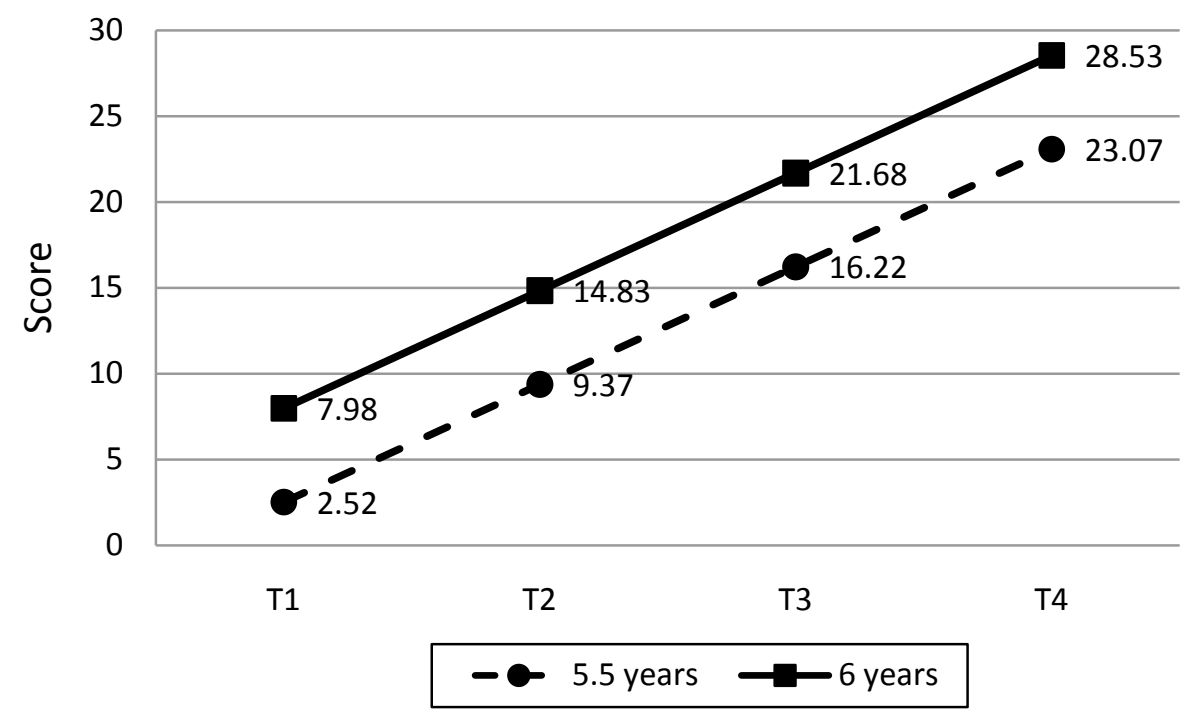

Figure 8. Graph of linear growth for 5.5 year olds and 6 year olds.

Number of Days Absent. Another regression analysis was conducted to determine whether a relationship existed between students' number of absences and the linear model that was used to test Hypothesis 1a. The regression analysis was also conducted to determine whether days absent interacted with time. The regression model was significant, $R^{2}=.17, F(1,114)=8.0, p<.01$. The results from the analysis indicated that students' number of absences did not make a significant difference in students' 
PWLA scores from Time 1 through Time $4, \beta=-.12, p=.17$. The interaction effect was not significant, $\beta=.02, p=.94$. Although a significance was not found in the main effect or interaction effect, the results suggested that students with less absences scored higher on the PWLA than students with more absences at all time points.

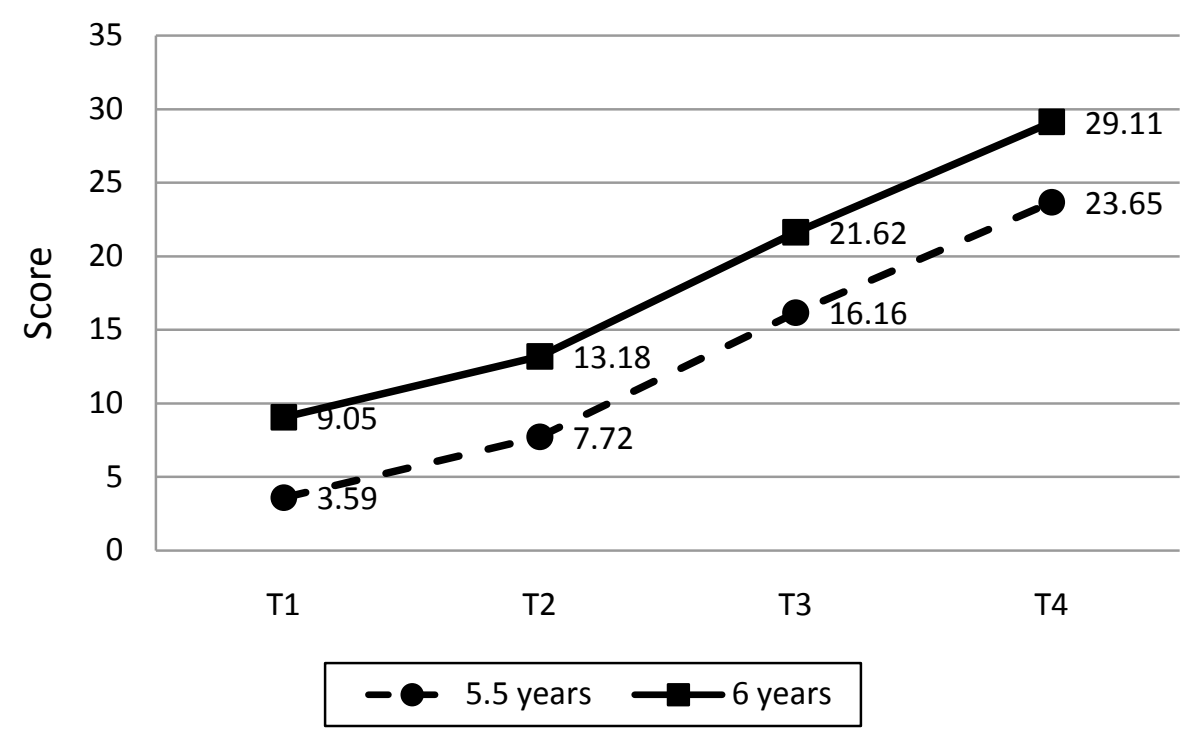

Figure 9. Graph of non-linear growth for 5.5 year olds and 6 year olds.

A non-linear regression analysis was also conducted to explore the relationship between students' number of absences and the non-linear model of students' PWLA scores during each phase. The non-linear regression analysis was also conducted to determine if an interaction between absences and time existed. The regression model was significant, $R^{2}=.19, F(2,111)=4.24, p<.01$. The results of this analysis did not yield significance for the main effect $(\beta=-.13, p=.19)$ or the interaction at Phase $1(\beta=.13, p$ $=.32$ ), Phase 2 (not enough data), and Phase $3(\beta=.13, p=.33$ ), indicating that there was no relationship between number of absences and students' performance on the PWLA during any phase of the study. However, although significance was not reached, non- 
linear results also suggested that students with fewer absences scored higher on the PWLA than students with more absences.

\section{Summarizing Hypothesis 1}

Hypothesis 1 stated that children who receive phonetic decoding instruction, regardless of the method of instruction (i.e., all children in study), will show growth in decoding skills from Time 1 to Time 4, and will likely produce higher change scores as the study progresses. This hypothesis was divided into two sub-hypothesis. A linear regression analysis was conducted to test Hypothesis 1a, which stated that children who receive phonetic decoding instruction, regardless of the method of instruction, will show growth in the PWLA from Time 1 to Time 4 (see Figure 2). The analysis indicated that students demonstrated a significant growth in decoding skills at each time point. A nonlinear regression analysis was conducted to test Hypothesis $1 \mathrm{~b}$, which stated that children will likely produce higher change scores as the study progresses. The non-linear analysis also indicated that students demonstrated a significant growth in decoding throughout each phase and increased in their ability to decode from Phase 1 to Phase 2 to Phase 3.

Since exploratory analysis warranted further exploration for the sex, ethnicity, age, and absences variables, linear and non-linear regressions for these variables were conducted to determine whether they related to the models used to test Hypothesis 1. Both linear and non-linear analyses for the sex variable were marginally significant $(p<$ .10). Boys demonstrated higher decoding skills than girls at each time point and during each phase. Both linear and non-linear analyses for the ethnicity and age variables were significant $(p<.01)$. Analyses for ethnicity indicated that non-Hispanic students outperformed Hispanic students on the PWLA at all time points and during each phase. 
Analyses for age indicated that older kindergarten students received higher scores on the PWLA, while younger kindergarten students received lower scores (at each time point and during each phase). Linear and non-linear analyses for absences indicated that students with fewer absences had higher scores on the PWLA than students with more absences; however, the results were not significant. There were no significant interactions found between any of the linear and non-linear analyses conducted to test Hypothesis 1. Overall, linear and non-linear models supported the researcher's first hypothesis that children who receive phonics instruction (regardless of the method of instruction) show growth in decoding skills as time progresses.

After conducting independent analyses for each demographic variable, a question of concern was whether or not the demographic factors explained overlapping variance or independent variance in decoding skills. Therefore, a multiple regression analysis was conducted to explore the relationship of sex, ethnicity, and age (simultaneously) on students' PWLA scores between Time 1 and Time 4. Overall, the analysis reached significance, $R^{2}=.30, F(4,113)=12.25, p<.01$.

The sex variable was significant and negative $(\beta=-.18, p<.05)$, indicating that girls performed significantly lower on the PWLA than boys at each time point. The ethnicity variable was also significant and negative $(\beta=-.25, p<.01)$, indicating that Hispanic students performed significantly lower than non-Hispanic students at each time point. The age variable was significant and positive $(\beta=.22, p<.01)$, indicating that older students performed significantly better than younger students on the PWLA at each time point. 
Figure 10 shows the differences in PWLA scores, while controlling for the demographic variables, such as sex, age, and ethnicity. The figure shows that young (e.g., five and a half year old), Hispanic girls, were the lowest performing students in the overall sample (as assessed by the PWLA) at each time point. On the contrary, older (e.g., 6-year-old), non-Hispanic boys, were the highest performing students in the sample.

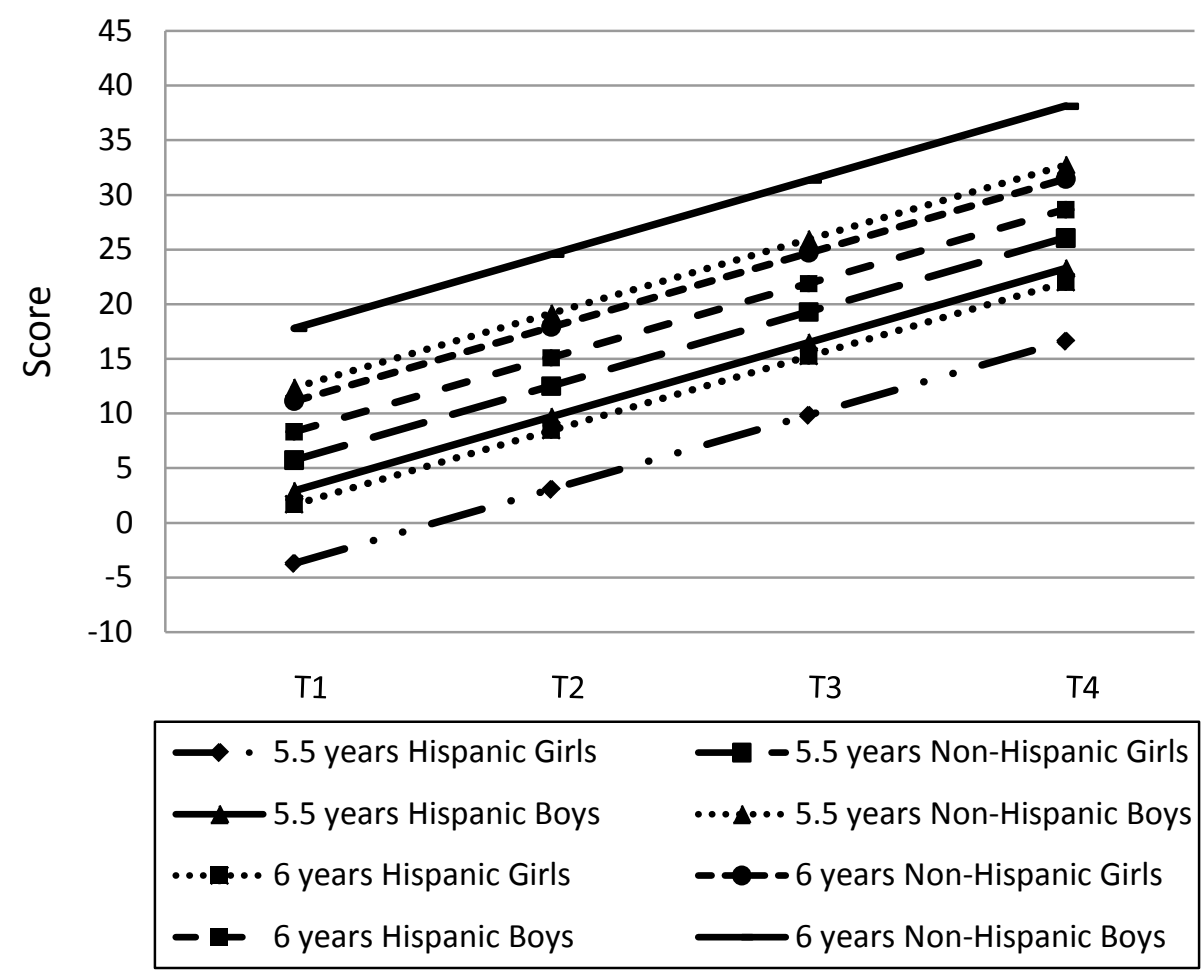

Figure 10. Graph for differences in PWLA scores while controlling for demographic variables.

\section{Addressing Hypothesis 2}

The second hypothesis was also divided into two sub-hypotheses. Hypothesis $2 \mathrm{a}$ stated that children who receive phonics instruction through the PPC will improve more in decoding skills than children who receive regular phonics instruction as shown in Figure 11. Hypothesis $2 \mathrm{~b}$ stated that students in the experimental group (who received 
the pseudoword phonics instruction) will demonstrate more sustained growth in phonetic decoding than students in the control group, even after returning to a regular phonics curriculum during Phase 3 (also shown in Figure 11).

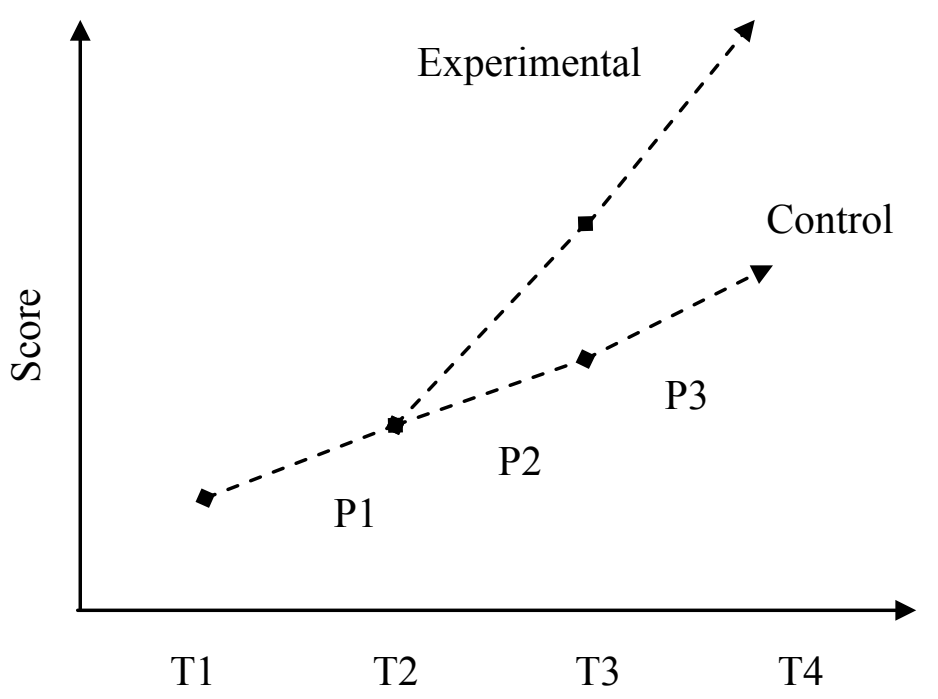

Figure 11. Graph for non-linear models for Hypothesis 2.

In order to address the sub-hypotheses, several multiple regression analyses were conducted. Means and standard deviations of scores and change scores on the PWLA for each group (experimental and control) were also examined. Mean scores and standard deviations for both groups across all time points and phases are presented in Table 11.

Mean scores and change scores indicated that both groups increased in PWLA scores at each time point, though there were differences in the degree to which each group increased. It is evident that at Time 1 the experimental group had nearly the same decoding skills as the control group. Additionally, the change scores between Time 1 and Time 2 (i.e., Phase 1), which measured baseline growth, indicated that the experimental group showed about the same gains (within 1 point) as the control group. 
Table 11.

Mean (SD) Scores for Experimental and Control Group across Time Points

\begin{tabular}{|c|c|c|c|c|c|c|c|c|}
\hline \multirow[t]{2}{*}{ Group } & & \multicolumn{4}{|c|}{ Mean Score (SD) } & \multicolumn{3}{|c|}{ Growth / Change } \\
\hline & & $\mathrm{T} 1$ & $\mathrm{~T} 2$ & $\mathrm{~T} 3$ & T4 & T1-T2 & T2-T3 & T3-T4 \\
\hline \multirow[t]{2}{*}{ Exp. } & $M$ & 4.44 & 9.00 & 19.75 & 28.53 & 4.56 & 10.75 & 9.13 \\
\hline & $S D$ & 10.97 & 15.73 & 18.21 & 23.12 & 5.74 & 9.81 & 10.93 \\
\hline \multirow[t]{2}{*}{ Control } & $M$ & 5.79 & 9.43 & 15.21 & 21.08 & 3.64 & 5.79 & 4.69 \\
\hline & $S D$ & 14.85 & 16.83 & 19.05 & 21.76 & 4.38 & 6.84 & 5.41 \\
\hline
\end{tabular}

Although the experimental group's change score for Phase 1 was slightly higher than the control group's change score, the control group continued to demonstrate more knowledge in decoding (as assessed by the PWLA) at Time 2. Interestingly, after receiving phonics instruction through the use of the PPC, the experimental group showed much larger gains than the control group. The change scores during the second phase of the study, which demonstrated the relationship between the PPC and students' ability to decode, were approximately 5 points higher for the experimental group than the control group. Since the experimental group performed higher than the control group on the PWLA at Time 3 and received higher change scores during Phase 2, there was a possibility that the researcher's second hypothesis was correct. Additional analyses were conducted to further investigate Hypothesis 2.

A non-linear analysis was conducted to determine if the difference in PWLA scores between the experimental and control groups during Phase 2 and Phase 3 (as shown in Figure 11) were significant. While the overall model was significant, $R^{2}=.18$, 
$F(3,110)=3.36, p<.01$, the group variable (experimental vs. control) was not significant $(\beta=.07, p=.45)$. Interaction effects between group and time were also analyzed and found not to be significant for Phase $1(\beta=.02, p=.92)$, Phase $2(\beta=.11, p$ $=.53$, and Phase $3(\beta=.16, p=.35)$. Figure 12 presents the non-linear change across all four time points for the experimental and control group. Based on this illustration, the hypothesis seems to be supported. Individual differences were not accounted for in this design (e.g. by using person vectors). Individual growth curves using multilevel models are presented in the subsequent section that account for this within-subject variation.

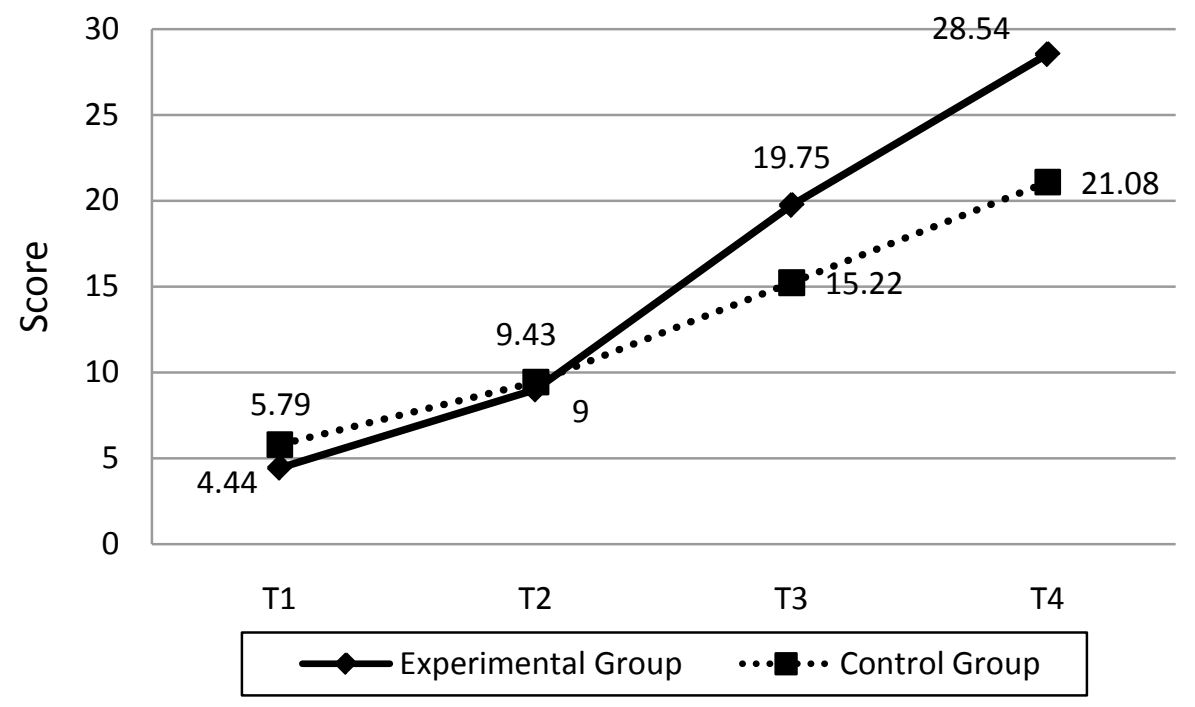

Figure 12. Graph of non-linear growth for experimental and control group.

Since there were differences between boys' and girls', Hispanics' and nonHispanics', and older and younger students' PWLA scores (see the exploratory analysis section), a similar multiple regression analysis was conducted that controlled for these demographic variables. Results of the overall model were found to be significant, $R^{2}=$ $.34, F(3,107)=5.48, p<.001$. However, like the previous model, the group main effect 
$(\beta=.06, p=.68)$ and group by phase interaction effects for Phase $1(\beta=.02, p=.91)$,

Phase $2(\beta=.11, p=.48)$, and Phase $3(\beta=.16, p=.29)$ were not significant. Figure 13 represents the non-linear change across time points in PWLA scores for the experimental and control group, while controlling for sex, ethnicity, and age.

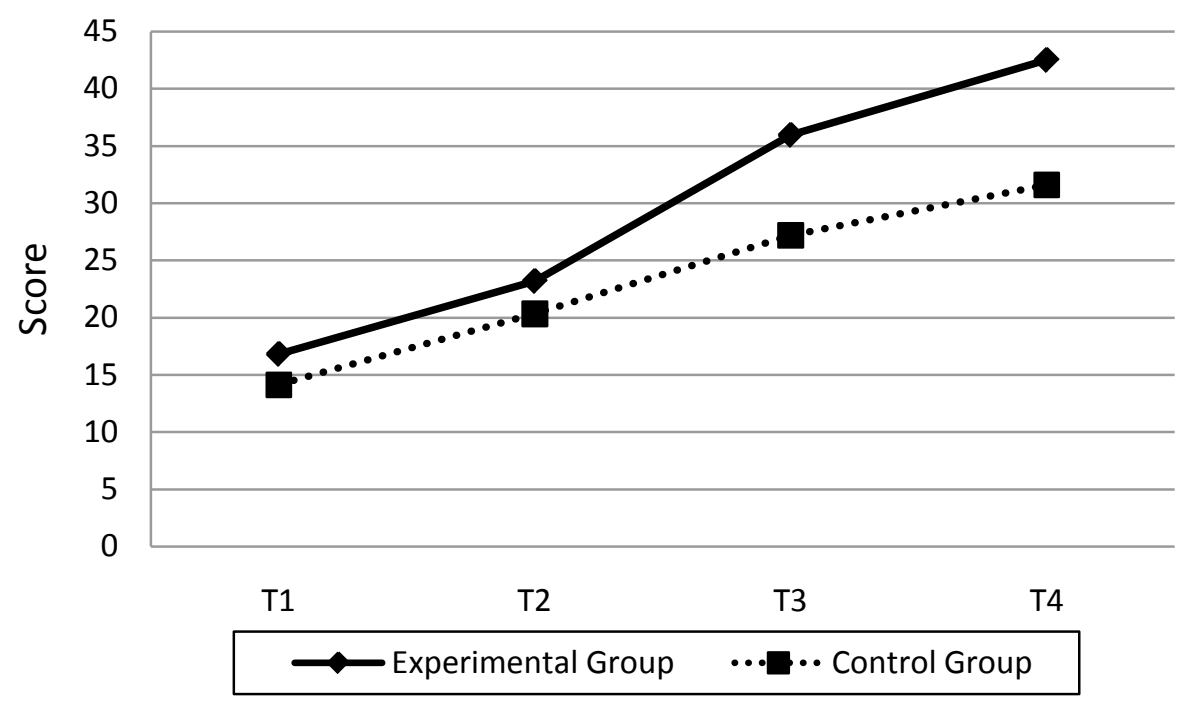

Figure 13. Graph of non-linear growth for experimental and control group while controlling for demographic variables.

After controlling for demographic variables, the pattern of change across the four time points remained highly consistent with the hypothesis (as shown in Figure 13). While the interaction terms were not found to be significant with the regression analyses, it was still important to explore the changes using an individual growth model because such a model considered the nested data structure of this study.

Sustained effects of students' ability to decode phonetically spelled words (Time 3 to Time 4) were also examined. Hypothesis $2 b$ stated that the students in the experimental group will demonstrate more sustained growth in phonetic decoding than 
students in the control group, even after returning to a regular phonics curriculum. Mean scores for Time 4 and change scores for Phase 3 are presented in Table 11. Mean scores indicated that the experimental group performed higher on the PWLA than the control group at Time 4. Not only did the students in the experimental group perform higher, but they also demonstrated larger increases in change scores between Time 3 and Time 4 compared to the students in the control group. Therefore, it is possible that the PPC improved the experimental students' ability to decode phonetically spelled words after receiving pseudoword phonics instruction and continued to improve their decoding skills after they returned to a regular phonics curriculum.

Figures 12 and 13 illustrate that the experimental group had larger increases in phonetic decoding during Phase 3 than the control group. A multiple regression analysis including only children in the experimental group (during Phase 3) was conducted to determine whether the demographic variables were affecting the sustained effects found in the previous models. The overall model for this analysis was significant, $R^{2}=.47, F$ $(4,26)=5.72, p<.01$. The analysis indicated that the $\operatorname{sex}(\beta=-.36, p<.05)$ and ethnicity $(\beta=-.39, p<.05)$ variables, independently, were related to decoding skills at Time 4, while age was not. Additional multiple regression analyses were conducted to examine experimental students' sustained growth between Time 3 and Time 4 in phonetic decoding, while controlling for the demographic variables as shown in Figure 14. The regression model was significant, $R^{2}=.41, F(2,28)=9.66, p<.01$. The girls' slope was much lower than the boys' slope, $\beta=-.37, p<.05$. Likewise, Hispanic students' slope was much lower than the non-Hispanic students' slope, $\beta=-.40, p<.05$. While not reaching significance, the interaction between sex and time $(\beta=-.84, p=.31)$ appeared 
large enough to consider when the multilevel model for change was explored (shown in Figure 14).

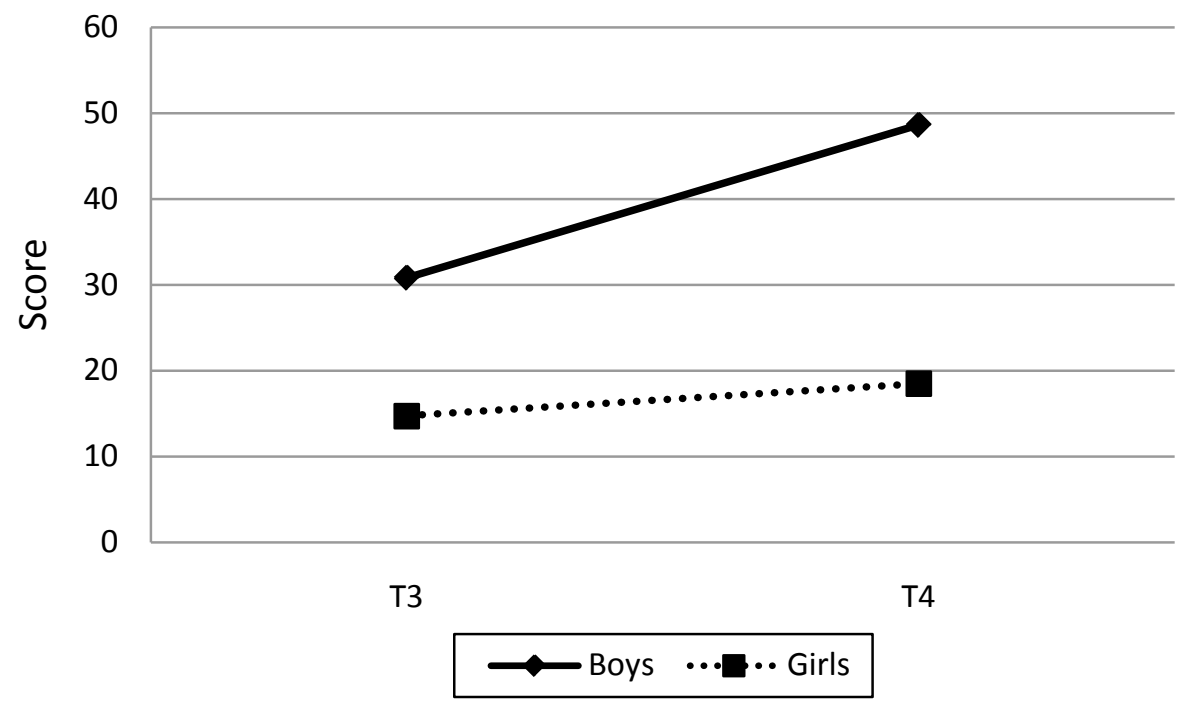

Figure 14. Graph of sustained growth for boys and girls in experimental group.

\section{Summarizing Hypothesis 2}

Hypothesis 2 was divided into two sub-hypotheses. Hypothesis 2 a stated that children who receive phonics instruction through the PPC will show larger increases in decoding skills than children who receive regular phonics instruction during Phase 2 (see Figure 11). Results indicated that the experimental group had higher scores on the PWLA compared to the control group during Phase 2 and also demonstrated larger change scores (see Figure 12). Since exploratory analyses warranted further exploration of demographic variables, a multiple regression analysis was conducted to control for sex, ethnicity, and age. Results of this analysis continued to support Hypothesis 2a suggesting that the demographic variables were not related to the larger growth made by the experimental group compared to the control group in Phase 2 (see Figure 13). 
Hypothesis $2 b$ stated that students in the experimental group will continue to have growth in phonetic decoding compared to students in the control group after returning to a regular phonics curriculum. Mean scores and change scores indicated that the experimental students continued to demonstrate growth in decoding during Phase 3 (see Table 11). This was further supported by multiple regression analyses (see Figures 12 and 13). These analyses also indicated that boys in the experimental group might have larger growth during Phase 3 compared to girls in the experimental group.

\section{Multilevel Model}

Hierarchical Linear Modeling (HLM) was used to create two multilevel models based on the results from the single-level regression analyses presented above. Two multilevel models (based on specifications in Singer \& Willet, 2003) were used to estimate individual growth curves for students' PWLA scores from Time 1 to Time 4. Both models explored the relationship between pseudoword phonics instruction and children's outcome as presented in Hypothesis 2 (see Figure 11). The first model (Model A) also included the demographic variables (sex, age, and ethnicity) found to be significant in the regression analyses. In addition to including the demographic variables (as was done in Model A), the second model (Model B) included interaction variables between group and sex because a clear difference was found between boys' and girls' sustained growth on the PWLA within the experimental group.

Model A consisted of two levels: (a) within-child level (i.e., children's growth on PWLA); and (b) child level (i.e., demographics and group). The within-child level treated students' ability to decode phonetically spelled words (i.e., number of words 
correct on the PWLA) as a function of the three phases within the study. The specific within-child model for PWLA score $Y_{\mathrm{ij}}$ of the $i$ th student in the $j$ th classroom was: $Y_{\mathrm{ij}}=\beta_{0 \mathrm{j}}+\beta_{1 \mathrm{j}} \mathrm{DTIME}_{\mathrm{ij}}+\beta_{2 \mathrm{j}} \mathrm{DTIME}_{\mathrm{ij}}+\beta_{3 \mathrm{j}} \mathrm{DTIME}_{\mathrm{ij}}+\epsilon_{\mathrm{ij}}$, where DTIME $1_{\mathrm{ij}}$, DTIME $2_{\mathrm{ij}}$, and DTIME $3_{\mathrm{ij}}$ were dummy coded variables to represent each time point of the study (Time 1 was the reference time with 0s for DTIME1, DTIME2, and DTIME3); and $\in_{\mathrm{ij}}$ was residual.

Variation was also modeled across each student's demographic information and group. The specific child-level model, which included main effects for demographic information and group, was as follows:

$$
\begin{aligned}
& \beta_{0 \mathrm{j}}=\gamma_{00}+\gamma_{10} \mathrm{GIRL}_{\mathrm{j}}+\gamma_{20} \mathrm{AGE}_{\mathrm{j}}+\gamma_{30} \text { ETHNICITY }_{\mathrm{j}}+\gamma_{40} \mathrm{GROUP}_{\mathrm{j}}+\eta_{0 \mathrm{j}}, \\
& \beta_{1 \mathrm{j}}=\gamma_{01}+\gamma_{11} \mathrm{GROUP}_{\mathrm{j}}+\eta_{1 \mathrm{j}}, \\
& \beta_{2 \mathrm{j}}=\gamma_{02}+\gamma_{12} \mathrm{GROUP}_{\mathrm{j}}+\eta_{2 \mathrm{j}}, \\
& \beta_{3 \mathrm{j}}=\gamma_{03}+\gamma_{13} \mathrm{GROUP}_{\mathrm{j}}+\eta_{3 \mathrm{j}},
\end{aligned}
$$

where $\operatorname{GIRL}_{\mathrm{j}}$ was a dummy variable for sex $(1=$ girl; $0=$ boy $)$; $\mathrm{AGE}_{\mathrm{j}}$ was a continuous variable for the students' age in months; ETHNICITY $\mathrm{j}_{\mathrm{j}}$ was a dummy variable for students' ethnic background ( 1 = Hispanic; 0 = non-Hispanic); GROUP was a dummy variable for the group $(1=$ experimental; $2=$ control); and $\eta$ was residual (random effect).

Table 12 displays the results from Model A. The model confirmed the findings that were revealed through the multiple regression analyses. Findings suggested that there was similar growth for all children during the first phase of the study (no significant differences found). However, during the second phase of the study, the model yielded 
significant differences between the control and experimental groups, where the experimental group performed decoded more words on the PWLA than the control group. There were also significant differences between both groups during the third phase of the study. The experimental group continued to decode more words on the PWLA than the control group.

Since previously conducted regression analyses warranted further exploration for the sex variable, an additional model (Model B) was created to determine whether a three-way interaction existed between phase, sex, and group. Like Model A, Model B consisted of two levels: (1) within-child level (i.e., children's growth on the PWLA); and (2) child-level (i.e., demographics and group). In addition to the same variables explored in Model A, Model B also included a sex by group interaction variable. The specific within-child level for PWLA score $Y_{\mathrm{ij}}$ of the $i$ th student in the $j$ th classroom was: $Y_{\mathrm{ij}}=\beta_{0 \mathrm{j}}+\beta_{1 \mathrm{j}} \mathrm{DTIME}_{\mathrm{ij}}+\beta_{2 \mathrm{j}} \mathrm{DTIME}_{\mathrm{ij}}+\boldsymbol{\beta}_{3 \mathrm{j}} \mathrm{DTIME}_{\mathrm{ij}}+\epsilon_{\mathrm{ij}}$, where DTIME $1_{\mathrm{ij}}$, DTIME $2_{\mathrm{ij}}$, and DTIME $3_{\mathrm{ij}}$ were dummy coded variables to represent each time point of the study (Time 1 was the reference time with 0s for DTIME1, DTIME2, and DTIME3); and $\epsilon_{\mathrm{ij}}$ was residual. The specific child-level model is presented below:

$$
\begin{aligned}
& \beta_{0 \mathrm{j}}=\gamma_{00}+\gamma_{10} \mathrm{GIRL}_{\mathrm{j}}+\gamma_{20} \mathrm{AGE}_{\mathrm{j}}+\gamma_{30} \text { ETHNICITY }_{\mathrm{j}}+\gamma_{40} \mathrm{GROUP}_{\mathrm{j}}+\eta_{0 \mathrm{j}}, \\
& \beta_{1 \mathrm{j}}=\gamma_{01}+\gamma_{11} \mathrm{GIRL}_{\mathrm{j}}+\gamma_{21} \mathrm{GROUP}_{\mathrm{j}}+\gamma_{31} \mathrm{GIRLxGROUP}_{\mathrm{j}}+\eta_{1 \mathrm{j},}, \\
& \beta_{2 \mathrm{j}}=\gamma_{02}+\gamma_{12} \mathrm{GIRL}_{\mathrm{j}}+\gamma_{22} \mathrm{GROUP}_{\mathrm{j}}+\gamma_{32} \mathrm{GIRLxGROUP}_{\mathrm{j}}+\eta_{2 \mathrm{j},}, \\
& \beta_{3 \mathrm{j}}=\gamma_{03}+\gamma_{13} \mathrm{GIRL}_{\mathrm{j}}+\gamma_{23} \mathrm{GROUP}_{\mathrm{j}}+\gamma_{33} \mathrm{GIRLxGROUP}_{\mathrm{j}}+\eta_{3 \mathrm{j}},
\end{aligned}
$$


where $\mathrm{GIRL}_{\mathrm{j}}$ was a dummy variable for $\operatorname{sex}(1=$ girl; $0=$ boy $)$; $\mathrm{AGE}_{\mathrm{j}}$ was a continuous variable for the students' age in months; ETHNICITY $j$ was a dummy variable for students' ethnic background ( 1 = Hispanic; 0 = non-Hispanic); GROUP was a dummy variable for the group $(1=$ experimental; $2=$ control $)$; GIRLxGROUP was the interaction between GIRL and GROUP; and $\eta$ was residual (random effect).

Table 12 also displays the data that represent Model B. Findings continued to show that there was similar growth for both the experimental and control groups during the first phase of the study. During the second phase of the study, significant differences were found for sex and group, but not for the three-way interaction between time (representing Phase 2), sex, and group. This indicated that boys demonstrated higher PWLA scores than girls, and the experimental group demonstrated higher PWLA scores than the control group during Phase 2. Similar findings were evident for Phase 3 with the addition of a significant effect for the three-way interaction between time, sex, and group. This indicated that while Hypothesis 2 was supported, the boys and girls responded differently to the experimental condition as shown in Figure 15.

Figure 15 shows that girls in the experimental and control group demonstrated similar growth during Phase 1, but girls in the experimental group displayed a boost in decoding after receiving pseudoword phonics instruction. However, after returning to regular real-word phonics, growth for both groups of girls was once again similar. In other words, the girls in the experimental group did not sustain the growth made during Phase 2. 
Table 12.

Data for Multi-level Models $A$ and $B$

\begin{tabular}{|c|c|c|c|c|}
\hline \multirow[t]{2}{*}{ Variable } & \multicolumn{2}{|r|}{ Model A } & \multicolumn{2}{|r|}{ Model B } \\
\hline & df & Coefficient (SE) & df & Coefficient (SE) \\
\hline Intercept & 25 & $-42.88(32.36)$ & 25 & $-49.44(31.46)$ \\
\hline Girl & 25 & $-9.06(5.01)$ & 25 & $-2.05(4.39)$ \\
\hline Age & 25 & $0.93(0.46)$ & 25 & $0.89(0.46)$ \\
\hline Ethnicity & 25 & $-9.82(5.67)$ & 25 & $-7.76(5.52)$ \\
\hline Group & 25 & $-2.51(5.10)$ & 25 & $0.40(4.77)$ \\
\hline DTime1 & 107 & $5.48(3.00)$ & 101 & $12.24(6.73)$ \\
\hline DTime1xGroup & 107 & $-0.92(1.79)$ & 101 & $-4.22(3.65)$ \\
\hline DTime1xGirl & & & 101 & $-9.52(8.07)$ \\
\hline DTime1xGroupxGirl & & & 101 & $4.50(4.70)$ \\
\hline DTime2 & 107 & $21.20(6.29)^{* * *}$ & 101 & $38.84(7.10) * * *$ \\
\hline DTime2xGroup & 107 & $-5.88(3.88)$ & 101 & $-14.42(4.55) * *$ \\
\hline DTime2xGirl & & & 101 & $-24.50(10.83)^{*}$ \\
\hline DTime2xGroupxGirl & & & 101 & $11.26(7.17)$ \\
\hline DTime3 & 107 & $33.45(10.17)^{* *}$ & 101 & $68.46(9.72)^{* * *}$ \\
\hline DTime3xGroup & 107 & $-9.44(6.12)$ & 101 & $-26.24(6.46)^{* * *}$ \\
\hline DTime3xGirl & & & 101 & $-49.54(14.60)^{* * *}$ \\
\hline DTime3xGroupxGirl & & & 101 & $22.42(9.86)^{*}$ \\
\hline Deviance & & 897.12 & & 869.66 \\
\hline \# of Parameters & & 13 & & 19 \\
\hline $\begin{array}{l}\mathrm{X}^{2} \text { for Model Difference } \\
(D f=6)\end{array}$ & & & & $27.46^{* * *}$ \\
\hline
\end{tabular}

The figure also shows that boys (in the experimental and control group) performed higher on the PWLA than girls at all time points and during each phase. Although boys in the experimental group demonstrated a little more growth in decoding than boys in the control group during Phase 1, boys in the experimental group displayed a tremendous 
increase after receiving pseudoword phonics instruction during Phase 2. During Phase 3, the boys in the experimental group continued to make similar gains as they made during Phase 2.

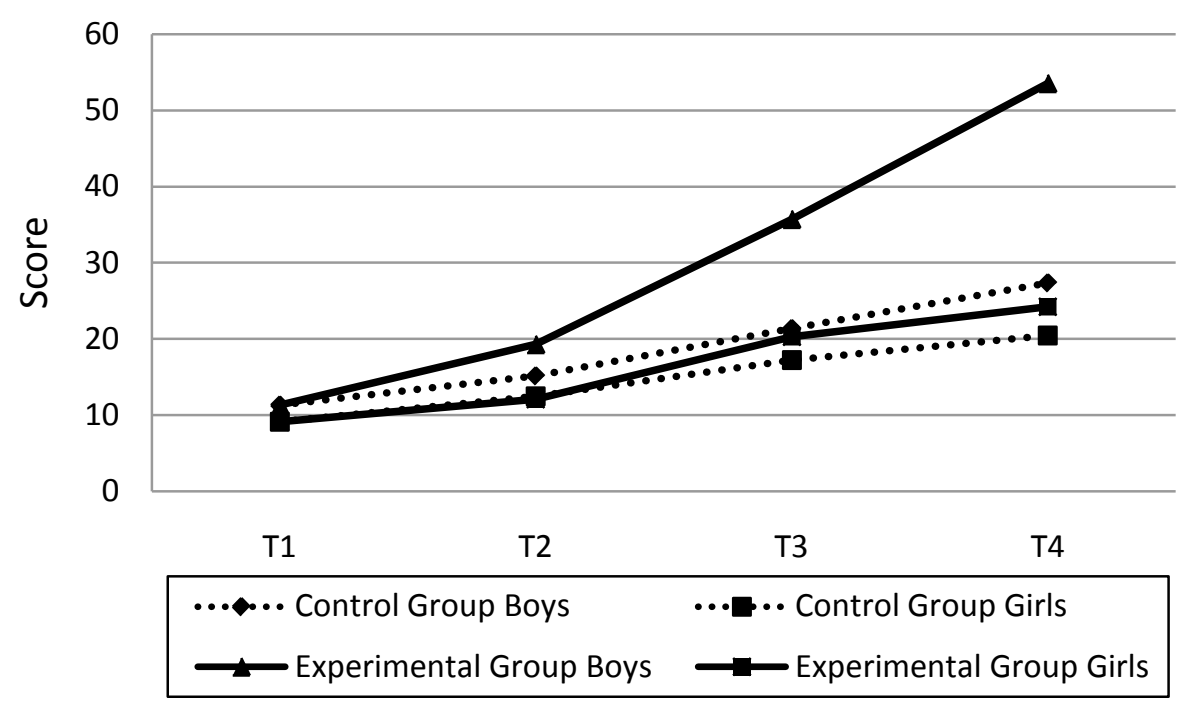

Figure 15. Graph of non-linear growth from HLM data for boys and girls in both groups.

Figure 16 further illustrates how boys and girls individually performed differently across the time points and phases as a result of the group to which they were assigned. As a reference point, the same aggregated lines displayed in Figure 15 are inserted into the corresponding individual growth graphs in Figure 16. Graph A displays individual growth of boys in the control group. This graph shows that most boys in the control group demonstrated growth in decoding throughout the course of the study. While there were a few steep slopes from Time 2 to Time 4 in the graph, there were also some lines that remained the same throughout the study or appeared to maintain the same slope (increase) during each phase. Therefore, some boys in the control group reacted particularly well to phonics instruction, in general, while others did not. 

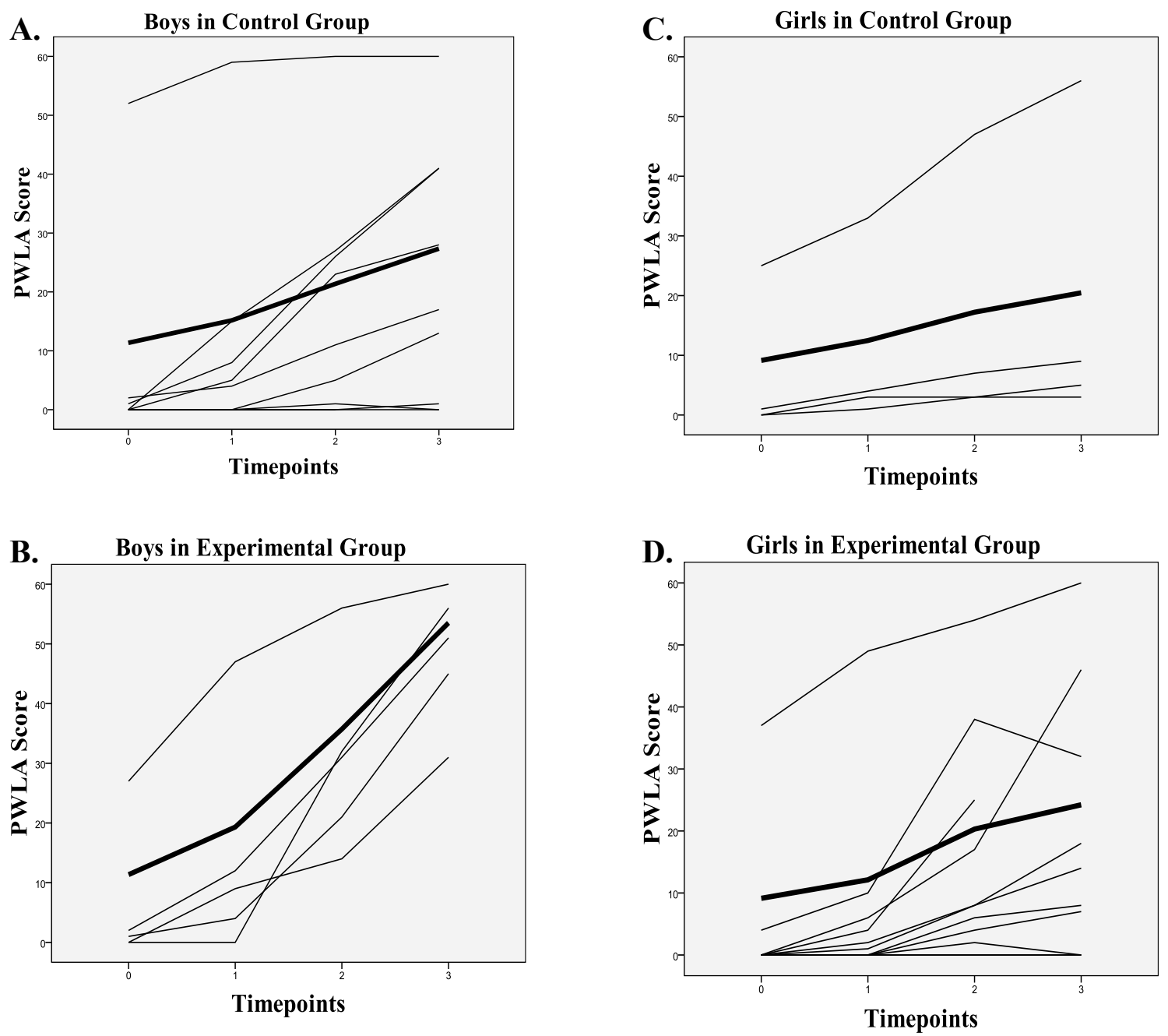

Figure 16. Individual growth graphs for boys and girls in both groups.

Graph B displays individual growth of boys in the experimental group. This graph clearly displays the increase in decoding skills that were made by all boys within this group. There were particularly steep slopes (increases) from Time 2 through Time 4 . These slopes support the findings that suggested that boys increased in decoding after receiving pseudoword phonics instruction, and continued to demonstrate sustained growth after returning to a regular real-word phonics setting. 
Graph C displays individual growth of girls in the control group. Despite the small number of girls within this group (further addressed in the Discussion section), it is evident that the individual growth of girls within this group was very similar. Their growth was linear and maintained a similar slope throughout the study. There were no sudden increases at any time point or within any phase. If the higher performing girl was omitted from the sample, the inserted bold aggregate line (from Figure 15) would appear much lower than is currently displayed in Graph C. Therefore, the individual growth lines suggest that most of the girls in the control group performed lower than what was actually estimated by the multilevel model.

Graph D displays individual growth of girls in the experimental group. Although individual growth of girls in the experimental group was not as steep as boys' individual growth in the experimental group, growth is still evident between time points and phases. While girls in the experimental group did not demonstrate as much growth throughout the study as boys in the experimental group, they still scored higher on the PWLA compared to girls in the control group. As depicted in Graph $\mathrm{D}$, most girls in the experimental group had higher increases from Phase 1 to Phase 2, but did not demonstrate the sustained effects that boys did during Phase 3 (see Graph B). The graphs in Figure 16 support the previous findings that boys decoded more words than girls overall, the PPC improved boys' decoding skills more than girls' decoding skills, and instruction using pseudowords during Phase 2 continued to improve boys decoding skills through Phase 3 when they returned to the regular real-word phonics curriculum. 


\section{CHAPTER V \\ DISCUSSION}

The major goal of this study was to examine the effects of a phonics curriculum using pseudowords on kindergarten students' success in phonetic decoding. Based on previous studies, which suggested that children who become competent in reading pseudowords may become more independent and successful readers (e.g., Byrne \& Fielding-Barnsley, 1993), the present study hypothesized that (a) children who receive phonetic decoding instruction, regardless of the method of instruction (i.e., all children in study), will show growth in the Phonetic Word List Assessment (PWLA) across the study, and will likely increase in the rate of decoding as the study progresses; and (b) children who receive phonics instruction through the Pseudoword Phonics Curriculum (PPC) will experience a steeper increase in the rate of word decoding compared to children who receive regular phonics instruction. To best discuss the results of this study, the current chapter provides a synopsis of the findings, interpretation of the findings, description of the implications and applications, addresses the limitations, and suggests some areas for future research.

\section{Synopsis of Results}

\section{Overall Effects of Phonics Instruction}

Findings from this study show that phonics instruction helps children develop decoding skills that can be used to read phonetically spelled words. Students in both the control and experimental groups increased in phonetic decoding skills (as assessed by the PWLA) throughout the course of the study, demonstrating that both methods of phonics instruction helped students become better decoders. Although boys performed higher 
than girls, non-Hispanic students performed lower than Hispanic students, and older students outperformed younger students, increases of all students' PWLA scores from the beginning to the end of the study were still evident. These results suggest that boys, nonHispanic students, and older kindergarten students are able to transfer the knowledge learned through phonics instruction to reading phonetically spelled words, more so than girls, Hispanic students, and younger kindergarten students. Indeed, findings showed that older (i.e., 6-year-old), non-Hispanic boys were the highest performing students, while younger (i.e., 5 and a half-year-old), Hispanic, girls were among the lowest performing students on the PWLA at all time points and during each phase of the study. Results of the Pseudoword Phonics Curriculum

Results indicated that students who received phonics instruction through the PPC demonstrated greater improvement in decoding than students who received phonics instruction using real words. Findings showed that the experimental group, who received pseudoword phonics instruction, demonstrated larger gains in their ability to decode phonetically spelled words compared to the control group, who received regular realword phonics instruction. Baseline data (collected prior to the implementation of the PPC) indicated that the control group began the study with slightly higher phonetic decoding skills than the experimental group. However, despite the initial advantage, the experimental group surpassed the control group in their ability to decode phonetically spelled words after receiving pseudoword phonics instruction. After controlling for the demographic variables, the same results were found indicating that the results were not the by-product of demographic variance. 
In order to determine if the PPC resulted in prolonged, sustained improvements, the experimental group transitioned from the pseudoword phonics instruction back to real-word phonics instruction during the final phase of the study. Findings indicated that the experimental group continued to show greater increases in phonetic decoding compared to the control group, who received real-word phonics instruction during all three phases of the study. Not only did the experimental group perform higher than the control group on the decoding assessment at the end of the study, they also maintained a higher rate of change after returning to real-word phonics instruction. Therefore, the phonetic decoding knowledge gained by the students in the experimental group during the pseudoword phonics instruction continued to play a role in their word decoding after the PPC ended. The findings also suggested that the increase in girls' scores were not as steep as the increase in boys' scores, suggesting a three-way interaction between group, sex, and time. A closer examination of this effect revealed that while both boys and girls in the experimental group increased in their decoding ability following the PPC (compared to the control group), boys increased to a higher extent. Overall, the PPC was found to increase students' phonetic decoding skills more than the real-word phonics curriculum (regardless of sex, ethnicity, or age).

\section{Interpretation}

This section presents an interpretation of the findings in relation to several of the topics discussed in the Literature Review. These topics include the effect of memory on reading, the use of alternative reading strategies, the role of intimidation in learning to read, and the importance of phonics. 


\section{The Role of Memory}

This study was designed to remove the possibility that children may be memorizing words during phonics instruction rather than developing the phonetic decoding skills needed to decode unknown words. Instead of relying on their memorized knowledge of words, the use of pseudowords during phonics instruction forced students to actually decode and not simply pull answers from memory. Therefore, it was expected that students would be able to improve their decoding skills during pseudoword phonics instruction because memory was not going to interfere. The results supported this notion. Students who were instructed with the pseudoword curriculum gained more decoding skills than their peers in the control group. These results suggest that children in the pseudoword group learned more decoding skills, which allowed them to decode phonetically spelled real words because they were not merely drawing upon previous knowledge of the words. In other words, the children who received the pseudoword phonics instruction were not able to simply recall words when learning phonics as they may have done when real words were used during instruction.

Further, the teacher of the experimental group observed that the use of pseudowords (in comparison to the real words used in the first phase of the study) allowed her students to grasp and understand that reading begins by blending letter sounds together to read words. Therefore, not only did the results demonstrate that pseudoword phonics instruction improved children's ability to decode phonetically spelled words, but the teacher's thoughts and first-hand observations supported these results as well. 


\section{The Use of Alternative Reading Strategies}

Children who struggle in decoding or fail to develop decoding skills early on tend to use other strategies to compensate for their lack of ability to decode words. Some of these strategies may include retrieving words from memory (i.e., reading by sight), making analogies between unknown words and known words, looking at pictures on the page, or using context clues (other words in text) to predict words. Although many of these strategies may help some students "read" the text, none of them provides the student with the decoding skills that will improve their future reading progress, particularly when the text does not lend itself to the use of these strategies (e.g., when there are no pictures next to the words). Ideally, children will use these strategies in combination with decoding.

Decoding words is one of the most important strategies for becoming a good reader. It provides children with a means for checking the accuracy of their deductions when reading with one of the other strategies listed above. It is possible that becoming proficient in phonetic decoding may reduce the amount of errors when reading, which will improve overall comprehension. One of the advantages of the present study is that it did not allow students in the experimental group the opportunity to rely on any other reading strategies while learning to decode because the pseudowords were comprised of a pronounceable combination of letters that were unable to be retrieved from memory, had no associated picture, and were not identifiable based on clues provided by other words in the text. Students had to learn and rely on phonetic decoding in order to sound out and read the pseudowords. This method for teaching phonics resulted in higher decoding performance on the word list assessment in which the words did not have context 
(thereby requiring reading of the words without clues). The experimental group, who learned phonics with pseudowords (a method without context clues), was more prepared to decode real words with no context compared to the control group.

\section{Confidence Builder}

Findings and anecdotal teacher records also suggest that pseudoword phonics instruction may have been particularly helpful for students who were intimidated by the process of learning to read. Although not explored empirically, several intimidated students in the experimental group made great strides in decoding during and after the pseudoword instruction (but not before). One 5-year-old boy who was not able to read any phonetically spelled words at the beginning of the study (Time 1) was able to read 32 words on the word assessment after receiving phonics instruction using pseudowords. This student also continued to show gains in decoding after returning to a regular phonics curriculum, reading a total of 56 out of a possible 60 words on the assessment by the end of the study (Time 4). Additionally, the student's teacher mentioned that his confidence level (along with several other students) had increased tremendously and he was not as intimidated to read anymore because he realized that he could use what he was learning through the PPC to sound out and read real words. She mentioned that while working in small groups, the child stated, "This is not even hard anymore." The teacher felt that using pseudowords to teach phonics was a great method because they did not intimidate her students. Since the students treated pseudoword phonics instruction like a game of reading "silly" words, they looked forward to the phonics block in their daily schedule. Interestingly, while students were having fun manipulating, blending, and reading 
pseudowords, they were also becoming better decoders as evident by the large gains made in the experimental group compared to the control group.

\section{Phonics}

Findings from this study suggest that phonics instruction improves children's ability to decode phonetically spelled words. Although it is possible that students' improved decoding skills across the study was associated with typical maturation, it seems more likely that the findings provide support for the importance of phonics instruction.

Phonics is a method of teaching that emphasizes sound-symbol relationships in language and is usually used in the early stages of reading instruction (Rasinski \& Padak, 2001). After children gain a strong foundation in phonetic decoding, children are able to apply their phonetic skills to other reading areas, such as fluency, comprehension, and vocabulary (Stahl et al., 1998). The teachers who participated in this study reported that the majority of their students demonstrated improvement across all reading aspects after receiving phonics instruction. They felt that students were transferring the newly acquired phonics knowledge to improve on other reading skills, a feeling which is supported by the linear improvement of all children across the duration of the study.

Chall (1996) found that if phonics skills are not acquired early on, then there is a higher chance that children will consequently struggle in word recognition, comprehension, and fluency. Similarly, Adams (1990) states that one must master phonics before excelling in reading and reading comprehension. She explains that before a child can understand written text, s/he must (a) understand the individual letters that comprise a word, (b) recognize the spelling and phonetic translation of the word, (c) 
analyze words within in a sentence, and (d) understand the individual sentences of a paragraph before being able to extract the full meaning of the written text. This supports the notion that phonics instruction is an essential element in children's early reading development. Without phonics, other aspects of reading may be affected. Findings from the present study support the role that phonics instruction plays in acquiring decoding skills because the increase in students' ability to decode words after receiving phonics instruction (regardless of the method) was evident.

Overall, this study (experiment and assessment) was designed to control for factors that may hinder children's development of phonetic decoding, such as memory, using alternative strategies, and intimidation to read. The results of this study suggest that the use of pseudowords to teach phonics may lead to a greater increase in decoding skills compared to the use of real words. By using pseudowords to teach phonics, children focus on the sound-symbol relationship within words instead of relying on other strategies (e.g., memory), which may serve as a crutch for learning decoding skills. Finally, anecdotal evidence suggests that pseudoword phonics instruction may also be beneficial for children who are intimidated by learning to read because they tend to view pseudoword instruction as a game that consists of reading "silly" words. It is possible that this type of instruction relieves the pressure of learning how to read and, perhaps, works as a confidence builder along the way. This may be particularly important for children learning to read in a second language or children who have had limited reading experiences at home. 


\section{Applications and Implications}

The results of this study are highly important for how and why phonics should be used in early elementary classrooms. Based on comments made by the participating teachers throughout the study, it seems that the use of phonics instruction was not only effective in terms of improving decoding skills but also in terms of the teachers' perceptions. The teachers noticed improvement in all of their students, during real-word and pseudoword phonics instruction, but particularly during the pseudoword instruction. They noted that not only did their students improve in decoding and blending sounds together to read, but they also demonstrated improvement in their overall concept of reading as well. This would imply that phonics instruction is necessary and beneficial for children as they develop their reading skills. Although it may have an effect on some students more than others, it is possible that the exposure and practice of decoding with pseudowords may help students develop a variety of reading strategies and techniques, and therefore, result in more successful reading.

Before implementing the pseudoword curriculum with her students, the teacher of the experimental group was skeptical as to whether the curriculum would have a positive effect, negative effect, or no effect at all. She mentioned that she was hesitant and worried about what the parents' reactions might be when they found out that their children would be participating in a study that will be teaching phonics through the use of non-words. She felt that the parents might think that it will delay students' reading process or may even confuse them. However, after a few weeks of implementation, she reported that she was actually surprised as to how well both the students and the parents were reacting to the pseudoword curriculum. The students were demonstrating more 
understanding of the reading process and acknowledging the sounds within words more than when she was teaching phonics using real words. She mentioned that the pseudowords were forcing her students to figure out the sounds in words and were also helping her identify which students were struggling with decoding because it ruled out the possibility of recognizing a word by sight. Interestingly, she noted that her students' confidence levels, specifically her lowest performing students, began to increase tremendously because they felt that reading pseudowords was like a game. After some time, her students began to realize that words are made up of letters, which are made up of sounds, and the sounds are blended together to read a word. Once the students grasped the concept, she noticed a sudden increase in their decoding skills. As such, it seems that the use of pseudowords for phonics is a very plausible way of teaching phonics. Indeed, using pseudowords may actually be an important technique to use with students who have low-confidence of their reading and decoding skills. By preventing students from using memory or other strategies to decode, the pseudoword phonics curriculum may also help the teachers gain a better idea of which children are actually able to decode and which children are not. It is possible that a small number of children with reading disabilities who "slip through the cracks" might be more apparent to teachers if they use non-words in their phonics instruction.

Overall, the teacher who implemented the pseudoword instruction enjoyed using pseudowords to teach phonics and also felt that her students enjoyed using pseudowords to learn phonics. She noticed larger gains in her students' ability to decode words during the phase of the study that used the pseudowords (compared to the phases that used the real words), and added that she would continue to use pseudowords with her students in 
the years to come in combination with the regular phonics curriculum that they are required to implement at her school. These anecdotal records imply that using pseudowords to teach phonics may be a better approach than using real words.

Pseudoword phonics instruction may also motivate students to read more and develop a positive perspective toward reading.

Findings from this study and anecdotal records from the participating teachers suggest important implications for reading education. While more research is still needed in this area, there is a possibility that using pseudowords to teach phonics may lead to better decoding than using real words. These results may also imply that students who receive this type of phonics instruction in kindergarten will become fluent in decoding words by sounding out letters and blending the sounds together to read words, and consequently, excel in reading throughout school. This would seem logical given that other studies (e.g., Pullen et al., 2005) have shown that children who are able to read pseudowords accurately and rapidly are also able to decode real words in running text with little difficulty. Based on these findings, school boards may want to consider altering their current early reading curriculums to include the use of pseudowords when teaching students how to decode.

Most importantly, the findings of this study imply that a pseudoword phonics approach may be most beneficial for teachers who teach reading in the primary grades, particularly kindergarten. Since teachers are always researching the best teaching methods, attending professional development sessions to learn new techniques and strategies, and collaborating with colleagues to share ideas and methods of teaching, it 
would be useful for teachers to try this new phonics approach to determine whether or not their students react positively and demonstrate improvement in decoding.

\section{Limitations}

Since there is little research on this topic, the researcher was unable to locate a previously used assessment that would have been appropriate for the study. Therefore, one limitation of this study is the use of the researcher-created PWLA, rather than the use of a standardized test or a phonics assessment that has been previously used by other researchers. While it would have been ideal to find a standardized assessment, the assessment that was created for this study did go through numerous revisions and was subjected to numerous pilot tests to increase the likelihood of its value as a good assessment. However, there was a limitation to the way in which the PWLA was administered. Since some of the words on the PWLA were read to students if they asked for help, it is possible that the children could have made a visual association of the words. The visual association of the words may have helped students on the following assessment time points. If none of the words on the PWLA were read to the students, then visual associations may have been less likely to occur.

Although this study was monitored periodically to ensure consistency and the research design was chosen carefully to account for teacher effects, another limitation of this study was that the teachers may not have been equally effective in teaching reading. With only one teacher for the experimental group and one teacher for the control group, it was difficult to test for and know if there were interaction effects between the teacher and the curriculum used. In other words, it is possible that the teacher of the experimental group was well-suited to teach phonics with pseudowords while the other teacher may 
not have been. Replications of this study should include additional teachers/classrooms in each group and explore the interaction effects of teacher with the curriculum.

Another limitation of this study is that the sample size was small, with only 14 students in the control group and 16 students in the experimental group, and limited to a single school. While the study utilized four assessment time points in a within-subjects design (providing more degrees of freedom) and the results of the study revealed medium-sized effects, small samples always make generalizing tentative without replication. It is possible that other school- or neighborhood-related factors affected the outcome of the study. Replication with more students across more schools will improve the generalizability of these results.

Finally, the disproportional number of boys and girls within the experimental and control group was also a limitation. Although the disproportionate number of boys and girls within each group was controlled throughout the analyses, it is difficult to feel completely confident about the results indicating that boys benefited more from pseudoword phonics instruction than girls. While it seemed consistent throughout the study (and regardless of group) that the boys performed better than the girls on decoding, it is possible that the small number of boys in the experimental group exacerbated the interaction between sex and condition.

\section{Future Research}

There are a few ways in which future studies can better investigate some of the areas examined in the present study. First, future research can be conducted to repeat the same study over a longer period of time; perhaps the entire school year (recall that this study is for only the second half of the kindergarten year). Doing so may provide a better 
idea as to whether or not pseudoword phonics instruction helps young children develop decoding skills in general or if limited exposure to pseudowords (as done in this study) is ideal. Implementing this study over a 2-year period with the same teacher but a different cohort of children each year might help determine if there is an interaction between the teacher and the students when using pseudoword instruction. Another future study could control for teacher effects by splitting a single classroom into control and experimental groups. In other words, the teacher will have to implement the phonics curriculum during small group phonics instruction with one group reading pseudowords and the other group reading real words. This way, both groups have the same teacher during the same time of year, but will receive a different form of phonics instruction. This will also allow for more controlled and better distribution of boys and girls and other demographic factors within groups.

Another consideration for future research is to use a larger sample for the study. In doing this, the researcher will be able to collect and analyze more data across more settings and schools. Pseudoword phonics instruction might also be extended into first, second, and third grade to determine if this type of instruction will make a difference in reading achievement in other grade levels. It is possible that this type of instruction would be more effective in a higher grade level, such as first grade (recall that kindergarten was used in the current study). Perhaps, students who are already reading and have a better understanding of the concept of reading will be able to understand the purpose of pseudoword instruction, and therefore, may benefit from pseudoword instuction more than younger students. 
Since the disproportionate numbers of boys and girls within each group was a major limitation of this study, a replication should be conducted with a better distribution of boys and girls between the two groups. Not only is it important to have a proportionate number of all the demographic variables (boys, girls, Hispanics, nonHispanics, age, etc.) within the entire sample, it is also important to have proportionate representation within each group. Finally, a future longitudinal study may include following the students who participated in this study into first, second, and third grade to compare the reading achievements (based on their scores on standardized tests) of students in the experimental group to those in the control group. This should help determine the longer lasting effects of the PPC used in the present study. 


\section{REFERENCES}

Adams, M. J. (1990). Beginning to read: Thinking about learning about print. Cambridge, MA: MIT Press.

Bruck, M., \& Treiman, R. (1992). Learning to pronounce words: The limitations of analogies. Reading Research Quarterly, 27(4), 374-388.

Byrne, B., \& Fielding-Barnsely, R. (1989). Phonemic awareness and letter knowledge in the child's acquisition of the alphabetic principle. Journal of Educational Psychology, 81, 313-321.

Byrne, B., \& Fielding-Barnsley, R. (1993). Evaluation of a program to teach phonemic awareness to young children: A 1-year follow-up. Journal of Educational Psychology, 85, 104-111.

Byrne, B., Fielding-Barnsley, R., \& Ashley, L. (2000). Effects of preschool phoneme identity training after six years: Outcome level distinguished from rate of response. Journal of Educational Psychology, 92, 659-667.

Chall, J. S. (1996). Learning to read: The great debate ( $3^{\text {rd }}$ ed.). New York: Harcourt Brace.

Curtis, M. E. (1980). Development of components of reading skill. Journal of Educational Psychology, 72, 656-669.

Dahl, K., Scharer, P. L., Lawson, L. L., \& Grogan, P. R. (1999). Phonics instruction and student achievement in whole language first-grade classrooms. Reading Research Quarterly, 34(3), 312-341.

Ehri, L. C. (1978). Beginning readers from a psycholinguistic perspective: Amalgamation of word identities. In F. B. Murray (Ed.), The recognition of words (pp. 1-33). Newark, DE: International Reading Association.

Ehri, L. C. (1991). Development of the ability to read words. In R. Barr, M. L. Kamil, P. B. Mosenthal, \& P. D. Pearson (Eds.), Handbook of reading research (Vol. 2, pp. 383-417). New York: Longman.

Ehri, L. C. (1998). Grapheme-phoneme knowledge is essential for learning to read words in English. In J. L. Metsala \& L. C. Ehri (Eds.), Word recognition in beginning literacy (pp. 3-41). London: Erlbaum.

Ehri, L.C., \&Robbins, C. (1992). Beginners need some decoding skill to read words by analogy. Reading Research Quarterly, 27, 13-26. 
Foorman, B., Francis, D., Novy, D., \& Liberman, D. (1991). How letter-sound instruction mediates progress in first-grade reading and spelling. Journal of Educational Psychology, 83(4), 456-469.

Groff, P. (2001). Teaching phonics: Letter-to-phoneme, phoneme-to-letter, or both? Reading and Writing Quarterly, 17, 291-306.

Harris, T. L., \& Hodges, R. E. (1995). The literacy dictionary: The vocabulary of reading and writing. Newark, DE: International Reading Association.

Hox, J. J. (1995). Applied multilevel analysis. Amsterdam: TT-Publikaties.

Hox, J. J. (1998). Multilevel modeling: When and why. In I. Balderjahn, R. Mathar \& M. Schader (Eds.), Classification, data analysis, and data highways (pp. 147-154). New York: Springer Verlag.

Johnston, R. S., \& Watson, J. E. (2004). Accelerating the development of reading, spelling and phonemic awareness skills in initial readers. Reading and Writing: An Interdisciplinary Journal, 17, 327-357.

Juel, C. (1988). Learning to read and write: A longitudinal study of 54 children from first through fourth grades. Journal of Educational Psychology, 80, 437-447.

Juel, C. (1996). What makes literacy tutoring effective? Reading Research Quarterly, $31,268-289$.

LaBerge, D., \& Samuels, S. J. (1974). Toward a theory of automatic information processing in reading. Cognitive Psychology, 6, 293-323.

Macnair, L., Evans, S., Perkins, M., \& Goodwin, P. (2006). Inside the classroom: Three approaches to phonics teaching. In M. Lewis \& S. Ellis (Eds.). Phonics: Practice, research and policy, (pp. 45-59). London: Paul Chapman Publishing.

National Reading Panel. (2000). A report of the national reading panel: Teaching children to read. Washington, DC: National Institute of Child Health and Human Development.

Newman, I., \& Newman, C. (2006). Conceptual statistics for beginners (3 ${ }^{\text {rd }}$ ed.). Lanham, MD:University Press of America.

Pikulski, J. J., \& Chard, D. J. (2005). Fluency: The bridge from decoding to reading comprehension. Reading Teacher, 58(6), 510-519. 
Pullen, P. C., Lane, H. B., Lloyd, J. W., Nowak, R., \& Ryals, J. (2005). Effects of explicit instruction on decoding of struggling first grade students: A data-based case study. Education and Treatment of Children. 28, 63-75.

Rasinski, T. V., \& Padak, N. D. (2001). From phonics to fluency: Effective teaching of decoding and reading fluency. New York: Addison Wesley Longman.

Raudenbush, S. W., \& Bryk, A. S. (2002). Hierarchical linear models: Applications and data analysis methods $\left(2^{\text {nd }}\right.$ ed.). Newbury Park, CA: Sage.

Savage, J. F. (2004). Sound it out! Phonics in a comprehensive reading program $\left(2^{\text {nd }}\right.$ ed.). Boston: McGraw-Hill.

Shankweiler, D., Lunquist, E., Katz, L., Stuebing, K. K., Fletcher, J. M., Brady, S., Fowler, et al. (1999). Comprehension and decoding: Patterns of association in children with reading difficulties. Scientific Studies of Reading, 3, 69-94.

Singer, J. D., \& Willet, J. T. (2003). Applied longitudinal data analysis: Modeling change and event occurrence. New York: Oxford University Press.

Stahl, S. A., Duffy-Hester, A. M., \& Doughtery Stahl, K. A. (1998). Everything you wanted to know about phonics (but were afraid to ask). Reading Research Quarterly, 33(3), 338-355.

Stanovich, K. E. (1986). Matthew effects in reading: Some consequences of individual differences in the acquisition of literacy. Reading Research Quarterly, 21, 360406.

Stuart, M., Masterson, J., \& Dixon, M. (2000). Spongelike acquisition of sight vocabulary in beginning readers? Journal of Research in Reading. 23, 12-27.

Torgesen, J. K., \& Burgess, S. R. (1998). Consistency of reading-related phonological processes throughout early childhood: Evidence from longitudinal-correlational and instructional studies. In J. Metsala \& L. Ehri (Eds.). Word recognition in beginning reading, (pp. 161-188). Hillsdale, NJ: Lawrence Erlbaum. 


\section{ENDNOTES}

${ }^{1}$ The concern about subjects being nested can be dealt with by using person vectors in a traditional regression design. However, person vectors require more complicated coding and more degrees of freedom. 
VITA

JESSICA MARIE CARDENAS

September 12, 1983

December 2004

January 2005 - May 2005

August 2005 - Present

December 2005
Born, Miami, Florida

B.S., Early Childhood Education Florida International University Miami, Florida

Teacher

Plymouth Preschool

Miami, Florida

Teacher

Frank C. Martin International Baccalaureate K-8 Center

Miami, Florida

M.S., Reading Education (K-12)

Florida International University

Miami, Florida 